\title{
Krachtvoer: the development, implementation and evaluation of an educational programme for 12-14- year-old students to promote healthy eating
}

Citation for published version (APA):

Martens, M. K. (2005). Krachtvoer: the development, implementation and evaluation of an educational programme for 12-14-year-old students to promote healthy eating. [Doctoral Thesis, Maastricht University]. Maastricht University. https://doi.org/10.26481/dis.20051216mm

Document status and date:

Published: 01/01/2005

DOI:

10.26481/dis.20051216mm

Document Version:

Publisher's PDF, also known as Version of record

Please check the document version of this publication:

- A submitted manuscript is the version of the article upon submission and before peer-review. There can be important differences between the submitted version and the official published version of record.

People interested in the research are advised to contact the author for the final version of the publication, or visit the DOI to the publisher's website.

- The final author version and the galley proof are versions of the publication after peer review.

- The final published version features the final layout of the paper including the volume, issue and page numbers.

Link to publication

\footnotetext{
General rights rights.

- You may freely distribute the URL identifying the publication in the public portal. please follow below link for the End User Agreement:

www.umlib.nl/taverne-license

Take down policy

If you believe that this document breaches copyright please contact us at:

repository@maastrichtuniversity.nl

providing details and we will investigate your claim.
}

Copyright and moral rights for the publications made accessible in the public portal are retained by the authors and/or other copyright owners and it is a condition of accessing publications that users recognise and abide by the legal requirements associated with these

- Users may download and print one copy of any publication from the public portal for the purpose of private study or research.

- You may not further distribute the material or use it for any profit-making activity or commercial gain

If the publication is distributed under the terms of Article $25 \mathrm{fa}$ of the Dutch Copyright Act, indicated by the "Taverne" license above, 


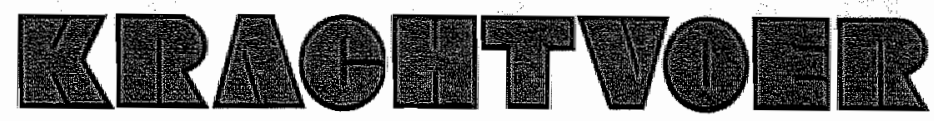

The development, implementation, and evaluation of an educational programme for 12-14-year-old students to promote healthy eating 
a क्ष 


\title{
Krachtvoer
}

\section{The development, implementation, and evaluation of an educational programme for 12-14-year-old students to promote healthy eating}

\section{Proefschrift}

\author{
ter verkrijging van de graad van doctor \\ aan de Universiteit Maastricht, \\ op gezag van de Rector Magnificus, Prof. Mr. G.P.M.F. Mols, \\ volgens het besluit van het College van Decanen, \\ in het openbaar te verdedigen op \\ vrijdag 16 december 2005 om 10.00 uur
}

door

Marloes Karina Martens 


\section{Promotor}

Prof.drifr. J. Brug (Erasmus Universitair Medisch Centrum)

\section{Co-promotoren}

Dr. P. van Assema

Dr. T. Paulussen (TNO kwaliteit van leven)

\section{Beoordelingscommissie}

Prof.dr. N.K. de Vries (voorzitter)

Prof.dr.ir. P.A. van den Brandt

Prof.dr. I. De Bourdeaudhuij (Universiteit Gent, België)

Prof.dr. J. van Eijk

Dr. H. Raat (Erasmus Universitair Medisch Centrum)

ISBN 90-8559-093-0

Interior and cover design by Anna Bosselaar | Zolets Communicatie, Rotterdam

Illustrations of 'Snacko, Splitter, and Sweetie' courtesy by Roel Venderbosch of LaVerbe Communicatie en grafische vormgeving, Nijmegen (The three cartoon characters were used in the nutrition education programme Krachtwoer.)

Printed by Optima Grafische Communicatie, Rotterdam

The study presented in this thesis was performed within the Nutrition and Toxicology Research Institute Maastricht (NUTRIM) which participates in the Graduate School VLAG (Food Technology, Agrobiotechnology, Nutrition and Health Sciences), accredited by the Royal Netherlands Academy of Arts and Sciences.
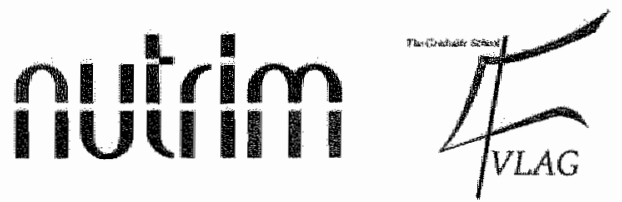

The studies described in this thesis were financially supported by the Netherlands Organisation for Health and Development (ZonMW, projectnummer 22000006) and by a grant of the Netherlands Heart Foundation (NHF-313.260)

Financial support by the Netherlands Heart Foundation for the publication of this thesis is gratefully acknowledged. 


\section{Contents}

Chapter 1 General introduction

Chapter 2 Opportunities and pitfalls of nutrition education for adolescents aged 12-14

Chapter 3 Why do adolescents eat what they eat? Personal and social environmental predictors of fruit, snack and breakfast consumption among Dutch 12-14-year-old students

Chapter 4 Krachtvoer: Effect evaluation of a Dutch healthy diet promotion 35 curriculum for lower vocational schools

Chapter 5 Krachtvoer: Process evaluation of a Dutch healthy diet 55 promotion curriculum for lower vocational schools

Chapter 6 Family-related correlates of adolescents' intakes of fruit and snacks and programme-induced changes in such intakes

Chapter 7 Overall discussion and conclusion

References

Summary

Samenvatting

Dankwoord

Curriculum vitae 
$\cdots$ 

a 


\section{Introduction}

This thesis reports on a number of studies into the development, implementation and evaluation of Krachtvoer*, a school-based educational programme to promote healthy eating habits among 12-14-year-old students. This introductory chapter describes the programme and its rationale, and presents an overview of the objectives and methods of the various studies. A brief outline of the thesis is given at the end of the chapter.

\section{Krachtvoer: a brief overview}

In developing the Krachtvoer programme, we applied some key aspects of Intervention Mapping (IM) (Bartholomew, Parcel, Kok, \& Gottlieb, 2001). Intervention mapping is a framework for effective decision-making at each step in the process of developing, implementing and evaluating of health education and health promotion programmes. As recommended in the IM procedure, we conducted an extensive literature search in the programme's developmental phase, in order to apply available theoretical and empirical knowledge as much as possible in our decision-making about the target population, the programme goals, the intervention's methods and strategies and the programme design. We then conducted additional studies among the target population and consulted experts. Subsequently, again as recommended in the IM procedures, we defined specific programme objectives at the level of dietary behaviours as well as important determinants of these behaviours.

Krachtvoer was developed for students of lower vocational (preparatory secondary vocational education) schools in the 12-14 year age bracket. The overall programme goals were to increase the consumption of fruit and fruit juice, decrease the consumption of high fat snacks and increase breakfast frequency and quality among this target group. More specific programme objectives were formulated based on self-management theory (Boekaerts, Rintrich, \& Zeider, 2000; Cameron \& Howard, 2003) and insights in the role of awareness of dietary risk behaviours. This means that students were expected to (1) self-assess their personal fruit, snack and breakfast intakes, (2) compare their intakes with recommended levels, (3) indicate reasons for observed discrepancies between their own intakes and recommendations, (4) propose solutions, i.e., set goals to close the gap with the recommended intake levels, (5) implement these solutions, (6) evaluate their personal goal performance. To achieve these objectives, the Krachtvoer programme included eight school lessons lasting fifty minutes each, and used a combination of materials: various so-called task forms for the lessons, postcards and posters, a "survival kit" (a lunchbox with 3 healthy food items - a piece of fruit, a health food snack and a breakfast product - and a flyer), a magazine, a video, a website, a take-home bag with a newsletter and food-items for the parents, taste-testing of various products and a manual to

\footnotetext{
We use the Dutch title of the programme throughout this thesis. A possible translation is Power Food, but this does not reflect the play on words in the Dutch title.
} 
instruct the teacher in providing the different lessons. Many of the materials featured three cartoon characters, each related to one of the targeted behaviours. The task forms formed the structuring elements guiding the students through the programme. Students completed these forms individually, in small groups or as a class. There were three types of tasks form: information forms, action forms and question forms. Information forms were aimed at providing the students with relevant knowledge and were always linked to an action or question form. An action form encouraged students to actually do something, for instance a tasting session test, assessing what distinguishes a 'real' fruit juice from other fruit-like drinks, making their own fruit shake, or writing down their own ideas for healthy recipes. A question form asked students to answer questions or to write down options or decisions, for instance reporting how many pieces of fruit they normally ate or setting and writing down personal goals for dietary change.

The Krachtvoer programme consisted of three main phases (Table 1). In phase one, (including lessons one to four) the initial activities aimed to raise students' enthusiasm for the programme; subsequent activities were linked to the first three performance objectives: monitoring behaviour, comparing observations with a particular norm and assessing reasons for inadequate intake. In phase two (including lessons four to seven) all activities aimed to help students to overcome their personal reasons for not eating a healthier diet (performance objective 4). In this phase, the Attitude-Social influence-Efficacy-Model and potential family-related factors were used as a framework to select the intervention methods and strategies (Baranowski et al., 2000; De Bourdeaudhuij, 1997; De Vries, Dijkstra, \& Kuhlman, 1988; Koivisto Hursti, 1999). In this phase, teachers were allowed to select activities and choose in the order in which they were carried out, but were expected to at least use the action form testing nutrition knowledge, show the video that illustrated how social influences affect dietary choices, discuss the magazine and carry out one or more optional activities: tasting unfamiliar foods, making a fruit shake, tasting various types of fruit and holding a 'kiwi fruit eating contest'. In the third and final phase (including lessons seven and eight), the activities were linked to the last two performance objectives, involving implementing solutions, setting goals and evaluating these personal goals. In this phase implementation intentions played a central role. Implementation intentions are if-then plans that connect good opportunities to act with cognitive or behavioural responses that are effective in accomplish one's goals. An implementation intention not only refers to what a person attends to achieve but also when, where, how the persons intend to achieve it. Research has shown that implementation intentions can be a powerful tool to enhance the probability of performance (Goliwitzer, 1999).

Krachtvoer was initiated by Maastricht University, the Netherlands Heart Foundation and the Netherlands Nutrition Centre. Maastricht University did the actual programme development with the help of different organisations that were represented in a consultation committee. 
Table 1

Description of the "Krachtvoer" programme: phases, lessons, performance objectives, behaviours and materials

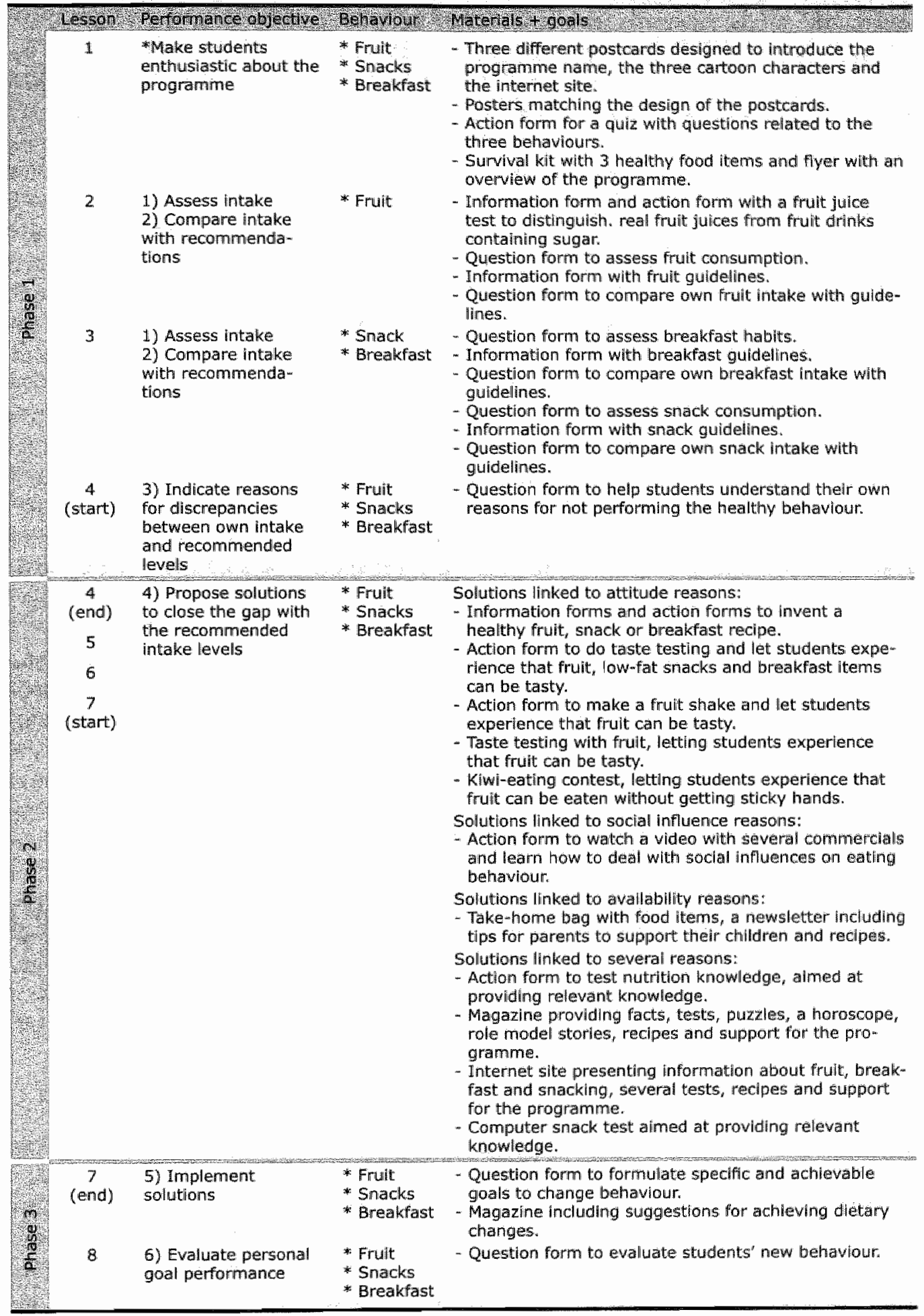




\section{Rationale}

Unhealthy eating habits increase the risk of certain health problems ( $W H O, 2003)$. The Krachtvoer programme focused on three specific unhealthy dietary habits, because previous studies evaluating evidence-based programmes for youngsters had revealed that a behaviourally focused approach that targets specific behaviours is more likely to result in behavioural changes than nutrition education interventions focused on nutrition in general (Contento \& Michela, 1999; Hoelscher, Evans, Parcel, \& Kelder, 2002; Perez-Rodrigo \& Aranceta, 2003).

Research has uncovered a protective effect of frequent fruit consumption on various types of cancer. The types of cancer most likely to be influenced by eating fruit are head and neck cancers and oesophageal and gastric cancers while the associations with bowel cancers remain unclear. Fruit consumption also plays a small but clear role in reducing lung cancer risk. Because of differences in study design and questionnaires used in studies, it is almost impossible to quantify the reduction of cancer risk resulting from fruit consumption ( $\left.K W F_{1}, 2004\right)$. Nor is it possible to attribute the reduction of cancer to specific fruits. A high consumption of fruits also seems to be protective against cardiovascular diseases (Hu \& Willet, 2002). In the Netherlands, it is recommended to eat at least two pieces of fruit per day (Gezondheidsraad, 1986; voedingscentrum, 1992). The Food Consumption Survey of 1997/1998 showed that the mean fruit intake among 12-16-year-olds was 0.88 pieces of fruit per day, with $68 \%$ of the boys and $61 \%$ of the girls eating less fruit than the recommended two pieces. The consumption of fruit has in fact decreased over the past decade.

Adolescents eat large quantities of sweets and snacks, with a relatively high saturated fat content (Voedingscentrum, 1998). A high intake of saturated fat is associated with a high serum cholesterol level, which is in turn associated with a greater risk of cardiovascular diseases (Willet, 1994). Furthermore, a high total fat intake is associated with obesity, which is also a risk factor for cardiovascular diseases, and the most important risk factor for type 2 diabetes (Visscher \& Seidell, 2001). The relationship between a high fat intake and the risk of cancer is less clear than the relation between fat intake and cardiovascular diseases. There are indications of an association between being overweight and cancer of the breast, bowel, uterus, kidney, oesophagus, ovary, pancreas and gallbladder (KWF, 2004). The Dutch national food consumption survey of 1997-1998 revealed that all participating 12-14-year-old adolescents ate snacks in between meals on both registration days. The amount of saturated fats that adolescents consumed exceeded the recommended maximum intake level. About $27 \%$ of the saturated fat intake could be attributed to snacks.

Skipping breakfast has been associated with high serum cholesterol levels, uncommon known metabolic fluctuations, and being overweight (Resnicow, 1991; Ruxton \& Kirk, 1997). Eating breakfast is especially important for students, since breakfast skipping is related to poor school performance (Cueto, 2001), although the causal relationship has not been fully established. The Dutch Nutrition Council (Voedingsraad, 1986) formulated the following conditions for a breakfast: a total energy content of $900-1500 \mathrm{~kJ}$, maximum $35 \mathrm{en} \%$ fat, maximum $10 \mathrm{en} \%$ saturated fat and more than $2 \mathrm{~g}$ of fibre per MJ. In addition, it is deemed advisable to eat breakfast every day. The 
Food Consumption Survey of $1997 / 1998$ showed that one in five of the $12-14$ yearolds sometimes skipped breakfast, among those who did take breakfast it contained too much saturated fat (Voedingscentrum, 1998).

These data show that dietary habits among Dutch adolescents are not in line with recommendations, which means that interventions are needed to change these unhealthy habits:

Twelve-to-fourteen-year-old students are an important target population, since this is the age at which children become more autonomous in their food choices. Although most of the above health consequences of poor eating habits will only become manifest in adulthood, healthy eating at an early age may influence taste preferences and thus food choices in later life (Kelder, Perry, Klepp, \& Lytle, 1994; Lytle, Seifert, Greenstein, \& McGovern, 2000; Young, Fors, \& Hayes, 2004). It is especially when children transfer from primary school to secondary school that their eating habits change and become less healthy (De Vries \& Da Costa Senior, 1992; Lytle et al., 2000), whereas some stability in the consumption of fruit and sugary foods has been reported in students aged 14 through 21 years (Lien, Lytle, \& Klepp, 2001). Interventions aimed at 12-14-year-olds may therefore prevent umhealthy eating behaviour from becoming habitual. Further, adolescents from lower socio-economic position (SEP) groups have less healthy diets than their peers from higher SEPs (Koivisto Hursti, 1999; Roos, Lahelma, Virtanen, Prattala, \& Pietinen, 1998). Interventions promoting a healthy diet should therefore be suitablle especially for lower SEP groups. Since 12-14-year-old children in the Netherlands all attend compulsory education, these children are all students.

At the start of the present study, severall organisations in the Netherlands were already offering nutrition education programmes to youngsters. However, these interventions were not coordinated, and they incompletely satisfied the effect enhancing conditions that have been suggested in the international literature (Contento \&. Michella, 1999; Contento, Randell, \& Basch, 2002; Hoelscher et al., 2002; PerezRodrigo \& Aranceta, 2003). No effect study of healthy diet interventions for Dutch children and adolescents had been completed before the present study.

\section{Objectives and methods of the research studies}

The developmental phase of the Krachtvoer programme involved two preliminary studies. First, focus group interviews were conducted with 45 adolescents aged 12-14 years, 21 teachers and 14 parents. The aim of the focus group interviews with students was to identify the adolescents' need for nutrition information, their specific areas of interest and their views about nutrition education. The focus group interviews with teachers examined the requirements in terms of overall programme design that would promote adoption and implementation of a healthy diet intervention in the schools, such as the number and duration of the lessons and the number of optional elements in the programme that would leave teachers some room to tailor the programme to their own teaching situation. The interviews with parents. gave additional information about their need for participation. The purpose of the 
second study in the developmental phase was to investigate the relative importance of personal and social environment predictors of the consumption of fruit, high-fat snacks and breakfast. Data were collected through written questionnaires that were completed in eight schools by 601 students of preparatory secondary vocational education schools.

The evaluation of the Krachtvoer programme consisted of two main parts: an effect study measuring changes in the targeted dietary behaviours and behavioural determinants, and a process study investigating several aspects of the implementation of the programme. The effect study used a cluster-randomised baseline-posttest experimental design, and data were collected by means of written questionnaires. The study included 10 experimental schools with 13 teachers, 37 classes and 879 students and 8 control schools with 31 classes and 734 students. The process study assessed the completeness and fidelity of the programme implementation, as well as the opinions of teachers and students about the programme. In addition, it examined the association between opinions and level of implementation. Data were collected through structured monitoring reports prepared by the teachers, in-class observations, in-depth interviews with teachers and items in the post-test student questionnaire.

A final study investigated the effects of family environment characteristics on the dietary behaviours of the children and tried to ascertain whether these family environment factors moderated the effects of the Krachtvoer programme. Written questionnaires were mailed to the parents of the students who participated in the programme, assessing several environmental characteristics. The questionnaires of 502 parents were matched with the baseline questionnaires of their children.

\section{Outline of the thesis}

Chapter 2 gives a full description of the focus group study among adolescents, and provides a summary of the mterview studies among teachers and parents. Data on fruit, snack and breakfast behaviours and corresponding determinants are presented in Chapter 3. Chapter 4 deals with the effect evaluation of the Krachtvoer programme, while information about the process evaluation of the programme is presented in Chapter 5. Chapter 6 presents the family environment study. Finally, the seventh and last chapter of this thesis relates the main findings of the studies to each other, discusses possible explanations for the findings, presents overall conclusions and provides recommendations for further implementation of the Krachtvoer programme. 



\section{Abstract}

In order to develop a nutrition education programme for adolescents, we wanted to identify the need for Information, areas of interest and views about nutrition education among our target population. We used focus group intervlews, a qualitative research method whose results reflect the ideas, thoughts, feelings and opinions of those interviewed. The 45 adolescents who took part in the interviews were not very enthusiastic about nutrition education, but accepted the fact that they were asked by the school to work on the subject. They felt that nutrition education could be fun, if it met certain criteria. The information should not be too complex and they should be able to absorb it in an active manner, for instance by means of games. The adolescents wanted all activities and materials to be challenging, not childish, funny, colourful ${ }_{r}$ exciting and even a bit shocking. We concluded that although designing inutrition education materials for adolescents aged 12-14 is not an easy task, it is essential to address nutrition in this age category in view of the current unfavourable dietary patterns and their adverse short- and long-term health consequences. The adolescents judge educational activities by certain criteria, which can be taken into account when designing these activities. Specific topics that interest some of the adolescents, like the consequences of skipping breakfast, can be used as a basis.

Published as: Martens, M., Wind, M., Van Assema, P, Brug, J. (2002). De (on) mogelijkheden wan voedingsvoorlichting aan twaalf- tot veertienjarige jongeren. Nederlands Tijdschrift voor Diêtisten, 57, 71-77. 


\section{Introduction}

The nutritional habits of many Dutch adolescents are less healthy than would be desirable and attempts should be made to change them. This was one of the main conclusions of an advisory report by the Netherlands Nutrition Centre on effective nutritional interventions (Voedingscentrum, 2000) that still consists today. One of the instruments that can be used to change nutritional behaviour is education. If a nutrition education intervention is to have its full effect, its content should be tailored as much as possible to the attitudes, motivations and preferences of the target group (Brug, Schaalma, Kok, Meertens, \& Van Der Molen, 2000; Green \& Kreuter, 1999). The present paper reports on the findings of a study among adolescents aged 12-14, using so-called focus group interviews. The aim of the study was to identify adoles cents' need for information, their areas of interest and their views about nutrition education. The findings are to be applied in the process of designing nutrition education interventions in curricula for the basic education stage of secondary school. We focused on adolescents aged 12-14 since this is the age at which they pass from primary to secondary education, a time at which they go through major changes in their eating and drinking habits (De Vries \& Da Costa Senior, 1992). This would therefore seem a good moment to intervene. On the one hand, it may still be possible at this time to prevent some of the unhealthy dietary behaviour, while on the other hand any unhealthy behaviour that has already been adopted may not yet have develloped into long-term habits and as such may still be modifiable.

Our study focused on three types of nutritional behaviour among adolescents: fruit consumption, the consumption of sweets and snacks and breakfast habits. The Food Consumption Survey of $1997 / 1998$ showed that the mean fruit intake among $12-16$-year-olds was 0.88 pieces of fruit per day, with $68 \%$ of the boys and $61 \%$ of the girls eating less fruit than the recommended two pieces. The consumption of fruit has in fact decreased over the past decade. In addition, the amount of saturated fats that adolescents consume exceeds the recommended level (Voedingscentrum, 1998). This is caused partly by adolescents eating large quantities of sweets and snacks, with a relatively high saturated fat level. On average, they tend to consume deepfried snacks on 1.5 occasions a week, a bag of crisps 2.5 times a week and candy bars or cakes 2.5 times a week (Schaalma et al., 1997). One in five of the adolescents in this age category sometimes skips breakfast (Voedingscentrum, 1998). This type of unhealthy dietary habits can have various consequences. Over-consumption of sweets and snacks increases the risk of becoming overweight, while an inadequate breakfast is associated with lack of concentration in school and hence possibly with poorer academic achievements (Matthews, 1996; Pollit, 1995, 1998; Van 't Bosch \& Spruijt, 1992). In the long term, inadequate fruit and saturated fat consumption and being overweight may increase the risk of chronic conditions like cardiovascular diseases, type II diabetes, and of cancer (Willet, 1994). 


\section{Methods}

A focus group interview is a qualitative research method whose results provide information about the ideas, thoughts, feelings and opinions of the participants on a particular subject. The focus group method has proved valuable in research into opinions on nutrition (Brug, Lechner, \& De Vries, 1995; Van Assema, Brug, Dolders, Kok., \& Steenhuis, 1996). A typical focus group interview lasts between one and two hours. Focus groups usually include elight to twelve persons who discuss a particular subject (Morgan \& Kreuger, 1998; Stewart \& Shamdasane, 1991; Van Assema, Mesters, \& Kok, 1992). The interview is led by an experienced chairperson who introduces the subject, stimulates interaction between the participants and guides the discussion. To this end, an interview scheme is drawn up in advance. For the duration of the interview, the participants are regarded as experts on the subject. We decided to use focus group interviews, as experience had led us to expect that the interaction between the participants would yield additional information (Morgan \& Kreuger, 1998; Van Assema et al., 1992).

\section{Recruitment procedure}

Five focus group interviews were held, involving a total of 45 adolescents. We recruited adolescents by contacting two schools in Maastricht by letter: One week after the letters had been posted, the management of each of the schools was telephoned to ask them whether they were willing to help recruit a number of adolescents in the basic education stage of secondary school for a single focus group interview. The schools then recruited the participants. The researchers divided the adolescents over the groups in such a way that participants in one group were as much as possible unacquainted with each other.

\section{Procedure during the focus group interviews}

Each focus group interview was attended by two of the researchers, one of whom chaired the session, assisted by the other. The chairperson explained the interview scheme to the participants and was responsible for guiding and stimulating the discussion. The assistant audiotaped the session and took notes on any relevant nonverbal behaviour and voice intonations. The assistant also supported the chairperson in guiding the process of the group interview. Each interview took between 60 and 90 minutes. The discussion was initiated using the interview scheme, which related to existing nutrition education activities at school, participants' areas of interest as regards nutrition education and their ideas for making such education more appealing. The adolescents were also asked at what times they were most receptive to nutrition education and in what form they would prefer to receive information on nutrition. Their opinion was asked on a series of potential nutrition education activities. Unlike the first three focus group interviews, the remaining two interviews concentrated especially on the range of potential activities. After the interview, the participants were given the opportunity to ask questions themselves. Finally, participants received a 
free cinema ticket in appreciation of their willingness to participate. The interview scheme had previously been submitted to a panel of experts for comment, and was adjusted on the basis of their views.

\section{Data processing and analysis}

The audiotapes of the interviews were transcribed, adding the notes on voice intonations and nonverbal behaviour. These transcripts were then analysed using the 'NUDIST' (version 4.0) software program. To this end, the research questions were used to define a classification into main topics and subsidiary topics. We then reviewed the transcripts, selected relevant sections and assigned them to the right topics. The transcripts were summarised per topic, and the summaries were submitted, together with the transcripts, to colleagues at the Department of Health Promotion and Education, who checked them.

\section{Findings}

Below, we first provide a description of the participants, after which we present the findings for each of the main subjects. The most relevant findings are illustrated by quotations.

\section{Participants}

A total of 45 adolescents were interviewed ( 26 girls and 19 boys). The smallest focus group included seven people, the largest 12 . The first three focus groups included both boys and girls, all from the first year of secondary school. The final two interviews used separate groups for boys and girls, as we had noticed that boys tended to dominate the first three interview sessions: some girls seemed to find it difficult to voice their opinions in the presence of boys.

\section{Opinions about existing nutrition education at school}

The participants indicated that nutrition education at school had so far been limited, though the subject of nutrition had been raised to some extent during classes. It was obvious that the adolescents were not very pleased with current nutrition education. The classes were felt to be boring and included many writing assignments, whereas they would prefer practical activities. 'These classes always leave us totally drained. The way they are presented is extremely boring'. The participants also indicated that the subject of nutrition was not much fun to study and that the information on this subject was not more interesting than the ather subjects discussed in the classes.

\section{Interest in nutrition education}

The adolescents were asked to indicate what type of nutritional information inter- 
ested them specifically. While a number of participants claimed not to be interested in any of $i t$, some did mention specific topics, such as "the consequences of skipping breakfast:. Another topic that raised some interest was the importance of consuming fruit: How important is fruit actually? What do apples do and what is so good about them? My mother always makes me eat fruit, so I'm used to it. But what good is it really?' Both boys and girls were interested in the relation between snacking and weight gain: "What is healthy and what would make you horribly fat? Everybody" likes to snack, but nobody really wants to become fat. They also mentioned that they should not only be told that certain foods are good or bad for them, but also why they are. On the other hand, some feared that such information might well be too difficult to understand: "I think they would only tell you stuff you don't understand anyway". Other topics that were mentioned included 'bad" food" and "particular combinations of foodstuff's" as well as 'information on the tastiest chewing gum or who can blow the best bubbles. When asked what they thought about information on the links between nutrition and sport, their response was lukewarm. In their view, engaging in sports simply meant they could eat a bit more, and that this was quite a healthy way of living.

\section{Ideas to make nutrition education more interesting}

The adolescents suggested that classes should address a range of mutrition topics. They also felt that assignments should not take too long. At the same time, they indicated that existing assignments often took them so little time to complete that they frequently had nothing to do in class. They emphasised the importance of being allowed to engage in practical activities during the classes: "As long as it's fun and you're allowed to actually do things yourself'. They expected that making the assignments more fun to do would also enable them to learn more from them: 'Actually doing things yourself means you learn from them". One of the things they would like to do is tasting various products, for instance by cooking a meal for themselves, preparing a fruitshake or comparing various types of Dutch and exotic fruits. The boys tended to prefer savoury products, while the girls preferred sweet products. The boys felt that such activities had to be done in class, rather than at occasions like school parties, 'as that could ruin the party'. The adolescents preferred working in groups. They also felt that it would be nice to include some elements of competition in the activities, especially if there were attractive prizes to be won: Like who is the best cook. And that group is then allowed to decide what they're going to cook'. Such competitions would have to be judged by an independent party, not by their own teacher: "I would say it shouldn't be the teacher, because if he likes someone, he would choose them: Some boys came up with the idea to construct a website on nutrition. Some of the adolescents liked the idea of somehow involving celebrities in nutrition education activities. This could be achieved by having posters showing these people, or by inviting them to give talks in class: 'It would be far more fun to listen to celebrities. Boys would be interested especially in sports personalities like football-players, field hockey players and tennis players, preferably young ones, as they could set a good example. The girls aiso liked the idea of involving celebrities to 
present the information in a more attractive way. They suggested Dutch pop stars as well as famous Dutch chefs.

\section{At what times would adolescents be receptive to nutrition education?}

The adolescents felt that nutrition education should be provided during class hours. Outside school hours, they would only be willing to work on nutrition, for instance in the form of homework, if the assignments were very attractive or if there were prizes to be won: 'In class, because you don't want to do a lot of homework. You'd rather spend your time doing other things". Although the participants felt that their parents were an important source of information on nutrition, they did not support the idea of involving parents in nutrition education activities. Only girls felt that parents should be informed about the school's nutrition education programmes. In addition to getting information on nutrition in class, the participants also liked the idea of being offered certain products during breaks, although they were not sure whether this would set them thinking about the health aspects. The same was said about the idea of tasting samples or being offered fruitshakes at school parties. The adolescents did not want to be presented with nutritional information at their sports clubs: 'There's never enough time anyway. You want to do other things there'.

\section{Types of educational activity}

Nutrition education for adolescents could take many forms. The chairpersons suggested a number of these types of education, and asked the participants to respond. Some of these activities (tasting products, preparing meals, being offered products, activities involving competition, designing a website) have been discussed above. Girls generally responded to the proposed intervention activities with greater enthusiasm than boys. Boys tended to be more straightforward in their response: if an activity appealed to them, they were willing to discuss it at length, but if they regarded it as boring, the discussion ended there and then. Girls as well as boys said they would like nutritional information to be provided on computer, for instance on CD-ROM. Such a CD should then contain useful information, but not too much text. Internet would be less suitable as a medium, as not everybody had access to it. The girls would appreciate a flyer providing an overview of all the school's nutritional activities for the year. Such a flyer would have to be humorous, for instance in the form of a comic. Boys did not respond to the idea of a flyer. The adolescents said that the school magazine was poorly read. The girls expected that nutritional information in a newsletter or the school magazine would only be read if it included recipes or a puzzle with prizes. As regards recipes, they said 'It would have to be something out of the ordinary, something novel'. Games and contests, like writing a rap song of developing a commercial were said to be great fun. But they also said that such contests were often too childish or not challenging enough: 'We're much too mature for that' and 'That's not really a challenge. You know in advance that you can do it. That's too easy really. Free postcards with short humorous messages about nutrition would probably be picked up and perhaps used. The boys felt that such postcards 
should contain something a bit 'shocking': 'Like when someone is hit on the head by a banana. That would be fun'. The adolescents also felt that postcards should be brightly coloured and eye-catching.

Participants reported that radio and TV were rarely used in existing classes on nutrition. They also reported that they hardly listened to the radio during their leisure time, and that they would not be interested in TV programmes on nutrition. The use of video in class would be appreciated. Opinions were divided about keeping a food diary. Boys were not interested, while girls were much more enthusiastic about the idea, although they were afraid it would take them a lot of time or it might mean they would have to go on a diet. Girls said they would enjoy doing tests of their own habits, like the Fruit and Vegetable Test or the Fat Test published by the Netherlands Nutrition Centre, although they admitted that they would not act upon the results. The boys failed to see the use of such a test. The idea of interviewing someone about nutrition drew a mixed response. Some boys liked the idea, while others thought it was boring. The girls were more enthusiastic about this activity, and came up with the idea of linking it to a project or presentation. The interviewers indicated several times that they would like nutrition education to take the form of contests or other competitive activities. They would prefer competing for many small prizes rather than for one big one: 'It's always stimulating if you win. Great!'. The participants also felt that it was very important to have humorous materials. "That's essential. If they're not funny, you wouldn't even look at them'. They also appreciated topics being repeated, and exciting activities.

\section{Discussion}

In interpreting the above findings, it should be remembered that this was a focus group interview study among a small, non-representative group (Morgan \& Kreuger, 1998; Van Assema et al., 1996). In fact, this type of research does not aim for representativeness, which was why we decided to do the study at a limited number of schools in the area around Maastricht. We did, however, try to include all relevant subpopulations, in this case boys and girls aged 12 to 14 , in the interviews. The present study tried to identify adolescents' ideas about nutrition education, rather than to assess the relative importance of various opinions. For instance, the participants indicated several requirements for nutrition education activities, such as that they should be humorous. The present study does not allow us to draw any conclusions about the relative weight of the various requirements. What can be concluded is that aspects like humour may make the activities more attractive to the target group and that the use of humour should be considered in designing new activities. Although we did not aim to compose a representative group, it should be noted that the groups did not include only those adolescents who took a special interest in the subject of nutrition. The participants clearly indicated that they had been motivated to take part in the interviews by the cinema token that they had been promised.

Each focus group interview was attended by two of the researchers. It was their impression that some of the adolescents were afraid to voice their opinions. Another 
aspect that is relevant in interpreting the findings is that the study was done among adolescents in the basic education stage of secondary school. In theory, all Dutch students in basic education are expected to be taught at the same level. In practice, however, several levels are being distinguished, and there are clear differences between these levels in nutritional habits and learning styles (Brug et al., 2000; De Vries, Lucker, Cremers, \& Katan, 1990; Kuit, Manschot, Rensink, Van Der Werf, \& Van Wezel, 1998; Voedingscentrum, 1998).

The findings of the present study are to be used in designing nutrition education activities that suit the needs of adolescents aged 12 to 14 . Designing adequate interventions will further require other, quantitative, types of research than the present study, for instance into the causes of undesirable food habits. However, focus group interviews are a useful initial method, especially if little is known about the target group to be studied. Unlike quantitative methods; they offer an opportunity to do exploratory research and at the same time discuss specific topics in greater detail. Besides interviewing students, we also held interviews with parents and teachers to supplement information from different points of view (see appendices 1 and 2).

The focus group interviews revealed that adolescents are not very enthusiastic about activities on the subject of nutrition. Nevertheless, at least some of them did appear to feel the need for information on a number of food-related topics, like the importance of eating fruit and the consequences of skipping breakfast. In any case, the adolescents appeared to be familiar with the idea of being educated about healthy nutrition. The fact that they were willing to help think of ways to present such education suggests that they accept the idea of being asked by the school to work on the subject. It also suggests that they do feel that the subject of nutrition can be taught in an attractive way. What did become clear is that such nutrition education would have to meet their requirements. It must not be too complicated and they must be allowed to absorb the information in an active manner, that is, through games, contests with prizes, computer programmes or actually preparing and tasting food. There was a preference for working in groups. All activities should to be challenging, not too childish, humorous, colourful, exciting and even a bit shocking. Activities outside class hours would only be accepted if they were exceptionally exciting. The idea of conducting nutrition education in cooperation with parents was rejected.

Our focus group study showed that designing nutrition education materials for adolescents aged 12 to 14 will not be an easy task. Nevertheless, it is important to address the subject of nutrition among youngsters of this age bracket, in view of the current unhealthy nutritional patterns and their potential short-term and long-term health consequences. The study has provided us with some ideas that may be useful in designing nutrition education activities. Such activities can be designed on the basis of requirements formulated by the adolescents themselves. They should include the topics that appear to interest at least some of the target audience. 


\section{Appendix 1}

Semi-structures interviews with teachers at preparatory secondary vocational education schools

We used semi-structured interviews to examine the ideas, thoughts, feelings and opinions of teachers at preparatory secondary vocational education schools about the feasibility and applicability of a nutrition education programme for 12-14-year-old students. Twelve interviews were held, involving a total of 21 teachers. The discussion was initlated using an interview scheme, which related to teachers' opinions about the existing nutrition education as well as about various activities planned as part of the 'Krachtvoer' nutrition education programme. The interviews were transcribed and analysed using the 'NUDIST' (version 4.0) software program.

All teachers who took part in the interviews indicated that they were interested in the topic of nutrition. Their students' breakfast habits in particular were a source of concern to them. Lessons about nutrition were mostly given at the beginning of the school year, and an average of 12 hours was spent to this topic. The teachers were generally positive about the existing curriculum on nutrition but felt that there were not enough practical assignments. Teachers said that they preferred to have some variety in the lessons, and to include practical lessons like cooking lessons and games with a high chance of winning. Besides, teachers stressed that taste preferences should be taken into account. The teachers also preferred activities almed at short-term consequences, because according to the teachers "children tend to live from one day to the next". The teachers were generally positive about the activities planned as part of the 'Krachtvoer' programme. They added that the activities and materials should be challenging, not childish, funny, colourful, not too difficult, positive, and exciting, so as to draw the attention of the students. They also underlined the fact that this age group is very hard to reach and no major dietary changes should be expected. 


\section{Appendix 2}

Focusgroup interviews with parents of 12-14-vear-old students from preparaton secondary vocational education students

We used focus group interviews to examine the ideas, thoughts, feelings and opinions of parents of 12-14-year-old students about nutrition education at school and their need to participate. Two focus group interviews were held, involving a total of 14 parents. The interview scheme related to perceived importance of school nutrition education and their need to participate in it, and to their opinions about various activities planned as part of the "Krachtvoer" nutrition education programme. The interviews were transcribed and analysed using the 'NUDIST' (version 4,0) software program.

All parents who took part in the interviews indicated that they were interested in the topic of nutrition and found it important that this topic was discussed at school. The parents mentioned that their children were at an age when they (the parents) lose sight of their children's nutritional habits. The parents also volced concerns about their children's dietary habits, fruit and snack consumption in particular being a source of concern. Most parents indicated that their children were mostly influenced by their peers, and that they tried to take their dietary preferences into account. Parents also mentioned that their children did not talk about the nutrition lessons at home. The parents wanted all activities and materials to be practical, interactive, positive, visual, not childish and not too difficult. In addition, they found it important that their children were given an opportunity to smell, feel and taste new products at school, since they would be more likely to taste new products in a peer group at school than at home. The parents liked to be involved in a nutrition ediucation programme but indicated that they should approached as a separate group. They doubted if their children would appreciate performing activities in cooperation with them. 


\section{Abstract}

The aim of the study was to investigate the relative importance of personal and social environmental predictors of the consumption of frult, high-fat snacks and breakfast. We used a schoolbased cross sectional survey Data were collected through written questionnaires that were completed in eight schools by six-hundred-and-one preparatory secondary vocational education schools. About one fourth of the variation in actual behaviours and intentions to change the behaviours could be explained. Stepwise multiple regression analysis revealed that, for all three behaviours, higher intention to change was especially associated with a more positive attitude and subjective norm, and higher intentions to increase fruit intake with more pasitive self-efficacy expectations. With regard to actual consumption, a more positive attitude towards eating frult was the only significant correlate of a higher consumption of fruit. $A$ more positive attitude towards eating high fat snacks, a perceived lower intake of the mother, and higher food availability and accessibility were associated with high-fat snack consumption, and a more positive attitude to breakfast more frequently was associated with more frequent breakfast consumption. The results ndicate that adolescents" attitudes are the most important determinants of different health-related eating behaviours and intentions to change. Healthy diet promoting interventlans for adolescents should include creative strategies to achieve positive associations. with healthy dietary changes.

Will be published as: Martens, M., Van Assema, P., \& Brug, 1. (in press) Why do adolescents eat what they eat? Personal and social environmental predictors of fruit, snack and breakfast consumption among Dutch 12-14-year-old students. Public Health Nutrition. 


\section{Introduction}

Unhealthy dietary habits, such as low fruit consumption, frequent consumption of high-fat snacks, and skipping breakfast ${ }_{x}$ are common among adolescents in the Netherlands as well as other western countries (Department of Health, 2000; Health Education Authority, 1999; Munoz, Krebs-Smith; Ballard-Barbasch, \& Cleveland, 1997; Schaalma et al., 1997; Voedingscentrum, 1998). These behaviours has been found to be associated with increased risk of overweight and obesity, difficulties concentrating in school and, in the longer run, a higher risk for chronic diseases such as diabetes, cardiovascular diseases, and certain types of cancer (Matthews, 1996; Pollit, 1995, 1998; Willet, 1994). Especially the number of adolescents that are overweight or obese is a rapidly growing problem in the Netherlands, as in many other countries (Gezondheidsraad, 2003; Hirasing, Fredriks, Van Buren, Verloove-Van Horick, \& Wit, 2001; WHO, 1998). Improving the nutritional habits of adolescents is therefore important. Moreover, healthy eating at an early age may be an important determinant for dietary choices later in life (Branen \& Fletcher, 1999; Krebs-Smith et al., 1995; Lytle et al., 2000). Especially when minors transfer from elementary school to secondary school their eating habits change and become less favourable (De Vries \& Da Costa Senior, 1992). Intervening at that age may therefore prevent unhealthy eating behaviour becoming habitual and thus difficult to change. Further, adolescents from lower socio-economic position (SEP) groups have less favourable diets compared to their peers from higher SEPS (Koivisto Hursti, 1999; Roos et al., 1998). Interventions promoting a healthy diet should therefore be suitable especially for lower SEP groups.

In order to develop planned interventions to promote healthy eating, it is necessary to gain insight into the potential determinants of dietary practices (Green \& Kreuter, 1999). The aim of the present study was to investigate the relative importance of personal and social environmental predictors of specific dietary behaviours. This in order to identify programme objectives for interventions aimed at encouraging 12-14-year-old lower vocational high school students to increase their consumption of fruit, decrease the consumption of high-fat snacks, and increase breakfast frequency and quality.

A model that has been used before for the assessment of determinants of dietary behaviour is the ASE (attitude-social-influence-efficacy) model (De Vries et al., 1988). In the ASE model, behaviour is considered to be primarily a result of behavioural intention. Three main psychosocial factors have been identified that predict intention, namely attitude, social influence and self-efficacy. A person's attitude towards a specific behaviour is the result of the expected effects of performing such behaviour. Social influence is a result of subjective norms that are relevant to this behaviour, perceived support from others to express or refrain from the behaviour and whether important others perform or refrain from such behaviour (descriptive norm). Self-efficacy expectations are the result of a person's beliefs about the abilities to perform the desired behaviour. Apart from its influence on behavioural intention, self-efficacy is also expected to influence behaviour directly. External variables, such as socio-demographic factors, are expected to influence behaviour through 
behavioural determinants and intention. Behaviour, or attempted behaviour, leads to feedback that may influence the determinants (De Vries et al. 1988) "A number of additional determinants have been proposed. For children, their family environment may be of special importance. In particular familly food rules about food - the restrictions or obligations for children to eat certain foods - have been found to influence the dietary behaviour of adolescents (De Bourdeaudhuij, 1997). Further, earlier studies have found that avallability and accessibility of foods are important predictors of children's dietary intake, which means that items of fruit or breakfast need to be avallable and accessible for children to be able to eat them (Baranowski et al., 2000; Kolvisto Hursti, 1999).

In the present study, the above-mentioned potential predictors of consumption of fruit, high-fat snack consumption and breakfast consumption were studied in a school-based survey.

\section{Method}

\section{Respondents and procedure}

In the Netherlands, secondary education is divided in different levels: university preparatory education, senior general secondary education and preparatory secondary vocational education. Children with a lower SEP background are over-represented in preparatory secondary vocational education schools. A random sample of eight schools was drawn from a list of addresses of preparatory secondary vocational education schools in the southern part of the Netherlands. All schools agreed to participate after they had received written and oral information about the study. In these schools, teachers selected one or more classes with 12-14-year-old-students. These students were asked to complete a written self-administered questionnaire during school hours. Completion took about 20 minutes. All students who were present during data collection hours agreed to participate.

\section{Questionnaire}

Separate questionnaires were developed for each of the three types of risk behaviour: consumption of fruit, high-fat snacks intake and breakfast habits. Administration of more than one of the questionnaires among the same students was not possible because of time restraints. Classes were therefore randomly assigned for all children in a class to receive one of the three questionnaires.

\section{Demographic factors}

In the first part of the questionnaire, some demographic factors were measured, such as gender and age. In addition, students were asked whether they lived with both parents or in a different home situation. Lastly, children were asked about the native country of their parents. 


\section{Dietary habits}

Consumption of fruit was assessed using the fruit questions from a validated fruit and vegetable food frequency questionnaire (Van Assema, Brug, Ronda, Steenhuis. I. \& Oenema, 2002). In two separate items, students indicated how many days a week they consumed fruit and fruit juice. They also indicated the number of pieces of fruit or glasses of fruit juice they consumed on such days students were also asked to write down which fruit and fruit juices they consumed most often. Frequency and quantity were multiplied to obtain estimates of mean consumption of frult in pieces per day and mean consumption of juice in glasses per day. Consumption of high-fat snacks was assessed using items from a larger validated food frequency questionnaire to assess fat intake (Van Assema, Brug, Ronda, \& Steenhuis, 2001). Four items questioned on how many days a week the following snacks were consumed: fried snacks, nuts and potato chips, pastries and candy-bars, and cookies. on the basis of these four items, a single score was calculated for the mean number of days per week on which these high-fat snacks were eaten. One item asking students on how many days a week they ate breakfast was used to assess breakfast habits. In addition, students were asked, using different answer categories, where they usually consume fruit and/or fruit juice, high-fat snacks and breakfast (e.g. in school, at home) and when they consume fruit and/or fruit juice and high-fat snacks (e.g. in the morning) most often.

\section{Personal and social environmental determinants}

Unless mentioned otherwise, five point scaled items were used (scales from -2 to +2 ). Intention was assessed with one item on plans to change the behaviour in the next six months. Attitude was assessed by means of twelve to fourteen items (depending on the dietary behaviour) on the consequences of the behaviour (e.g. eating fruit is tasty, eating snacks is enjoyable, I can concentrate better if I have breakfast). The scores on these items were summed and divided by the number of items to obtain a single score for attitude (Cronbach's alpha's between 0.62 and 0.76 ). The descriptive norm was assessed by two items that questioned perceived behaviour of the mother and father. The inter-item correlation of the two items was low and therefore no scalle could be formed for descriptive norm. Four items about the percelved norm of mother, father, brother(s)/sister(s), and friends measured the subjective norm. The scores on these items were summed and divided by four to obtain a single score for subjective norm (Cronbach's alpha's between 0.69 and 0.84). Two items assessed social support of mother and father by asking how strong the desired behaviour was supported by mother or father. The items were summed and divided by two to obtain a single score for social support (inter-item correlation between 0.60 and 0.61 ). Self-efficacy was assessed with two items measuring how confident students were about showing the desired behaviour and how easy it was to show this behaviour. The inter-item correlations however were moderate (inter-item correlation between 0.34 and 0.54 ). Further, the answer to the question on how confident students were was extremely biased toward the positive answers (high confidence) for all three types of behaviour. This indicates that inclusion of this item did not result in substantial variance in self-efficacy for a large majority of the respondents. Therefore, only the item dealing 
with the easiness of showing the desired behaviour was included in the analyses as a measure for self-efficacy.

In the fruit and breakfast questionnaire, the presence of family food rules was measured with one itern with two possible answers (i.e. yes, there are rules in some way - no attention is paid). In the snack questionnaire the presence of food rules was measured for three different snack categories (fried snacks, nuts and potato chips, pastries, candy-bars and cookies) separately. These three items were summed and divided by three to obtain one score for food rules (Cronbach's alpha $=0.70$ ). Subsequently the score was transformed to a categorical scalle similar to the food rules scores for fruit and breakfast. We assumed that the family food rules encouraged performance of the desired behaviours. In the fruit questionnaire, availability and accessibility of food was measured with 7 items (is fruit/ fruit juice availlable at home, is there enough variety of fruit at home, if you were to indicate at home that you like a certain fruit/ fruit juice would your parents buy them, is fruit available in a fruit bowl, do you get fruit to take to school). Three-point scales were used to answer these items (usually yes, sometimes, usually no). The item-scores were summed to form a single score for a food availability and accessibility index. Food availability and accessibility was measured in a similar way in the snack questionnaire, using 7 items (if you were to indicate at home that you like certain fried snacks/ nuts or potato chips/ pastries candy-bars or cookies would your parents buy them, are fried snacks/ nuts or potato chips/ pastries candy-bars or cookies available at home, do you get snacks to take to school). The breakfast questionnaire measured food availability and accessibility in a similar way $y_{r}$ using 4 items (if you were to indicate at home that you like certain breakfast items would your parents buy them, are breakfast items available at home, is the table set for breakfast, are you having breakfast at a table).

\section{Analyses}

Statistical analyses were performed using the SPSS program (version 9.01; SPSS Inc, Chicago, IL). To identify potential predictors of the three types of behaviours in the study, two sets of stepwise regression analyses were conducted for each type of behaviour. Firstly, the intention to adopt a particular type of behaviour was regressed in three steps on the hypothesised personal and social environmental predictors, being gender, age (Step 1), attitude, descriptive norm of the mother, descriptive norm of the father, subjective norm, social support, self-efficacy (Step 2), existence of food rules, and fruit availability and accessibility (Step 3). Secondly, the consumption score was regressed on the same set of variables, in which intention was included as an additional independent variable in Step 2. Normality of the dependent variables was found to be acceptable for performance of regression analyses.

\section{Results}

The results will be presented for each behaviour separately. Since the results did not 
show any substantial differences between the different steps in the regression anialysis, only the final regression models will be discussed.

\section{Fruit}

Two-hundred-and-four students, $52 \%$ male, completed the fruit questionnaire. Ten percent was 12 years, 53\% 13 years and 37\% 14 years old. Most students (75\%) lived with both parents. Most students had parents whose native country was the Netherlands: $82 \%$ of the mothers and $80 \%$ of the fathers.

Mean fruit intake was $1.1(S D=0.9)$ pieces of fruit per day. Favourite fruits were apples, bananas, pears, and oranges. Seventy-six percent of the students did not eat the 2 pieces of fruit per day that are recommended in the Netherlands. Mean fruit juice intake was $1.4(S D=1.0)$ glasses of fruit juice per day. However, fake fruit beverages such as soft drinks with fruit taste, lemonade and yoghurt drinks with a fruit taste, were often reported as most frequently consumed fruit juices. Therefore, analyses for fruit were done on the basis of the consumption of fresh fruit only. Almost all students indicated that fruit was mostly eaten at home $(94 \%)$, instead of at school $(1 \%)$ or ellsewhere $(5 \%)$. Also, most students indicated that they eat fruit on varying times (92\%). The remaining students $(8 \%)$ reported to eat fruit exclusively during one of the main meals.

Except for social support, the mean scores on the personal and social environmental predictors of consuming fruits were positive (Table 1). Especially the perceived be-

\section{Table 1}

Means and SD of selected potential personal predictors of fruit, snack and breakfast consumption (measured on scales from -2 to +2 )

\begin{tabular}{|c|c|c|c|}
\hline 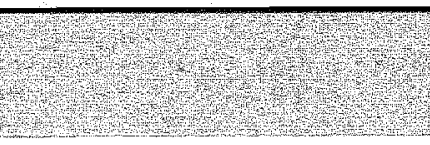 & $\begin{array}{l}\text { consumption } \\
\text { chut }\end{array}$ & 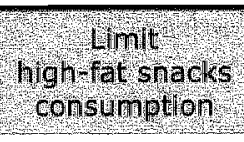 & $\begin{array}{l}\text { Breakfast } \\
\text { consurpton }\end{array}$ \\
\hline Attitude ${ }^{1}$ & $0,35(0,54)$ & $0,01(0,45)$ & $0,65(0,78)$ \\
\hline Perceived behaviour mother ${ }^{2}$ & $0,46(1,01)$ & $0,93(0,91)$ & $0,97(1,30)$ \\
\hline Perceived behaviour father ${ }^{2}$ & $0,11(1,15)$ & $0,53(1,02)$ & $0,65(1,35)$ \\
\hline Subjective norm ${ }^{3}$ & $0,22(0,78)$ & $-0,20(0,87)$ & $0,33(0,77)$ \\
\hline Social support ${ }^{4}$ & $-0,48(1,12)$ & $-0,14(1,14)$ & $-0,32(1,23)$ \\
\hline Self efficacy ${ }^{5}$ & $1,29(0,81)$ & $0,72(1,10)$ & $0,93(1,02)$ \\
\hline Intention to change $\mathrm{e}^{6,7}$ & $0,10(1,20)$ & $0,14(1,26)$ & $-0.30(1,30)$ \\
\hline
\end{tabular}

1 A positive score on attitude indicates a positive attitude towards eating frut, limiting mighwat snack consumption and hawing breakfast.

${ }^{2}$ A pasitive score on the descriptive norm indicates that students percelved thelr mother/father as eating many fruits, few high fat snacks and having breakfast frequently.

${ }^{3}$ A positive score on subjective norm indicates that students thought that other people thintir that they should eat fruit ilmit their consumption of hilgh-fat snakks and thave breakfast.

A positive score on social support indicates that the students percelwed their environment as supportive towards eating fruits; limit their high-fat smack comsumption and having breallfast.

${ }^{5}$ A positive score on self-efficacy indicates that students found it easy to eat more fruit, limit their highfat sinack consumption and breakfast regulanly.

\$ A positive score on intention indicates that students intended to increase their fruit consumption, limit their consumption of high-fat snacks and have breakfast more frequently in the next six momths.

Only students who were not already eating a breakfast seven days a week were selected. 
haviour of the mother and self-efficacy towards eating fruit were positive, indicating that the students perceived their mothers as great fruit eaters and that they found it easy to eat more fruit. Perceived social support towards the consumption of fruit was negative, indicating that students perceived their environment as not supportive for eating fruit. The average score on intention to eat more fruits was almost neutral. Twenty-seven percent of the students reported that there are rules at home about eating fruits (not in Table). Fruits were perceived to be widely available and accessible at home (Mean $10.9, \mathrm{SD}=2.0$ ).

Attitude, perceived behaviour of the mother, perceived behaviour of the father, subjective norm, social support and self-efficacy were significant correlates of inten-

\section{Table 2}

Results of stepwise regression analyses with intention to perform a given behaviour as dependent variable and gender, age (STEP 1), attitude, descriptive norm of the mother, descriptive norm of the father, subjective norm, social support, self-efficacy (STEP 2$)^{1}$, food rules, and fruit availability and accessibility (STEP 3) as predictor variables.

\begin{tabular}{|c|c|c|c|c|c|c|c|}
\hline 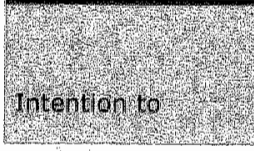 & 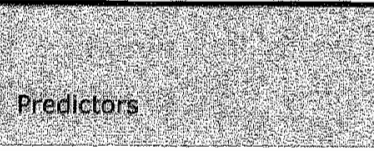 & Wenglo & $x^{2} p^{2}$ & 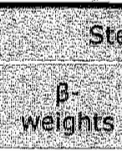 & $\frac{2}{42}$ & 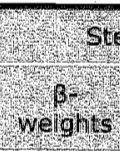 & (3) \\
\hline $\begin{array}{l}\text { Increase } \\
\text { consumption of } \\
\text { frutt } \\
(n=204)\end{array}$ & $\begin{array}{l}\text { Gender } \\
\text { Agle } \\
\text { Attitude } \\
\text { Percelved behaviour mother } \\
\text { Perceived behaviour father } \\
\text { Subjective norm } \\
\text { Social suppoit } \\
\text { Self-efficacy } \\
\text { Food rules } \\
\text { Food avaliability and } \\
\text { accessibillty }\end{array}$ & $\begin{array}{r}0,09 \\
-0,02\end{array}$ & 0,01 & $\begin{array}{c}0,08 \\
-0,05 \\
0,25 * \\
-0,15 * \\
-0,19 * \\
0,20^{*} \\
0,17 * \\
0,15 *\end{array}$ & $0,26 *$ & $\begin{array}{c}0,06 \\
-0,04 \\
0,26^{*} \\
-0,14^{*} \\
-0,18^{*} \\
0,19^{*} \\
0,19^{*} \\
0,16^{*} \\
0,05 \\
-0,10\end{array}$ & $0,27 *$ \\
\hline $\begin{array}{l}\text { Limit consumption } \\
\text { of high fatt snacks } \\
(\mathrm{n}=194)\end{array}$ & $\begin{array}{l}\text { Gender } \\
\text { Age } \\
\text { Attitude } \\
\text { Perceived behaviour mother } \\
\text { Perceived behaviour father } \\
\text { Subjective norm } \\
\text { Social stupport } \\
\text { Self fiflcacy } \\
\text { Food rules } \\
\text { Food awallability and } \\
\text { accessibllity }\end{array}$ & $\begin{array}{l}0,24 \\
0,04\end{array}$ & 0,06 & $\begin{array}{l}0,19 * * \\
0,07 \\
0,39 * * \\
0,05 \\
0,05 \\
0,19 * * \\
-0,01 \\
-0,12\end{array}$ & $0,26 *$ & $\begin{array}{l}0,20 * 3 \\
0,08 \\
0,35 * \\
0,04 \\
0,06 \\
0,17 * \\
-0,04 \\
-0,11 \\
0,04 \\
0,10\end{array}$ & 0,27 \\
\hline $\begin{array}{l}\text { Have breakfast: } \\
\text { more frequently } \\
(\mathrm{n}=163)\end{array}$ & $\begin{array}{l}\text { Gender } \\
\text { Age } \\
\text { Attitude } \\
\text { Percelved behaviour mother } \\
\text { Percelved behavlour father } \\
\text { Subjective norm } \\
\text { Social support } \\
\text { Self-efficacy } \\
\text { Food rules } \\
\text { Food avallability and } \\
\text { accessibllity }\end{array}$ & $\begin{array}{l}0,10 \\
0,03\end{array}$ & 0,01 & $\begin{array}{c}0,14 \\
0,05 \\
0,33 \\
0,16 \\
0,02 \\
0,26 \\
=0,07 \\
0,04\end{array}$ & $0,20 \%$ & $\begin{array}{c}0,14 \\
0,02 \\
0,33 \\
-0,15 \\
0,02 \\
0,26 \\
-0,07 \\
0,04 \\
-0,02 \\
-0,00\end{array}$ & 0,20 \\
\hline
\end{tabular}

* $p<0,05$ and $\rho<0,01$ 1 See the footnotes of Table 1 for the direction of the potential personal predictors of firuit, snack and
breakfast consumption

"Only students who were not always eating a breakfast were selected 
tion to increase consumption of fruit (Table 2). Students who had a greater intention of increasing their fruit consumption had a more positive attitude towards eating fruit, perceived their mother and father to eat few fruits, thought that other people think that they should eat fruits, perceived their environment to support them in eating fruits, and found it easy to eat more fruits than students who had less intention to increase fruit consumption. Attitude was the only significant correlate of fruit consumption (Table 3). The intention towards increasing fruit consumption and the perceived behaviour of the mother were borderline significant ( $p$-values 0.053 and 0.052 , respectively). Students who ate more fruit, had a more positive attitude to-

\section{Table 3}

Results of stepwise regression analyses with behaviour as dependent variable and gender, age (STEP 1), attitude, descriptive norm of the mother, descriptive norm of the father, subjective norm, social support, self-efficacy, intention to perform a given behaviour (STEP 2) ${ }^{1}$, food rules, and fruit availability and accessibility (STEP 3) as predictor variables.

\begin{tabular}{|c|c|c|c|c|c|c|c|}
\hline The behaviour & predictors. & Wegrepts & $x^{2}+x^{2}$ & 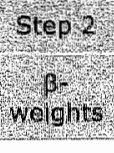 & $r^{2} p^{2} x^{2}$ & 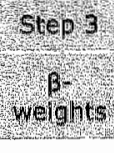 & 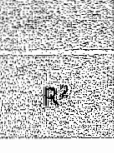 \\
\hline $\begin{array}{l}\text { Consumption of } \\
\text { firuit } \\
(n=204)\end{array}$ & $\begin{array}{l}\text { Gender } \\
\text { Age } \\
\text { Attitude } \\
\text { Perceived behaviour mother } \\
\text { Perceived behaviour father } \\
\text { Subjective norm } \\
\text { Sacial support } \\
\text { Self-efficacy } \\
\text { Intention to change } \\
\text { Food rules } \\
\text { Food availabillity and } \\
\text { accessibility }\end{array}$ & $\begin{array}{l}0,02 \\
0,06\end{array}$ & 0,004 & $\begin{array}{c}0,07 \\
0,04 \\
0,47 * * \\
0,13 \\
0,11 \\
-0,10 \\
0,06 \\
0,07 \\
-0,14 *\end{array}$ & $0,29^{* * * *}$ & $\begin{array}{c}0,08 \\
0,04 \\
0,48^{* * *} \\
0,13 \\
0,10 \\
-0,10 \\
0,08 \\
0,07 \\
-0,14 \\
-0,05 \\
0,00\end{array}$ & 0,30 然冰 \\
\hline $\begin{array}{l}\text { Consumption of } \\
\text { high-fat snacks } \\
(\mathrm{n}=194)\end{array}$ & $\begin{array}{l}\text { Gender } \\
\text { Age } \\
\text { Attitude } \\
\text { Perceived behaviouir mother } \\
\text { Perceived behaviour father } \\
\text { Subjective norm } \\
\text { Soclal support } \\
\text { Self-efficacy } \\
\text { Intention to change } \\
\text { Food rules } \\
\text { Food avallabillity and } \\
\text { accessibility }\end{array}$ & $\begin{array}{c}-0,14^{*} \\
0,06\end{array}$ & 0,02 & $\begin{array}{c}-0,06 \\
0,01 \\
-0,42 * * \\
0,11 \\
0,04 \\
-0,61 \\
0,02 \\
-0,05 \\
-0,11\end{array}$ & $0,26^{\text {*** }}$ & $\begin{array}{l}-0,08 \\
-0,01 \\
-0,36 * * \\
0,13 * \\
0,03 \\
-0,05 \\
0,07 \\
-0,06 \\
-0,08 \\
-0,07 \\
-0,17 *\end{array}$ & $0,29 *$ \\
\hline $\begin{array}{l}\text { Breakfast } \\
\text { frequency } \\
(n=203)\end{array}$ & $\begin{array}{l}\text { Gender } \\
\text { Age } \\
\text { Attitude } \\
\text { Perceiwed behaviouir mother } \\
\text { Perceiwed behaviouir father } \\
\text { Subjective norm } \\
\text { Social support } \\
\text { Self-efficacy } \\
\text { Intention to change } \\
\text { Food rules } \\
\text { Food availlability and } \\
\text { accessibility }\end{array}$ & $\begin{array}{l}-0,18^{*} \\
-0,09\end{array}$ & 0,04 & $\begin{array}{l}-0,10 \\
-0,08 \\
0,31 * * 3 \\
0,06 \\
0,11 \\
0,09 \\
0,02 \\
0,06 \\
0,11\end{array}$ & $0,27^{* * * *}$ & $\begin{array}{l}0,08 \\
-0,07 \\
0,28 * \\
0,05 \\
0,09 \\
0,07 \\
-0,06 \\
0,07 \\
0,11 \\
0,07 \\
0,12\end{array}$ & $0,29 * *$ \\
\hline
\end{tabular}

* $p<0,05$ and *** $\rho<0,01$

1 See the footnotes of Table 1 for the direction of the potential personal predictors of frutt, snack and breakfast consumption 
wards eating fruit, percelved their mother as greater fruit eaters, and had a more negative intention towards increasing the fruit consumption, than students who ate less fruits.

\section{High-fat snacks}

One-hundred-and-ninety-four students, $41 \%$ male, completed the snack questionnaire. Thirteen percent was 12 years, $42 \%$ was 13 and $45 \%$ was 14 years old. Most students $(80 \%)$ lived with both parents. Elghty percent of the mothers and $77 \%$ of the fathers of the students were born in the Netherlands.

On average the students ate the different categories of high-fat snacks on 2.4 $(S D=1.3)$ days a week. Most students $(63 \%)$ indicated to consume fried snacks and nuts/potato chips most often at home as compared to at school $(2 \%)$, elsewhere $(14 \%)$, or varying $(21 \%)$. Also, most students indicated that snacks were mainly eaten in the evening $(67 \%)$. Fewer students $(33 \%)$ indicated to mainly eat them during the afternoon. About half the students reported to eat pastries, candy-bars, or cookies, most often at home (52\%), as compared to at school (36\%), or elsewhere $(12 \%)$. Also, most students reported these snacks were most often eaten during the afternoon $(87 \%)$. Fewer students reported to eat them in the evening $(12 \%)$ or in the morning $(1 \%)$.

Except for subjective norm and social support, the mean scores on the personal and social environmental predictors of limiting the consumption high-fat snacks were positive (Table 1). Especially the percelved behaviour of the mother and father and self-efficacy were positive, indicating that the students perceived their mother and father to eat few high-fat snacks and that they found it easy to limit their high-fat snack consumption. The subjective norm and social support were negative, indicating that students perceived that other people do not think that they should limit their consumption of high-fat snacks, and students perceived their environment as not really supportive towards eating fewer high-fat snacks. The mean attitude and intention scores were close to neutral. Fifty-eight percent of the students reported some parental rules at home about eating high fat-snacks (not in Table). High-fat snacks were perceived generally as avallable and accessible at home (Mean 9.0, SD = 2.8).

Gender, attitude, and subjective norm were significant correlates of intention to limit consumption of high-fat snacks (Table 2). Students who had greater intentions to limit high-fat snack consumption were more likely to be girls, had a more negative attitude towards eating high-fat snacks and were more likely to think that other people expect them to limit their high-fat snack consumption than students who had less intention. Attitude, perceived behaviour of the mother and food availability and accessibility were significant correlates of high-fat snack consumption (Table 3). Students who consumed more high-fat snacks had a more negative attitude towards limiting high-fat snack consumption, they perceived their mother to eat less high-fat snacks, while they perceived snack availability and accessibility to be higher than students who ate fewer high-fat snacks. 


\section{Breakfast}

Two-hundred-and-three students, $52 \%$ male, completed the breakfast questionnaire: Twenty-one percent was 12 years, $40 \%$ was 13 and $39 \%$ was 14 years old. Most students $(70 \%)$ lived with both parents. A large majority of the students had parents whose native country was the Netherlands: $75 \%$ of the mothers and $68 \%$ of the fathers was born in the Netherlands.

Mean breakfast consumption was $4.8(\mathrm{SD}=2.5)$ days a week. Eight percent never had breakfast and $50 \%$ reported to eat breakfast every day. Most students who had breakfast indicated that they had it at home $(87 \%)$, some reported to eat breakfast at school $(9 \%)$, on their way to school $(2 \%)$, or elsewhere $(2 \%)$.

Except for social support and intention to have breakfast more frequently, the mean scores on the personal and social environmental predictors of breakfast consumption were positive (Table 1). Especially the perceived behaviour of the mother and self-efficacy towards having breakfast were positive, indicating that the students perceived their mothers as having breakfast frequently and that they found it easy to have breakfast regularly. Forty-seven percent of the students reported that there are rules at home about having breakfast (not in Table). Breakfast items were perceived generally available and accessible at home (Mean 5.5, SD =1.6).

Attitude and subjective norm were significant correlates of intention to eat breakfast more frequently (Table 2). Students who had a greater intention to have breakfast more frequently had a more positive attitude towards eating breakfast and more strongly thought that other people expect them to eat breakfast than students who had less intention. Attitude was the only significant correlate of breakfast consumption (Table 3). Frequent breakfast eaters had a more positive attitude towards eating breakfast than those who had breakfast rarely.

\section{Discussion}

In this study, we have investigated the relative importance of personal and social environmental predictors of consumption of fruit, high-fat snacks and breakfast. The results show that mean fruit intake was below recommended intake levels, although intake of fruit juice was not accounted for. It was quite remarkable that fake fruit beverages such as soft drinks with a fruit taste, lemonade and yoghurts with a fruit taste were often reported as most frequently consumed fruit juices. This indicates that students have difficulties to distinguish a fruit juice from non-reall juice beverages. Once in every three days the students in the present study, consumed different categories of high fat snacks, and half of the students did not have breakfast every day. Between twenty and thirty percent of the variation in actual behaviour and in intention to change the different behaviours could be accounted for by the combination of demographic, psychosocial and social environmental factors that were included in the present study. Our analyses showed a number of significant predictors of intention to eat more fruit, to limit snack intake, and to have a breakfast more frequently. Especially attitudes and subjective norms appeared to be relevant predictors of in- 
tention of all three dietary behaviouirs, while self-efficacy appeared to be relevant for fruit intake. For intention to improve fruit intake social influences seem to play a more important role than for snack intake and breakfast frequency. Girls had higher intentions to limit the consumption of high fat snacks than boys. Attitude was the only consistent predictor of the three dietary behaviours.

Recent research has shown that low fruit consumption, frequent snacking of highfat foods, and skipping breakfast are common among adolescents (Department of Health, 2000; Health Education Authority, 1999; Munoz et al, 1997; Schaalma et al., 1997; Voedingscentrum, 1998). The most recent Dutch national food consumption survey showed, for example, that mean fruit intake among 10-16-year-old students was 0.9 pieces of fruit per day. Furthermore, sixty-five percent of these students did not eat the 2 pieces of fruit that are recommended in the Netherlands (Voedingscentrum, 1998). Likewise, Schaalma et al. found that 12-14-year-old students ate 1.1 pleces of fruit per day (Schaalma et al., 1997). These findings are in line with the results in the present study. For our findings on snack intake and breakfast frequency, no comparable Dutch data among a similar age group are available. In this study it was quite unique to have a close to $100 \%$ response rate to the questionnaire. However the teacher chose the classes for the study, which may have had implications for the results. Teachers may have selected classes with a high interest for nutrition education. However; observations and discussions with the teacher do not indicate this potential selection bias.

The amount of variance explained is in line with previous research, where on average no more than $30 \%$ of the variance in nutrition behaviour could be explained (Baranowski, Cullen, \& Baranowski, 1999). Although we included potential determinants additional to the ASE-determinants, like food rules and food avallability and accessibility, this did not result in higher explained variance. Family food rules were identified as relevant predictors of adolescents" eating behaviours in a study conducted in Belgium (De Bourdeaudhuij, 1997). However, in the present study, family food rules seemed unimportant predictors for eating fruits and having breakfast, but this might be due to low validity of the measure. Nevertheless, more research is needed towards other factors that could enhance the explanatory variance of consuming fruits, snacks and breakfasts. Earlier research has argued that behaviour performed repeatedly over a long period of time, like nutrition behaviour, becomes habitual. If students experience the nutrition behaviour as a habit they may become less aware of the reasons of performing behaviour. Nutrition behaviour is not only dependent on personal factor's, also environmental factors may be important. Recently conducted research found that general parenting style may be a relevant environmental predictor of adolescents' fruit and vegetable behaviour (Kremers, Brug, De Vries, \& Engels, 2003; Lytle et al., 2003).

Attitude was found to be the most important predictor of behavioural intentions. This could be due to the fact that attitude was measured in more detail than the other determinants. However, our results are in line with previous research, in which attitude was also found to be an important factor influencing food choice decisions (Dennison \& Stepherd, 1995). Secondary analysis found that especially the following beliefs contribute to differences in intentions to increase consumption of fruit 
$(+=$ positive association; $-=$ negative association), if I eat fruit 1 feel good $(+)$, eating fruit makes me eat less snacks $(+)$, eating fruit is good $(+)$, eating fruit is only necessary when feeling sick $(-)$, if you are young eating fruit is not necessary $(-)$. For limiting snacks the beliefs eating snacks is sociable (-) eating snacks is bad for dieting $(+)$, if I feel bad-tempered I have to eat snacks $(-)$, if I eat snacks I feel guilty $(+)$, and towards breakfast more often the beliefs eating a breakfast is good $(+)$ and eating a breakfast is suitable for persons like me $(+)$ especially contributed. Targeting these beliefs in healthy diet promotion interventions may strengthen attitudes towards healthy dietary habits and improve intentions to change. Besides attitude, subjective norm was an important predictor of behavioural intentions. Larger weight consciousness among girls might explain their higher intention to limit snack intake. For fruit intake different social influences as well as self-efficacy seem to be more important than for the other two behaviours. It may be that because fruit intake has already been targeted in nutrition education interventions in recent years that students are more aware of the norms promoting fruit intake as well as potential barriers towards eating more fruit.

Attitude was also the main predictor of actual behaviour. In addition, for snack consumption mothers ${ }^{\prime}$ behaviour as well as perceived availability of relevant foods may be relevant predictors of students' intake levels. However, students' snack intake was inversely related to perceived intake of their mothers. Students who more frequently eat high fat snacks may perceive their mothers' consumption to be low as compared to their own consumption levels. A more relevant finding may be the positive association between availability and accessibility of high fat snacks and high-fat snack eating, indicating that restricting availability may help to limit snack intake.

In this study we studied possible predictors of both intention to change and actual behaviour. The correlates (potential determinants) of intake may help to explain present behaviour, which provides more insight into why adolescents eat what they eat. However, for promotion of more healthful diets, dietary change may be required, and in order to detect relevant variables that should be targeted in such interventions, insight into correlates of the intention to change is more relevant.

The results presented here imply that interventions to increase fruit and fruit juice consumption, decrease high-fat snack consumption and increase breakfast consumption should at least include methods and strategies aimed at achieving positive attitudes towards these behaviours. Attitude change is most often aimed at by means of persuasive communication, l.e. nutrition education leaflets, brochures et cetera, that communicate arguments for dietary behaviour change. However, since the results indicate that dietary behaviour may not be strongly reasoned actions in this age group, healthy diet promoting intervention are advised to look for more creative and alternative ways to achieve that adolescents will have positive associations with healthy dietary changes. Mere exposure is an example of such an alternative. Mere exposure implies that students should be frequently exposed to fruits , low-fat snacks and breakfast items (Zajonc, 1968). Strategies based on mere exposure, such as preparing foods, taste testing lessons, and exposure to low fat snack samples may enhance students to eat more fruits, eat a low fat snack instead of a high-fat snack and have breakfast more frequently. Other creative ways that may enhance students 
to make positive changes towards dietary changes are puzzles, tests and a comic. It is recommended to consider these findings in the development of new nutrition education programmes. 


\begin{abstract}
The ain of this study was to evaluate a school-based healthy diet promotion intervention implemented in lower vocational schools. The effects were assessed in a cluster-randomised baseline post test experimental design, and data were collected by means of written questionnaires. The final sample consisted of 10 experimental schools with 13 teachers, 37 classes and 879 students, and 8 control schools with 10 teachers, 31 classes and 734 students (total no. of students $\mathrm{n}=1613$ ). Fixed and mixed regression analyses revealed beneficial effects on some, but not all behawloural measures relating to fruit intake, high-fat snack intake and breakfast habits. Some positive behavioural effects occurred in the total target population, others mainly or only among students with more unfavourable intakes at baseline. Simllar patterns were found for effects on intention to change, attitudes, subjective and descriptive norms, self-efficacy, awareness of risk behaviour, interest in the topic, perceived food rules and the avallability and accessibility of food at home. Although we did not find effects on all outcome indicators, the total pattern of results suggest that Krachtvoer offered a surplus value over existing curricula. However, some programme elements need to be revised to improve effectiveness, and more information is needed about the long-term effects of the programme.
\end{abstract}

Submitted as: Martens MK, Van Assema P, Paulussen GW, Schaalma H, Van Breukelen $G, \&$ Brug J. Krachtvoer: Effect evaluation of a Dutch healthy diet promotion curriculum for lower vocational schools. 


\section{Introduction}

In the Netherlands, as in most European countries, few evidence-based interventions are available to encourage healthy dietary habits. At the time of writing, no comprehensive effect study of healthy diet interventions for Dutch children and adolescents had been completed. The availability of such healthy diet interventions is important, since unhealthy eating habits, such as low intake of fruit and high intake of saturated fat, are very common in youngsters and may contribute to the high incidence of cardiovascular diseases, diabetes and certain types of cancer at a later age (Vereecken, Ojala, \& Delgrande Jordan, 2004; Voedingscentrum, 1998; WHO, 2003). The dietrelated prevalence of adolescent overweight and obesity is an additional rapidly growing problem (Hirasing et al., 2001; WHO, 1998). It is particularly important to develop effective interventions for young people, as healthy eating at an early age may be an important determinant of dietary choices in later life (Kelder et al., 1994; Lytle et al., 2000).

More examples of evidence-based programmes for youngsters are available especially in the United States (Contento \& Michela, 1999; Contento et al., 2002; Hoelscher et al., 2002; Perez-Rodrigo \& Aranceta, 2003). An examination of studles evaluating these programmes revealed a number of elements that are helpful in developing a successful nutrition education programme. For instance, a behaviourally focused approach that targets specific behaviours was found to be more likely to result in behavioural changes than interventions focused on nutrition in general. Nutrition education interventions should also provide opportunities for adolescents to taste and enjoy a wide variety of healthy foods in positive social-affective contexts, and increase the availability of healthy foods. Further more, interventions should include self-evaluation or self-assessment with a personal feedback component. Other features that have been found to contribute to effectiveness are adequate time for the intervention and adequate intensity, as programmes with longer duration and more contact hours achieve better results than shorter programmes.

This article describes the results of a trial to assess the effects on dietary behaviours and behavioural determinants of the Dutch healthy diet promotion programme called Krachtvoer for 12-14-year-old students of lower vocationall (preparatory secondary vocational education) schools. The programme focused on this age group because it is especially when children transfer from primary school to secondary school that their eating habits are likely to change and become less healthy (De Vries \& Da Costa Senior, 1992; Lytle et al., 2000). Intervening at this age may therefore prevent unhealthy eating behaviour becoming habitual. The programme targeted students of lower vocational schools, since they tend to belong to lower socio-economic position groups, which are known to have less favourable diets than their peers from higher socio-economic position groups (Koivisto Hursti, 1999; Roos et al., 1998). The Krachtvoer programme focused on the intake of fruit, high-fat snacks and breakfast, because these behaviours are under the students" volitional control and can be influenced during school hours or are important for school performance. The Krachtvoer programme built upon earlier international attempts to improve adolescents' diets, which were adapted to the Dutch situation. 


\section{Method}

\section{Intervention}

\section{Objectives and theoretical framework}

In the development of the Krachtvoer programme some key aspects of Intervention Mapping were applied (Bartholomew et al., 2001). Intervention Mapping is a framework for effective decision making at each step in the process of developing, implementing and evaluating theory- and evidence-based health education programmes. As recommended by Intervention Mapping we systematically used the available theories and evidence to make decisions on programme goals and target group, the behaviour change methods and strategies, the programme design, and implementation strategies. We conducted a thorough needs assessment to gain further insight into specific personal and situational determinants of the target behaviours and opinions on nutrition and nutrition education in our specific target population, i.e. Dutch adolescents in lower vocational schools (Martens, Van Assema, \& Brug, in press; Martens, Wind, Van Assema, \& Brug, 2002). We defined programme objectives by breaking down the dietary behaviours under study into specified performance objectives.

The overall aim of the programme was to increase the consumption of fruit and fruit juice, to decrease the consumption of high-fat snacks and to increase breakfast frequency and quality. Self-management theory (Bartholomew et al., 2001; Boekaerts et al., 2000; Cameron \& Howard, 2003) and the results of the aforementioned preliminary studies helped us to define the performance objectives. Selfmanagement theory describes how individuals can be motivated and become able to self-correct their behaviours. Self-management is regarded as a cyclic procedure involving three phases: (a) monitoring one's own health behaviour or health status; (b) comparing this self-evaluation with a certain norm (e.g., earlier states of behavlour or health, recommendations, or other people's health behaviours), describing a problem or a divergence from the norm, and analysing the causes of this divergence; and (c) attempting a behavioural correction to get closer to the norm (Boekaerts et al., 2000).

The following performance objectives were formulated: students were expected to (1) self-assess their personal fruit, snack and breakfast intakes, (2) compare their intakes with recommended levels, (3) indicate reasons for abserved discrepancies between their own intakes and recommendations, (4) propose solutions, i.e., set goals to close the gap with the recommended intake levels, (5) implement these solutions, (6) evaluate their personal goal performance. The first two of the performance objectives were considered relevant as previous research into behavioural determinants had shown that many people wrongly think that their eating habits are healthy and are therefore not motivated to change their nutrition behaviour. This unawareness of risk behaviour may be due to ignorance of the recommended intake levels, or to a self-serving bias in comparing one's own dietary habits with those of others (Brug, Van Assema, \& Kok, 1998; Van Assema et al., 1996). However, awareness is not the only important determinant of healthy eating. Dietary habits are complex behaviours, and the personal determinants of healthy eating may vary substantially between 
students. An understanding of why people eat what they eat may help to specify objectives for change. Hence, the programme"s third performance objective was that students should assess their own reasons for not eating enough fruit and eating too many snacks, or for skipping breakfast. The results of the quantitative preliminary study based on the Attitude-Social influence-Efficacy-Model (De Vries et al., 1988) and additional family environmental determinants (Martens et al., in press; Martens et al., 2002) indicated that more positive attitudes and subjective norms in particular appeared to be associated with greater intentions to change, for all three dietary behaviours, and more positive self-efficacy expectations with higher intentions to increase fruit intake. Attitude was also the main predictor of actual consumption. Perceived behaviour of the mother as well as availability of relevant foods were found to be major determinants relating to snack consumption. The preliminary qualitative study conducted among students, parents and teachers further indicated that taste preferences should be taken into account (Martens et al., 2002). Subsequently, this qualitative study and a literature review helped to identify theory-based methods and practical strategies to influence these determinants. The study also examined the requirements in terms of overall programme design that would promote adoption and implementation, such as the number and length of the lessons and the number of optional elements. During the whole development process, a consultation team consisting of experts in the field of nutrition and the theory of education advised us about the programme.

\section{Intervention components}

The Krachtvoer programme consisted of three main phases (Table 1 ). In phase one, (including lessons one to four) initial activities aimed to raise students' enthusiasm for the programme; subsequent activities were linked to the first three performance objectives: monitoring behaviour, comparing observations with a certain norm and assessing reasons for inadequate intake.

In phase two (including lessons four to seven) all activities aimed to help students to overcome their personal reasons for not eating a healthier diet (performance objective 4 ). In this phase, teachers were allowed to vary the activities and the order in which they were carried out, but were expected at least to offer the action form to test nutrition knowledge, show the video that illustrated how social influences affect dietary choices, discuss the magazine and carry out one or more optional activities: tasting unfamiliar foods, making a fruit shake, tasting various types of fruit and holding a "kiwi-eating contest.' In the third and final phase (including lessons seven and eight), the activities were linked to the last two performance objectives, involving the implementation of solutions and evaluation of their personal goal performance.

The Krachtvoer programme consisted of eight schooll lessons lasting fifty minutes each, and used a combination of materials: various so-called task forms for the lessons, postcards and posters, a 'survival kit' (a lunchbox with 3 healthy food items, viz., a piece of fruit, a health food snack and a breakfast product, and a flyer), a magazine, a video, a website, a take-home bag with a newsletter and food-items for the parents, taste-testing of various products and a manual to instruct the teacher in providing the different lessons. Many of the materials featured three cartoon 
Table 1

Description of the "krachtvoer" programme: phases, lessons, performance objectives, behaviours and materials

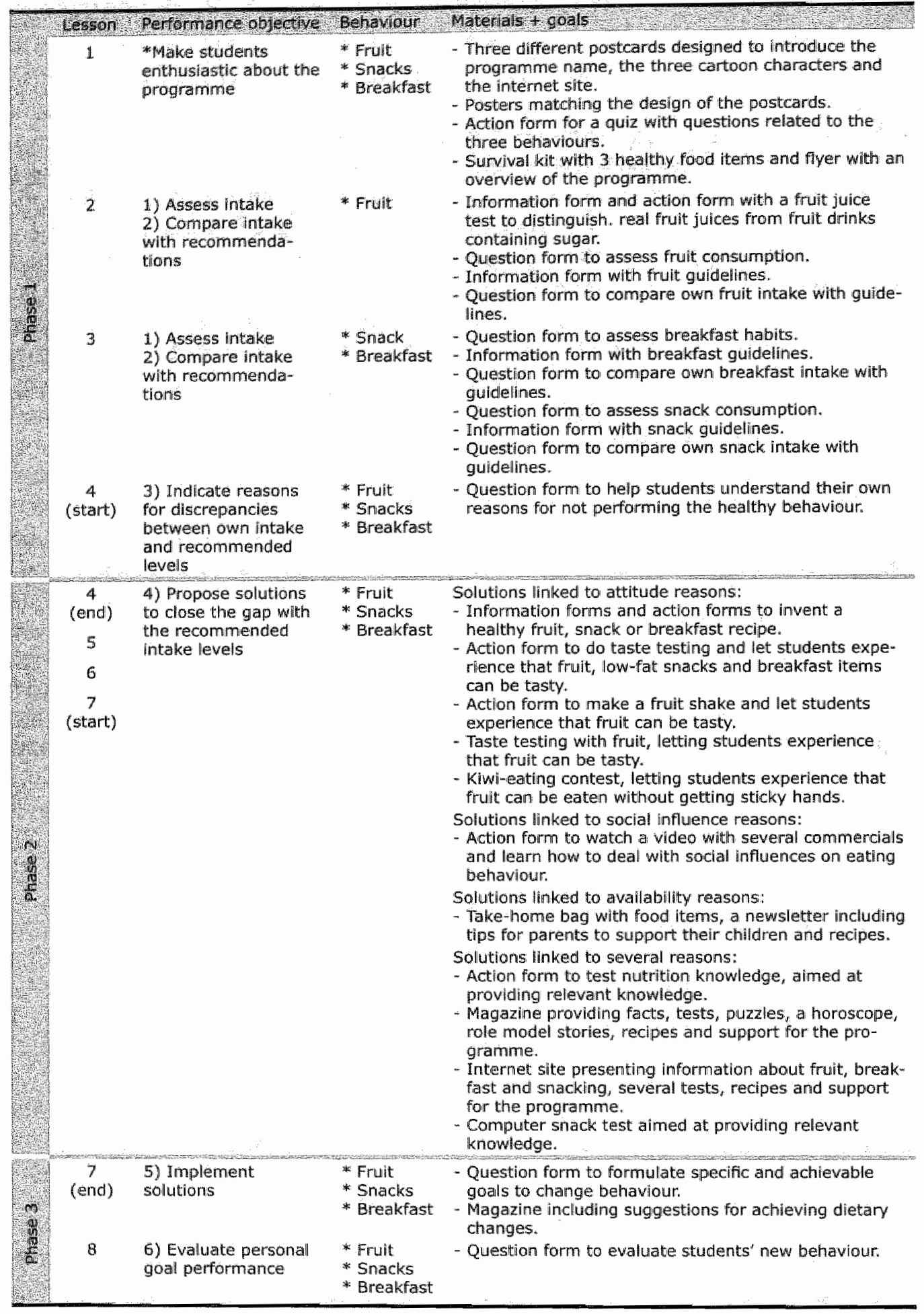


characters related to the three behaviour-change goals. The task forms guided the students through the programme. Students completed these forms individually, in small groups or as a class. There were three types of task forms: information forms, action forms and question forms. Information forms were aimed at providing relevant knowledge and were always linked to an action or question form. An action form encouraged students to actually do something, for instance a taste test, assessing what distinguishes a 'real' fruit juice from other fruit-like drinks, making their own fruit shake, tasting different breakfast cereals or writing down their own ideas for healthy recipes. A question form asked students to answer questions or to write down options or decisions, for instance reporting how many pieces of fruit they normally ate or setting and writing down personal goals for dietary change.

\section{Study design and sample}

The study used a cluster-randomised baseline-post-test experimental design. Twentyfive lower vocational schools were recruited in the southern and central parts of the Netherlands. To avoid too large a variation between the schools in the study, inclusion criteria were (1) a maximum of $50 \%$ students of foreign origin, and (2) implementation of one of the three most commonly used nutrition education curricula in the Netherlands. Each participating school was asked to select a number of classes in such a way as to have 50 to 150 students in the targeted age group participating in the study in each school. After recruitment, the schools were randomly assigned to the Krachtvoer group (13 schools) or the control group (12 schools). Control schools kept using their usual nutrition education curriculum and experimental schools replaced their usual curriculum with the Krachtvoer programme.

\section{Measures}

Students were requested to complete a baseline questionnaire in the classroom (September 2002) and a post-test questionnaire three months later (December 2002). The teachers supervised the completion of the questionnaires. The questionnaire was a classroom activity, but students were told that they could perform another task in case they objected to completion of the questionnaire. Baseline and post-test questionnaires were matched on the basis of school, class and date of birth.

\section{Dietary intakes}

Dietary intakes were assessed by using food frequency questions and by using a selfadministered 24-hour recall.

Consumption of fruit was assessed using the fruit questions from a validated fruit and vegetable food frequency questionnaire (Van Assema et al., 2002). In two separate items, students indicated on how many days a week they consumed fruit and fruit juice and the number of servings of fruit and fruit juice they consumed on these days. Frequency and quantity were multiplied to obtain estimates of mean consumption of fruit in servings per day, and of fruit juice in glasses per day.

Two items measuring snack consumption were derived from a fat-intake question- 
naire (Van Assema et al., 2001). Students were asked to indicate the number of days a week they usually consumed sweets and savoury snacks, as well as the amount of sweets and savoury snacks they consumed on these days. Frequency and quantity were multiplied to obtain estimates of the mean consumption of sweets and savoury snacks in servings per day.

In one item, students were asked on how many days per week they normally ate breakfast. In addition, in line with the Dutch recommendation for an adequate breakfast (Voorlichtingsbureau voor de Voeding, 1997), the students' breakfast quality was assessed by asking them on how many days a week they included food items high in fat (butter), carbohydrates (bread products and cereal products), protein (yoghurts, cheese or meat products, eggs or milk) and vitamin $C$ (fruit or fruit juice) in their breakfast. Multiple items for one nutrient were summed to obtain a single score for foods that contribute to one of these inutrients.

Students also wrote down yesterday's fruit and fruit juice consumption and snack consumption, and today's breakfast consumption. Nutrient intakes were calculated using the Becel nutrition programme (2002) and Dutch food codes and weights (Donders-Engelen, Van der Heijden, \&. Hulshof, 2003).

\section{Behavioural determinants}

Potential personal and social environmental determinants for dietary behaviour were assessed separately. Unless stated otherwise, these variables were measured on bipolar five-point scales (coded as -2 to +2 ).

The intention to improve the behaviour in the short term was assessed using a single item. Attitude was assessed by the mean score on four to nine items (depending on the dietary behaviour) assessing the expected consequences of the behaviour (e.g., eating fruit is tasty / enjoyable / healthy) (Cronbach's alphas between 0.51 and 0.79 ). Perceived subjective norms were assessed asking the students what their parents and friends preferred them to eat. To assess descriptive norms, perceived behaviour of parents as well as friends (not for breakfast) was questioned in two items. Family support was assessed with a single item, measuring how strongly the desired behaviour was supported within the family. Self-efficacy was assessed with one Item on students' perceived confidence regarding performing the desired behavlour. One item asked the students whether they self-rated their intake as high or low. Subsequently, students were allocated to one of four categories of awareness, on the basis of their self-rated intake levels as compared to the results of the more objective intake assessment: aware or unaware of inadequate intake, or aware or unaware of adequate intake (Brug, Van Assema, Kok, Lenderink, \& Glanz, 1994). Awareness was only assessed for fruit intake and breaktast frequency, as clear cut-off points for adequate intake were available for these behaviours (two pieces of fruit per day and having breakfast on five days a week (Voedingscentrum, 1992). One item on personal interest in the dietary behaviour was included. The presence of family food rules was measured by the sum of scores of two to three items, depending on the behaviour le.g., are there rules at home for when you should eat fruit, what you should have for your breakfast, how many snacks you are allowed to eat), with two possible answers (yes, there are rules of some kind - no, no attention is paid to this). In accordance 
with a study conducted by De Bourdeaudhuij (2000) (De Bourdeaudhiij \& Van Oost, 2000), we assumed that the presence of family food rulles encouraged performance of the desired behaviours.

Availability and accessibility were assessed by the sum of scores of four to five items, depending on the dietary behaviour (e.g., if you were to indicate at home that you like a certain type of fruit, would your parents buy them; are snacks available at home; is the table set for breakfast). Different answering scales were used for these items and these were recoded to a uniform three-point scale (usually yes (1), neutral $(0.5)$, usually no (0)). Finally, students were asked to state their gender and age and the native country of their mother and father.

\section{Analysis}

Analyses were performed using SPSS (version 11; SPSS, 2001), unless mentioned otherwise.

Descriptive statistics (percentages and means) were used to describe key participant characteristics and variable scores for the experimental and control groups, both at baseline and post-test.

Multiple logistic regression of dropout (yes/no) on baseline variables and treatment condition was done to identify causes of dropout and thereby also as potential bias in analyses of post-test data. This dropout analysis was done twice: once with all schools of which baseline questionnaires were received, and once with all schools of which baseline and post-test questionnaires were received.

In all effect analyses, persons with a missing post-test value due to school, class or individual dropout were included by replacing the missing post-test value with the baseline value (i.e., the last observation carried forward method). In the sequel these analyses will be referred to as intention to treat analyses.

Since the fruit and snack frequencies variables were not normally distributed, the data were transformed by taking the square root of the frequency scores, which improved the variance and the normality. The breakfast frequency variable was extremely skewed and was therefore dichotomised based on the recommendation (at least five days a week vs. fewer days).

Post-test differences between study conditions were first analysed with fixed linear or logistic regression. Each post-test measure of behavilour or a behavioural determinant was regressed on study group, gender, age, baseline value of the outcome at hand, and interaction terms of study group with gender, age and baseline value. To simplify the interpretation of study group effects in the possible presence of interactions, the baseline value was always centred (i.e. the overall sample mean was subtracted from each individual baseline value such that the baseline mean became zero), and gender and age were centered if they interacted with treatment. Due to this centering, the B-value and significance of the treatment effect cam be interpreted as average treatment in the presence of interaction with covariate. Non-significant interactions were removed from the model one by one. In case of a significant interaction with the baseline, the sample was stratified into three approximately equally large subgroups based on the baseline value. All analyses that gave a significant ef- 
fect on a behavioural outcome were rerun with complete cases analyses (i.e. excluding dropouts). Also, multilevel (mixed) regression analyses were conducted to verify the behavioural outcomes that were significant in the fixed regression analyses, by taking intraclass correlation into account (Snijders \& Bosker, 1999). Mixed logistic regression analyses were run in Miwin 1.10.0007 (Rasbash et al., 1999). More specifically, the fixed regression model was extended with a random school effect and a random class effect. Since schools were randomized, no mixed interaction of treatment by school or class could be tested. All mixed analyses that showed a significant effect on a behavioural outcome were repeated without dropouts cases (i.e. excluding dropouts). In all analyses, an $a=0.05$ two-tailed was used for primary outcomes (behavioural outcomes), and $a=0.01$ two-tailed for secondary outcomes (behavloural determinants) to prevent type I errors due to multiple testing. An $a=0.05$ one-tailed was used for intra-class correlations of the primary autcomes (Snijders \& Bosker, 1999; Verbeke \& Molenberghs, 2000).

\section{Results}

\section{Response rates, attrition and respondents}

Before the actual start of the baseline measurements, one experimental school and two control schools withdrew because of time problems and because one of the teachers left. The baseline questionnaires of another experimental school and two control schools were never received, even though two schools claimed to have sent the completed questionnaires to the study centre. One experimental school was excluded during the study, as its staff did not implement Krachtvoer and had the questionnaires completed by students who were not supposed to be in the study. The final sample for the intention to treat analyses thus consisted of 10 experimental schools with 13 teachers, 37 classes and 879 students, and 8 control schools with 10 teachers, 31 classes and 734 students (total $n=1613$ ). Post-test questionnaires were received from 10 experimental schools with 13 teachers, 37 classes and 781 students, and 6 control schools with 8 teachers, 21 classes and 469 students. The main reasons for not receiving post-test questionnaires from schools and classes were postal delivery problems. Of all participating schools and classes, 98 individual experimental students and 107 control students did not complete the post-test. The main reason was absence during the hours when they were supposed to complete the questionnaire. None of the students objected to completing the questionnaire. Multiple logistic regression of dropout on baseline variables showed that girls, older students and control group students dropped out significantly more often than boys, younger students and Krachtvoer students, respectively. The treatment group and age effect on dropout remained significant and the gender effect disappeared when the drop-out analyses were limited to the schools of which baseline and post-test questionnaires were received.

Boys and girls were equally represented in the sample. In the final sample, $32 \%$ of the students were aged 12 years or younger, $53 \%$ were 13 years old and $15 \%$ 
were 14 years or older. The majority of the students had parents who had both been born in the Netherlands ( $83 \%$ ). Mean variables scores at baseline and post-test with individuals as unit of analysis are presented in Table 2, 3, and 4. Very similar mean values were found using schools instead of individuals as unit of analysis.

\section{Fruit infake and behavioural determinants at post-test}

The results of the effect analyses for fruit consumption and its behavioural determinants are summarised in Table 2 . Note that the centring of baseline values allows the main effect of study group ( $B$ value) to be interpreted as average treatment effect even in the presence of treatment-by-baseline interaction. No convincing interaction effects between age or gender were found.

\section{Primary outcomes}

At post-test, respondents in the Krachtvoer condition reported a higher fruit frequency and higher fruit consumption during the previous day (main treatment effects) compared to the control group. The main treatment effect on fruit frequency was due to an effect in the subgroups of students with a medium baseline frequency value. The main treatment effect on fruit consumption during the previous day was due to an effect in the subgroup of students with the least desirable baseline values.

With respect to the outcomes fruit juice frequency and fruit juice consumption during the previous day, we found no main effect, but an interaction effect in the sense that the intervention had a significant but negative effect among the students in the tertile with the most desirable baseline values.

In the analyses with complete-cases the main effect for fruit frequency was no longer found $(\beta=0.04, P$-value $=0.09)$. In the remaining complete-cases analyses no convincing differences in $B$ values, effect sizes and significance levels were found compared to the intention to treat analysis. The mixed regression analyses yielded a class effect regards fruit consumption during the previous day ( $P$-value $<0.05$ onetalled, intra-class correlation 0.14), and fruit juice consumption during the previous day ( $P$-value $<0.05$ one-talled, intra-class correlation 0.17 ). No convincing differences in $B$ values and effect sizes were found compared to the fixed analyses. The effects on fruit frequency and fruit consumption during the previous day were no longer significant in the mixed analyses ( $P$-value for fruit frequency $=0.23$ and $P$-value for fruit consumption during the previous day $=0.06$ ).

\section{Secondary outcomes}

At post-test, respondents in the Krachtwoer condition had more positive attitudes towards eating fruit, and perceived a more positive subjective norm of friends towards eating fruit (main treatment effects) compared to the control group. The main treat ment effect on the subjective norm of friends was due to an interaction effect in the sense that there was a treatment effect in the subgroup of students with the least desirable baseline values.

With respect to the subjective norm of the parents, we found an interaction effect in the sense that the intervention had a significant but negative effect among the 


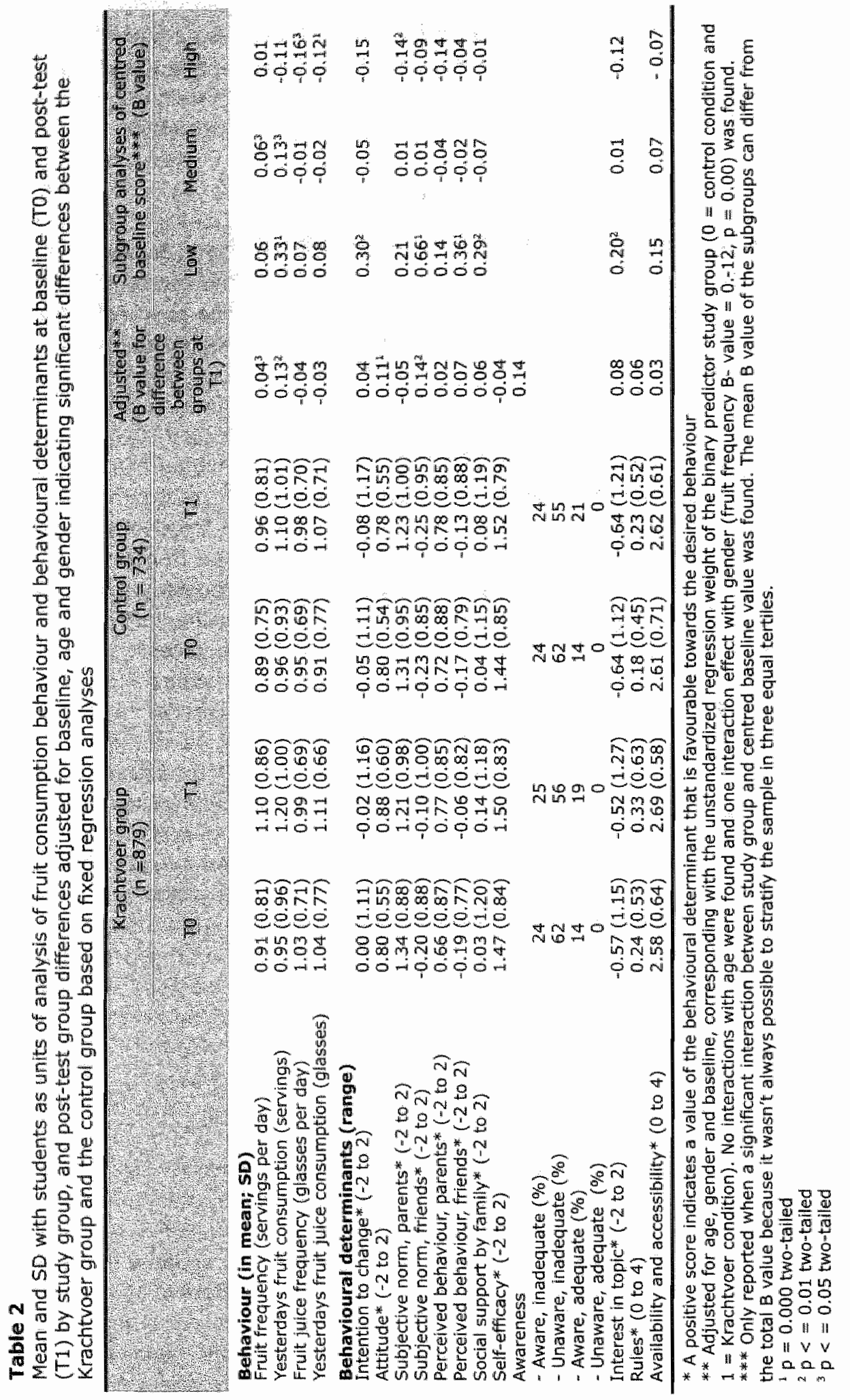


students in the tertile with the most desirable baseline values.

With respect to intention to change, percelved behaviour of friends, social support by family and interest in the topic, we found an interaction effect in the sense that the intervention had a significant beneficial effect among the students in the tertile with the least desirable baseline values.

\section{Snack intake and behavioural determinants at post-test}

The results of the effect analyses for snack consumption and its behavioural determinants are summarised in Table 3 . No convincing interaction effects between age or gender were found.

\section{Primary outcomes}

With respect to snack frequency and total fat intake from snacks consumed during the previous day, we found an interaction effect in the sense that the intervention had a beneficial effect among students with the least desirable baseline intakes. As regards the number of snacks consumed during the previous day, the intervention had a negative effect among students in the tertile with the most desirable values at baseline, but a beneficial effect among students in the tertile with the least desirable values at baseline.

In the analyses with complete-cases no convincing differences in $B$ values and effect sizes were found compared to the intention to treat analysis. The beneficial intervention effects on the number of snacks consumed during the previous day among students with the least desirable baseline intakes was no longer found $(\beta=0.05, P$. value $=0.64$ ) in the complete cases analysis. Complete-cases analyses for totall fat from snacks on the day before administration vielded results that were comparable but not significant (students in the tertile with the least desirable values at baseline $\beta$ $=-2.74$, P-value $=0.43$ ). Mixed regressilon analysis for snack behaviour did not show any school or class effects and no convincing differences in $B$ values, effect sizes and significance level were found compared to the fixed regression analysis.

\section{Secondary outcomes}

Table 3 shows that at post-test, students in the Krachtvoer condition reported a more positive intention to eat fewer snacks, a more pasitive subjective norm annong friends towards eating fewer snacks, a more positive intention to eat healthier snacks, a more positive attitude and greater percelved self-efficacy towards eating healthier" snacks, a greater interest in the topic of snacks, and lower availability and accessibility of snacks at home compared to respondents in the control group (main treatment effects). All average treatment effects were due to an effect in the subgroup of students in the tertile with the least desirable baseline values. With respect to perceived behaviour of parents we find a positive overall effect. However, there was a negative effect in the subgroup of students in the tertile with the highest desirable baseline values.

With respect to self-efficacy towards snacking frequency, subjective norm of the parents towards eating healthier snacks, and social support towards eating healthier 


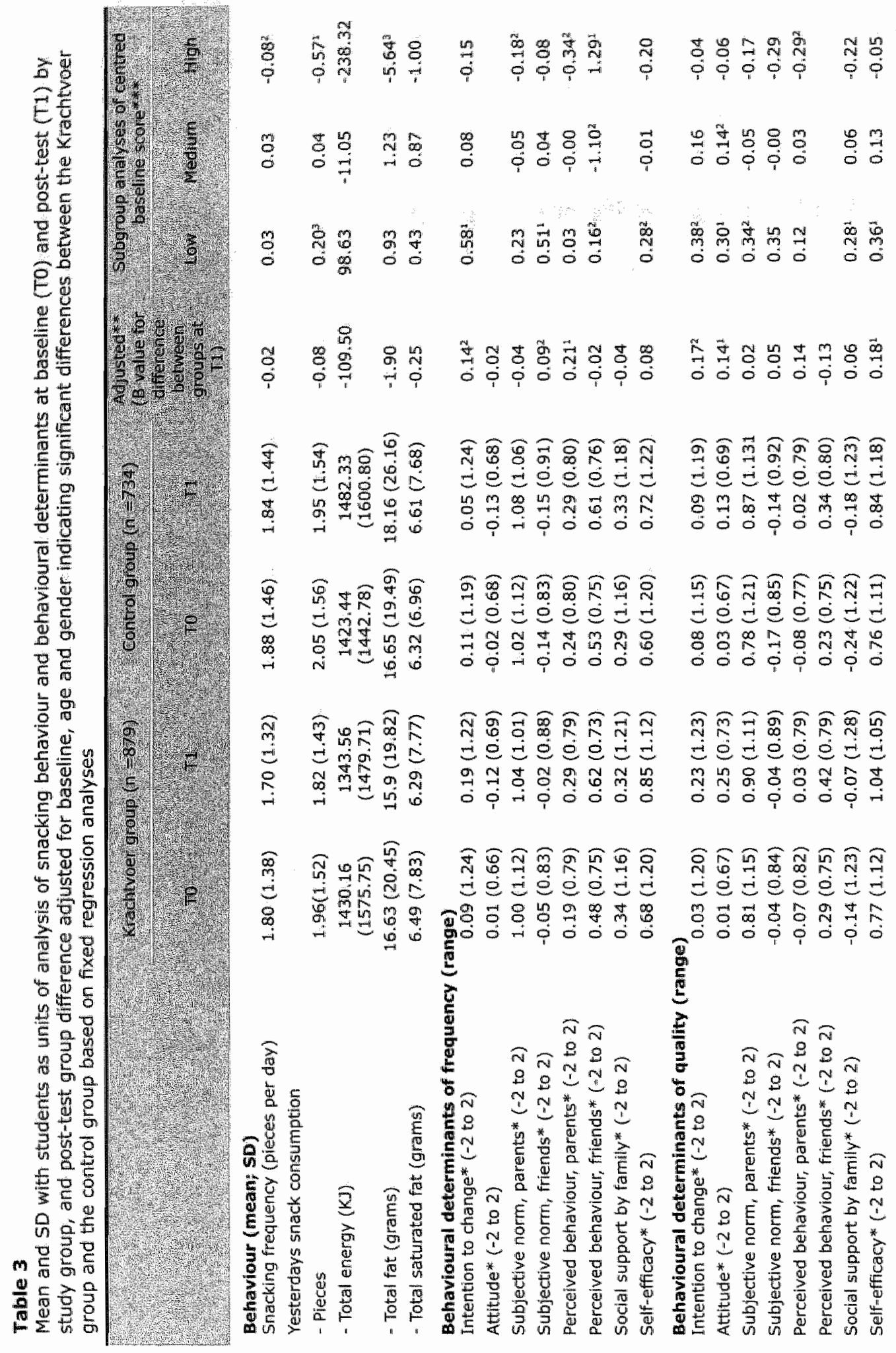




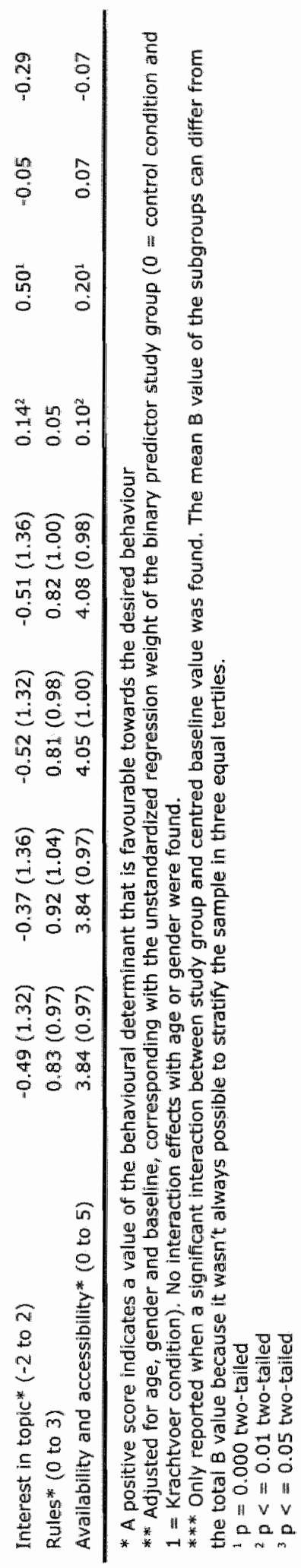




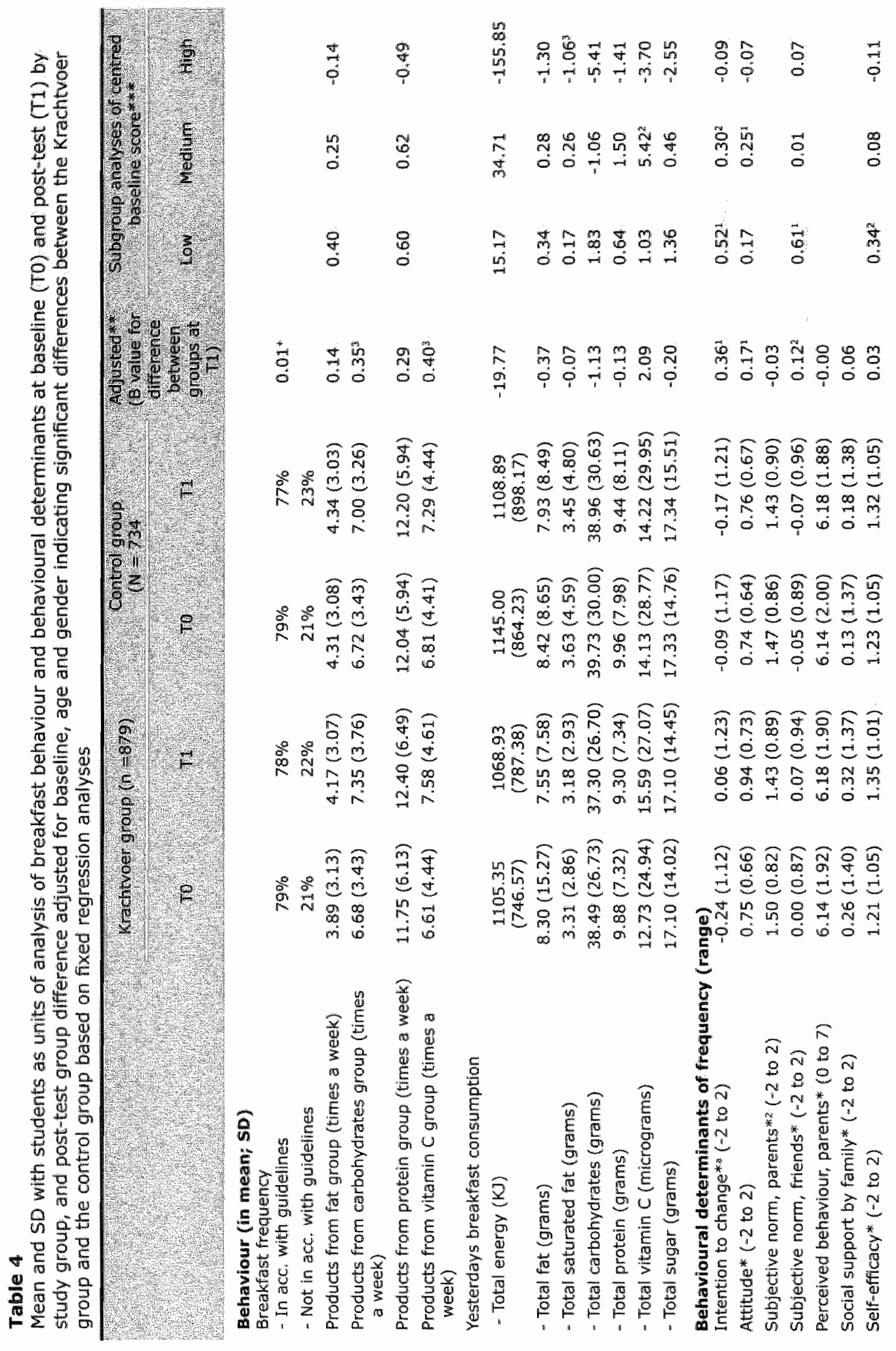




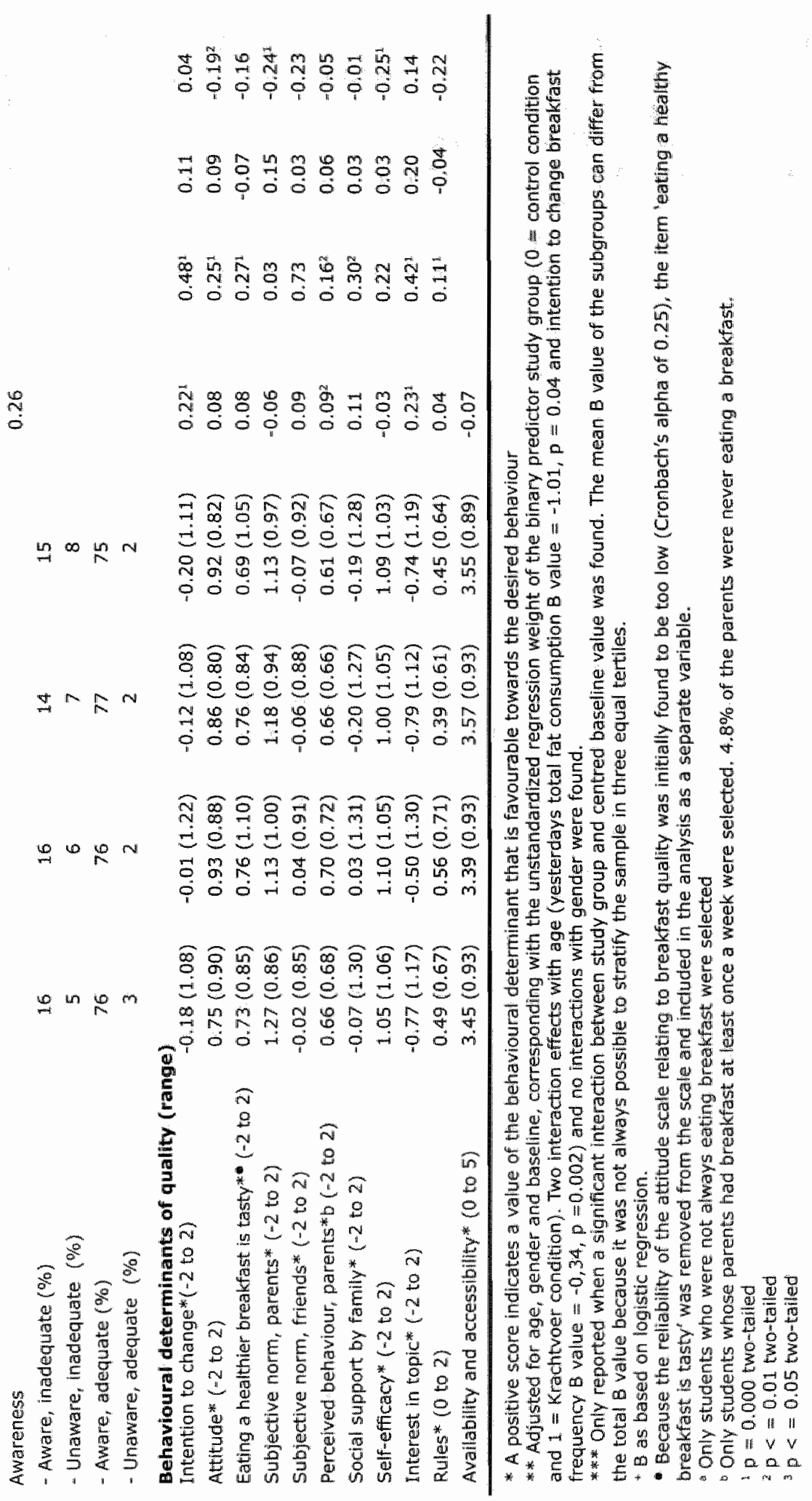


snacks we found an interaction effect with baseline value, in the sense that treatment had a beneficial effect among situdents in the tertile with the most desirable baseline values. With respect to perceived behaviour of friends in terms of snacking frequency, the intervention had a beneficial effect among students in the tertiles with the highest desirable and least desirable baseline values but a negative effect among students in the middle tertile. As regards the perceived behaviour of parents in terms of eating healthier snacks we found an interaction effect with baseline value, in the sense that treatment had a negative effect among students in the tertile with the most desirable baseline values.

\section{Breakfast intake and behavioural determinants at post-test}

The results of the effect analyses for breakfast consumption and its behavioural determinants are summarised in Table 4 . No convincing interaction effects between age or gender were found.

\section{Primary outcomes}

Table 4 shows that students who participated in the Krachtvoer intervention reported higher intake of breakfast products from the carbohydrates and vitamin $C$ groups than students in the control group.

Additionally, significant interaction effects of study group by baseline value were found for several other outcomes. In terms of vitamin $\mathrm{C}$ intake at breakfast on the day before questionnaire administration, we found a significant beneficial effect among students in the middle intake tertile at baseline. We found a significant negative intervention effect among students with the most desirable values at baseline for total saturated fat intake during the previous day.

In the analyses with complete cases the main effect for breakfast products from the carbohydrates group was no longer found $(\beta=0.29$, $P$-value $=0.13)$. The interaction effect of study group by baseline value for total saturated fat intake and vitamin $C$ intake on the day before administration was no longer found in the complete-cases analyses. Mixed regression analysis for breakfast behaviour did not show any school or class effects and no convincing differences in $B$ values and effect sizes were found compared to the fixed regression analysis.

The effects on intake of breakfast products from the carbohydrates and vitamin $C$ groups were no longer significant in the mixed analyses ( $P$-value carbohydrates group $=0.23$ and $P$-value for vitamin $C$ group $=0.34$ ) .

\section{Secondary outcomes}

Table 4 shows that students who participated in the Krachtvoer intervention had a more positive attitude and perceived a more positive social norm among friends towards eating breakfast, had more positive intentions towards eating breakfast and eating a healthier breakfast, perceived their parents as eating a healthy breakfast, and were more interested in health and breakfast than respondents in the control group.

In addition, there were various interaction effects between baseline values and 
study group on many of the outcome variables that showed a main effect (see table 4). These average treatment effects were mainly due to a significant beneficial effect among students in the tertile with the least desirable baseline values. With regard to intention to change breakfast frequency, there was also a significant beneficial treatment effect among students in the middle intention tertile at baseline. The main effect on attitude towards breakfast frequency was attributable to the students who scored in the middle attitude tertile at baseline.

Additionally, significant interaction effects of study group by baseline value were found for several other outcomes. We found a significant negative intervention effect among students with the most desirable values at baseline for subjective norm of the parents towards breakfast quality and self-efficacy towards breakfast quality. With respect to the belief that eating a healthier breakfast is tasty and to social support by the family, we found that treatment had a significant beneficial effect among students with the least desirable values at baseline. The intervention had a significant beneficial effect on attitude towards breakfast quality among students in the tertile with the least desirable values at baseline but a significant negative effect among the students in the tertille with the most desirable values at baseline.

\section{Discussion}

This study used a cluster-randomised design to investigate the effects on dietary behaviours and behavioural determinants of the Dutch healthy diet programme called Krachtvoer, intended for 12-14-year-old students of lower vocational schools. Fixed regression intention-to-treat analyses revealed predominantly beneficial effects on some, but not all behaviourall measures with regard to fruit intake, high-fat snack intake and breakfast habits. Some positive behavioural effects occurred in the total target population, others mainly or only among students with the least desirable values at baseline. Similar patterns were found with respect to effects on intention to change, attitudes, subjective and descriptive norms, self-efficacy, awareness of risk behaviour, interest in the topic, perceived food rules and the availability and accessibillity of food at home. Also some negative effects occurred among students with the most desirable values at baseline. However, these effects were smaller than the effects for the students with the least desirable values at baseline. The complete cases and mixed regression analysis found comparable $\beta$ values and effect sizes for the behavioural outcomes. However, many of the main significant favourable effects on behavioural outcomes were not found in mixed regression analyses.

The significant short-term behavioural effects regarding fruit are in line with the findings of previous research, which found programme effects between 0.2 and 1 pieces of fruit (Ammerman, Lindquist, Lohr, \& Hersey, 2002; Contento et al., 1995). No comparable effect studies on breakfast and snack consumption are avallable, since previous evidence-based programmes were mostly aimed at nutrients like total fat, energy and carbohydrates, rather than at specific breakfast or snacking behavlours. The fact that several programme effects were strongest or were only found among students with the least desirable values on dietary behaviour and behavioural 
determinants at baseline, can be considered to be additional favourable results, as they imply that it was especially the students who needed the programme most who benefited most from it.

Nevertheless, our findings are definitely not optimal. This might be due to intervention-related aspects as well as aspects of study methodology. We definitely blame the poor implementation of the last part of the programme which was revealed by the process evaluation (Martens, Van Assema, Paulussen, Schaalma, \& Brug, submitted). Furthermore, the failed main effect on fruit juice intake might be due to the fact that students have difficulties distinguishing fruit-juices from beverages that are not real fruit juices (Martens et al., 2002). It is possible that the intervention made students better able to distinguish fruit juices from other beverages, as a result of which the reported fruit-juice consumption at post-test was lower in the Krachtvoer group. The less than optimall effect on breakfast frequency may be related to the fact that $79 \%$ of the students already had an adequate breakfast intake. Earlier studies on breakfast prevalence showed inconsistent results (Currie et al, 2004; De Vries \& Da Costa Senior, 1992; Voedingscentrum, 1998), but in our study population, skipping breakfast was definitely not yet a major health behaviour problem. However, as eating breakfast has been found to rapidly decline during adolescence (Currie et al., 2004), the Krachtvoer intervention might be effective in the longer run in that fewer students quit eating breakfast.

Important methodological considerations include our data analyses. More control than experimental schools withdrew, making the numbers of participants in the study arms unequal. However, we dealt with this problem by conducting intention-totreat analyses as the primary analyses. We further took the clustering of students in classes and schools into account by checking all significant behavioural effects from the fixed regression analysis with the help of mixed regression analyses. Not all our positive findings were confirmed in these further analyses. This may be due to type $\Pi$ errors, that is, low statistical power caused by the smaller number of respondents. For that reason we are careful not to draw too favourable conclusions from results that were not confirmed in the mixed regressions. Further, all analyses that gave a significant effect on a behavioural outcome were rerun with complete-cases analyses. Another possible limitation is that all of the data were self-reported by students and may thus be subject to memory and recording errors. However, we included several self-reported measures, i.e., food frequency questions as well as recording of daily consumption, and results for these different self-reports were largely consistent.

The dietary intakes were assessed using validated questionnaires. A number of behavioural determinants were measured in a manner consistent with the theory and as described in earlier studies. On the other hand, some of the behavioural determinants were assessed with single items, which may be less reliable than multiple item assessments (Conner \& Sparks, 1996).

Although we did not find effects on all outcome indicators, the total pattern of results made us conclude that Krachtvoer had a certain surplus value over existing curricula. However, some parts of the programme need to be revised to improve its effectiveness, and more information is needed about the long-term effects of the programme. 


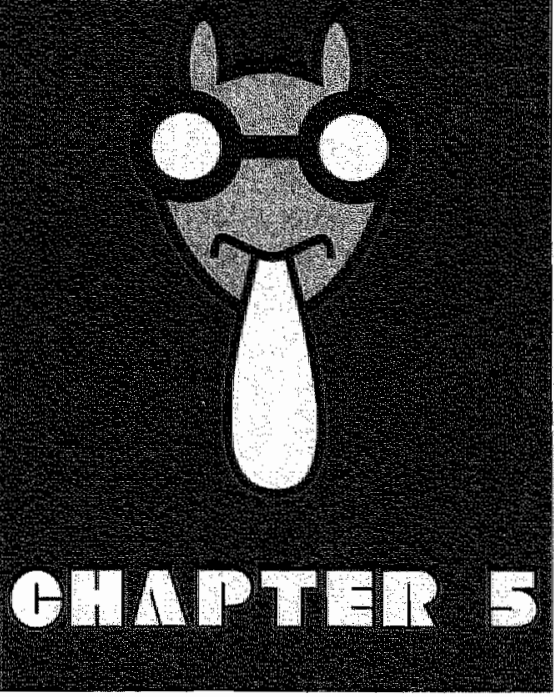

Krachtvoer:

Process evaluation of a Dutch healthy diet promotion curriculum for lower vocational schools 


\begin{abstract}
The aim of this study was to examine the fidelity and completeness of the implementation of a school based healthy diet promotion programme called Krachtvoer, aimed at lower vocational training students aged $12-14$. The opinions of teachers and students about the programme were also assessed, as well as the association between these opinions and the level of implementation. Data were collected through structured teachers' monitoring reports, in-class observations and indepth interviews with teachers. Further data were drawn from a student questionnaire included in a concurrent cluster-randomised baseline-posttest experimental study evaluating the effects of the programme. The present study indicates that the teachers implemented the Krachtvoer programime largely accoirding to pllan, that the teachers appreciated most parts of the proigramme and that the students who were exposed to Krachtvoer were more appreciative of their nutrition education lessons than students who followed the usual curriculum However, programme elements that teachers did not like very much were often not implemented, We conclude that the Krachtvoer programme is a promising tool to encourage students in lower vocational schools to adopt healthier diets. The present study revealed the stronger and weaker parts of the programme and can thus guide the revision process for further programme improvement.
\end{abstract}

Submitted as: Martens MK, Van Assema P, Paulussen GW, Schaalma H, \& Brug 1. Krachtvoer: Process evaluation of a Dutch healthy det promotion curriculum for lower vacational schools. 


\section{Introduction}

As health promotion and health education interventions become more complex, there is a greater need to document and analyse the processes of these interventions, in order to interpret programme outcomes and failures and to guide future intervention efforts. The literature on health promotion therefore stresses the importance of process evaluation (Bartholomew et al., 2001; Green \& Kreuter, 1999).

This article describes the process evaluation of the Krachtvoer programme. Krachtvoer is a Dutch nutrition education programme for lower vocational (preparatory secondary vocational education) students aged 12 to 14 years. Krachtvoer aimed to increase students" consumption of fruit and fruit juice, decrease the consumption of high fat snacks, and increase breakfast frequency and quality. The effect of the programme was assessed in a cluster-randomised baseline-posttest experimental design in which schools were randomly allocated to either the Krachtvoer intervention or a control condition. The Krachtvoer intervention was completed in eleven schools between September and December 2002. The Krachtvoer curriculum consisted of eight lessons that had to be completed within a three-month period, while the control schools conducted their standard curriculum during that same period. The effect evaluation revealed beneficial effects on some, but not on all behavioural measures with regard to fruit intake, high-fat snack intake and breakfast habits. Some positive behavioural effects occurred in the total target population, others mainly or only among students with the least desirable values at baseline. Similar patterns were found with respect to effects on intention to change, attitudes, subjective and descriptive norms, self-efficacy, awareness of risk behaviour interest in the topic, perceived food rules and the availability and accessibility of food at home. Also some negative effects occurred among students with the most desirable values at baseline. However, these effects were smaller than the effects for the students with the least desirable values at baseline. To enrich and enable the interpretation of these results, the present process evaluation was conducted by collecting further data among the teachers and students in the Krachtvoer schools.

The aim of the present study was to investigate the completeness, fidelity and appreciation of the implementation of the Krachtvoer programme. Completeness indicates the proportion of programme activities and components that are actually delivered, whereas fidelity is the degree to which a programme is implemented with its methods and strategies intact (Bartholomew et al., 2001). We also examined the opinions of the teachers and students about the programme, as well as the association between these opinions and the level of implementation.

\section{The intervention}

\section{Target behaviours}

Unhealthy dietary habits, such as insufficient fruit consumption, frequent consumption of high-fat snacks, and skipping breakfast, are common among adolescents in 
the Netherlands as well as in many other countries (Department of Health, 2000; Health Education Authority, 1999; Munoz et al., 1997; Schaalma et al. 1997; Voedingscentrum, 1998). The aforementioned dietary behaviours have been found to be associated with increased risk of overweight and obesity, concentration problems at school and, in the longer run, an elevated risk of chronic diseases such as diabetes, cardiovascular diseases and certain types of cancer (Matthews, 1996; Pollit, 1995, 1998; Willet, 1994). Improving the nutritional habits of adolescents is therefore important. Moreover, healthy eating in youth may help to establish healthier dietary choices in later life (Branen \& Fletcher, 1999; Krebs-Smith et al., 1995; Lytle et al., 2000). It is especially when children transfer from primary school to secondary school that their eating habits change and become less healthy (De Vries \& Da Costa Senior. 1992). Intervening at this age may therefore prevent unhealthy eating behaviour becoming habitual. Further, adolescents from lower socio-economic position (SEP) groups have less favourable diets than their peers from higher SEPS (Koivisto Hursti, 1999; Roos et al., 1998). Interventions promoting a healthy diet should therefore be suitable especially for lower SEP groups.

\section{Objectives and theoretical framework of the 'Krachtvoer' programme}

The development of the 'Krachtvoer' programme applied some key aspects of Intervention Mapping (IM) (Bartholomew et al., 2001). Intervention mapping is a framework for effective decision making at each step in the process of developing, implementing and evaluating health education programmes. As recommended in the IM procedure, available theoretical knowledge was used and additional studies were conducted to justify the many decisions that had to be made in the process of developing a behavioural change programme. These included decisions on general programme goals and specific learning and performance objectives, the target group, but also decisions on the theoretical intervention methods and practical strategies to develop the final intervention programme.

The overall programme goals were to increase the consumption of fruit and fruit juice, decrease the consumption of high fat snacks, and increase breakfast frequency and quality. More specific performance objectives were formulated based on selfmanagement theory (Bartholomew et al.,2001; Boekaerts et al., 2000; Cameron \& Howard, 2003) and preliminary qualitative (Martens et al., 2002) and quantitative studies (Martens et al., submitted) on personal and social environmental predictors of the target behaviours. Self-management theory describes how individuals can be motivated and enabled to self-correct unhealthy habits. Self-management is regarded as a cyclic procedure involving three phases: (a) monitoring one's own health behaviour or health status; (b) comparing this self-evaluation with a certain norm (e.g., earlier states of behaviour or health, recommendations, or other people's health behaviours), describing a problem or a divergence from the norm, and analysing the causes of this divergence; and (c) attempting a behavioural correction to get closer to the norm (Bartholomew et al., 2001; Boekaerts et al., 2000; Cameron \& Howard, 2003). Based on self-management theory and the aforementioned preliminary studies (Martens et al., 2002; Martens et al., submitted) the following performance objec- 
tives for the intervention were formulated: students were expected to (1) self-assess their personal fruit, snack and breakfast intakes, (2) compare their intakes with recommended levells, (3) indicate reasons for observed discrepancies between their own intakes and recommendations, (4) propose solutions, i.e., set goals to close the gap with the recommended intake levels, (5) implement these solutions, (6) evaluate their personal goal performance.

Focus group interviews with students; parents and teachers were conducted to examine the requirements in terms of overall programme design that would promote adoption and implementation, such as the number and length of the lessons and the number of optional elements (Martens et al., 2002). During the whole development process, a consultation team consisting of experts in the field of nutrition and the theory of education advised us about the programme.

\section{Intervention components}

The 'Krachtvoer' programme consisted of eight lessons lasting fifty minutes each, and used a combination of materials: various so-called task forms for the different lessons, postcards and posters, a 'survival kit' (a lunchbox with 3 healthy food items, viz., a piece of fruit, a health food snack and a breakfast product, and a flyer), a magazine, a video, a website, a take-home bag with a newsletter and food-items for the parents, taste-testing of various products, and a manual to instruct the teacher in providing the different lessons. Many of the materials featured three cartoon characters related to the targeted behaviours. The task forms guided the students through the programme. Students completed these forms individually, in small groups or as a class. There were three types of task forms: information forms, action forms and question forms. Information forms were aimed at providing rellevant knowledge and were always linked to an action form or question form. An action form encouraged students to actually do something, for instance a taste-test, assessing what distinguishes a 'real' fruit juice from other fruit-like drinks, making their own fruit shake, tasting different breakfast cereals or writing down their own ideas for healthy recipes. A question form asked students to answer questions or to write down options or decisions, for instance reporting how many pieces of fruit they normally ate or setting and writing down personal goals for dietary change.

The 'Krachtvoer' programme consisted of three main phases (Table 1). In phase one, (including lessons one to four) the first activities aimed to raise students' enthusiasm for the pragramme; the subsequent activities were linked to the first three performance objectives: monitoring behaviout, comparing observations with a certain norm and assessing reasons for inadequate intake.

In phase two (including lessons four to seven) all activities aimed to help students to overcome their personal reasons for not eating a healthier diet (performance objective 4). In this phase, teachers were allowed to vary the activities and the order in which they were carried out, but were expected at least to offer the action form to test nutrition knowledge, show the video that illustrated how social influences affect dietary choices, discuss the magazine and carry out one or more optional activities: tasting unfamiliar foods, making a fruit shake, tasting various types of fruit and a 
Table 1.

Description of the "Krachtvoer" programme: phases, lessons, performance objectives, behavlours and materials

\begin{tabular}{|c|c|c|c|c|}
\hline & 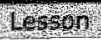 & 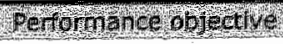 & 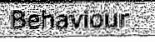 & Maghastrogro \\
\hline 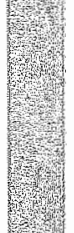 & 1 & $\begin{array}{l}\text { Make students } \\
\text { enthustatic about the } \\
\text { programme }\end{array}$ & $\begin{array}{l}\text { Fruit } \\
\text { Snacks } \\
\text { Breakfast }\end{array}$ & $\begin{array}{l}\text { - Three different postcards designed to introduce the } \\
\text { programme name, the three cartoon characters and } \\
\text { the internet site. } \\
\text { - Posters matching the design of the postcards. } \\
\text { - Adton form for a quiz with questions related to the } \\
\text { three belhewous. } \\
\text { - Surval kit wh } 3 \text { healthy food items and flyer with an } \\
\text { overview of the programme. }\end{array}$ \\
\hline 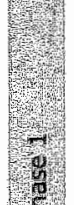 & 2 & $\begin{array}{l}\text { 1) Assess intake } \\
\text { 2) Compare Intake } \\
\text { with recommenda } \\
\text { tons }\end{array}$ & * Fruit & $\begin{array}{l}\text { - Information form and action form with a firuit juice } \\
\text { test to distinguish. real frutt juices from frult drinks } \\
\text { containing sugar. } \\
\text { - Question form to assess fruit consumption. } \\
\text { - Information form with fruit guidelines. } \\
\text { - Question form to compare own frut intake with guide- } \\
\text { lines. }\end{array}$ \\
\hline 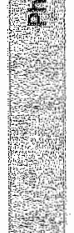 & 3 & $\begin{array}{l}\text { 1) Assess intake } \\
\text { 2) Comprare intake } \\
\text { with reconmenda } \\
\text { tions }\end{array}$ & $\begin{array}{l}\text { * Snack } \\
\text { * Breakfast }\end{array}$ & $\begin{array}{l}\text { - Question form to assess breakfast habits. } \\
\text { - Information form with breakfast guidelines. } \\
\text { - Question form to compare own breakfast intake with } \\
\text { guidelines. } \\
\text { - Question form to assess snack consumption. } \\
\text { - Information form with snack guidelines. } \\
\text { - Question form to compare own sinacki intake with } \\
\text { guidelines. }\end{array}$ \\
\hline 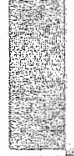 & 4 & $\begin{array}{l}\text { 3) Indicate reasons } \\
\text { for discrepancies } \\
\text { between own intake } \\
\text { and recommended } \\
\text { levels }\end{array}$ & $\begin{array}{l}\text { * Frult } \\
\text { * Snacks } \\
\text { * Breakfiast }\end{array}$ & $\begin{array}{l}\text { - Question form to help students understand thelr own } \\
\text { reasons for nat performing the healthy behaviour. }\end{array}$ \\
\hline & 4 & 4) Propose sollutions & * Fruit. & Solutions linked to attitude reasons: \\
\hline & (end) & to close the gap with & & - Information forms and action forms to imvent a \\
\hline & 5 & $\begin{array}{l}\text { me necommended } \\
\text { intake levels }\end{array}$ & & - Action form to do taste testing and let students expe- \\
\hline & 6 & & & $\begin{array}{l}\text { rience that fruit, low-fat snacks and breakfast items } \\
\text { can be tasty. }\end{array}$ \\
\hline 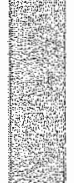 & $\begin{array}{c}7 \\
\text { (start) }\end{array}$ & & & $\begin{array}{l}\text { - Action form to make a fruit shake and let stwdents } \\
\text { experience that fruit can be tasty. } \\
\text { - Taste testing with fruit, letting students experience } \\
\text { that fruit can be tasty. } \\
\text { - Kiwi-eating contest, letting students experience that } \\
\text { fruit can be eaten without getting sticky hands. }\end{array}$ \\
\hline Mt & & & & $\begin{array}{l}\text { Solutions linked to social infuerce reasons: } \\
\text { - Action form to watch a video with severai conmerciels } \\
\text { and leam how to deal with social influences on eating } \\
\text { behaviour. }\end{array}$ \\
\hline & & & & $\begin{array}{l}\text { Solutions linked to avallability reasons: } \\
\text { - Take-home bag with food items, a newstetter including } \\
\text { tips for parents to support their children and recipes. }\end{array}$ \\
\hline $\begin{array}{ll}4 \\
4 \\
4\end{array}$ & & & & $\begin{array}{l}\text { Soluthons linked to several reasons: } \\
\text { - Action form to test nutrition knowledge, almed at } \\
\text { providing relevant knowledge. } \\
\text { - Magazine proviling facts, tests, puzzles, a horoscope, } \\
\text { role model stories, recipes and support for the pro- } \\
\text { gramme. } \\
\text { - Internet site presenting information about fruit, break- } \\
\text { fast and smacking, seweral tests, recipes and support } \\
\text { for the programme. } \\
\text { - Computer snack test aimed at providing relevant } \\
\text { knowledge. }\end{array}$ \\
\hline 1 & (end) & $\begin{array}{l}\text { 5) Implement } \\
\text { solutions }\end{array}$ & $\begin{array}{l}\text { Fruit } \\
\text { Snacks } \\
\text { Breakfast }\end{array}$ & $\begin{array}{l}\text { Question form to formulate specific and achievable } \\
\text { goals to change behawiour. } \\
\text { - Magazine including suggestions for achieving dietary } \\
\text { changes. }\end{array}$ \\
\hline (2) & 8 & $\begin{array}{l}\text { 6) Evaluate personal } \\
\text { goal performance }\end{array}$ & $\begin{array}{l}\text { Fruit } \\
\text { * Snacks } \\
\text { Breakfast }\end{array}$ & - Question form to evaluate students" new lbehaviour. \\
\hline
\end{tabular}


'kiwi-eating contest'. In the third and final phase (including lessons seven and eight), the activities were linked to the last two performance objectives, involving the implementation of solutions, setting goals and evaluation of their personal goals.

\section{Adoption strategy}

A random sample of eighty schools was drawn from a list of addresses of preparatory secondary vocational educations schools in the Netherlands. Twenty five schools agreed to participate and met the inclusion criteria. The main reasons for non-participating were time problems or not complying the inclusion criteria. The twenty five schools were randomiy assigned to the Krachtvoer group (13 schools) or the control group (12 schools). Two experimental schools and four control schools withdrew during the study. Before the start of the programme al schools were attended and verbal information of the intervention procedure was given. During the intervention two researchers were available for questions, comments or problems.

Eleven schools with 15 teachers, 41 classes and 1021 students participated in the Krachtvoer programme. Boys and girls were equally represented. Thirty-five percent of the students were aged 12 years or younger, $51 \%$ were 13 years old and $14 \%$ were 14 years or older at the start of the programme.

\section{Method}

Data were collected throughout the implementation period of the programme (September to December 2002), by means of 'triangulation', i.e., using multiple data sources and methods to measure the same process and effect indicators (McGraw et al., 1996). Methods included structured teachers' monitoring reports, in-class observations, in-depth interviews with teachers and a student questionnaire.

\section{Teachers' monitoring reports}

Data on programme implementation were collected with forms with questions on teaching time, activities completed, materials used, general impressions and student reactions, to be completed by the teachers in the Krachtvoer schools after each lesson. The forms were structured according to the topics and lessons of the programme and most questions were open-ended to give the teachers the maximum opportunity to express their opinions. Based on the completed forms the researcher wrote an overall summary report for each topic and lesson. These summaryareports were checked by two other researches.

\section{In-class observations}

In-class observations were used to assess fidelity of implementation. We aimed to observe at least one lesson with two observers in each experimental school. During and immediately after the lessons, each of the observers completed a structured 
form on the activities completed, materials used, teaching procedure, the students' reactions and participation and potential obstructing factors. The researcher wrote summary reports based on the observation forms and these reports were again checked by two other researchers.

\section{Teacher interviews}

Semi-structured interviews were conducted with the participating teachers of the experimental schools to assess the opinions of the teachers about the programme, their perception of the students' opinions as well as additional information about programme implementation. The teachers were also to give a general impression of the Krachtvoer programme, to state their opinion on the various programme materials, and to report on the students' reactions to the programme. Further, as an indirect indicator of the teachers' opinions, we asked about their perceptions of the effect of Krachtvoer on their students' dietary habits. Finally, additional information about the implementation was collected by questions on perceived difficulties with the implementation and perceived gaps. The interviews were held one to three months after completion of the intervention and lasted approximately 30 minutes. The interviews were tape-recorded and transcribed. Intonations and observed non-verbal behaviour were noted on the transcripts. All relevant text fragments from the transcripts were coded and categorised by the researcher according to the list of interview topics and summary reports were written, and checked by two other researchers.

\section{Student questionnaire}

In order to assess the students ${ }^{\prime}$ opinions about the programme, a section with process questions was included in the post-test questionnaire that was part of the effect evaluation study (Martens, Van Assema, \& Brug, submitted). The process questions in this questionnaire consisted mainly of close-ended questions with five-point answering scales, and the questionnaire was completed in the classroom under teacher supervision in December 2002 in the Krachtvoer schools as well as in control schools that were exposed to the normal nutrition education curriculum.

The general opinion about the programme was measured by asking students in the Krachtvoer and the control schools to indicate how pleasant (very pleasant - very unpleasant), interesting (very interesting - very uninteresting), difficult (very easy

- very difficult) and new (very new - very familiar) they found the nutrition lessons. The students were further asked if they had talked about their nutrition lessons at home. In addition, the students in the Krachtvoer schools were asked to rate the Krachtvoer lessons on a scale from 1-10 and to give their opinion on the various programme materials, and were asked to indicate how closely they had read the magazine and the information on the website (did not look at it - read it all), and whether they had asked their parents to buy the products that had been tasted during lessons (yes - no).

Statistical analyses of the quantitative process data were conducted with SPSS version 11.0. Analysis of variance was conducted with the study condition as the 
independent variable and perceived pleasantness, interestingness, difficulty, and movelty as the dependent variables. Chi-square tests were conducted to evaluate the relation between conditions and talking about the lessons at home. A significance level of 0.05 was used.

\section{Results}

\section{Response}

Of the 15 teachers who implemented Krachtvoer, 10 returned the monitoring reports. Five teachers failed to provide the monitoring reports, stating postal delivery problems and time investment problems as their reasons. Ten teachers in eight schools were observed. All 15 participating teachers of the experimental schools were interviewred. All students who were present during the data collecting hours completed the post-test questionnaire ( $N=1021$ in the Krachtvoer schools and $N=591$ in control schools).

\section{Completeness of implementation}

The monitoring reports and interviews revealed that eight teachers had spent between four and eight lessons lasting 100 minutes each, while six teachers had spent between seven and eleven lessons lasting 50 minutes each, and one teacher had spent seven lessons lasting 60 minutes each on the Krachtvoer programme. All teachers spend the requested 400 minutes on the Krachtvoer intervention and most teachers spend even more time to the intervention.

The findings from the monitoring reports, the in-class observations and the teacher interviews showed that 14 of the 15 teachers had followed the phased structure of the Krachtvoer programme. One teacher had used the Krachtvoer programme more as a supplement to the standard curriculum. All 15 teachers had completed phase one. Eleven of the 15 teachers had offered all the prescribed elements of phase 2, while two teachers had failed to offer one optional activity, and the two remaining teachers had also failed to offer the action form testing nutrition knowledge and the social influences video. All 15 teachers had discussed the magazine with their students. Optional activities frequently included taste-testing unfamiliar foods (all teachers) and making a fruit shake (ten teachers). Less favourite among the optional activities were the taste-testing various types of fruit (five teachers) and the 'kiwi-eating contest' (zero teachers). Only four of the 15 teachers had completed all elements of phase three. Five teachers had discussed the goal-setting forms but had failed to discuss the related behaviour evaluation form. The other six teachers had not discussed any of these forms.

According to the monitoring reports and interviews, additional activities and materials were used during the Krachtvoer programme, for instance, watching a video with general nutrition information, tasting healthy snacks other than those provided by Krachtvoer, making healthy snacks, preparing and eating luncti during school 
hours or other cooking practices, using general nutrition internet sites, drawing of nutrition products as a preparation for the recipe contest, making advertisements, using information on healthy diets from books that are part of the standard curriculum, and visiting a greengrocer's to inspect the variety of fruits on affer:

Based on the in-class observations, the students' participation was evaluated as good. The students asked many questions during the observed lessons, exhibited an active, participating attitude, worked seriously and participated in discussions on the materials and activities. However, some students, especially in classes with many students, were observed to be easily distracted, and noisy surroundings were identified as possible obstructing factors.

\section{Fidelity to the programme}

The in-class observations revealed that seven of the lessons were executed according to the Krachtvoer curriculum. In three of the observed lessons, the teacher used procedures that conflicted with the Krachtvoer programme. Some teachers used selfdeveloped task forms, changed the order of the main phases and one teacher used the Krachtvoer programme as a supplement to the standard curriculum. Further, the in-class observations revealed that some of the additional activities implemented by teachers on their own initiative, such as watching a nutrition education video, using nutrition information internet sites and using information on healthy diets from books that are part of the standard curriculum, interfered with the phase-structure or behavioural focus of the Krachtvoer programme.

\section{Opinions about the programme}

\section{General impressions}

The teachers' monitoring reports and interviews both indicated that most teachers had favourable opinions on the Krachtvoer programme. They praised the programme for its practical approach, the design of the materials, the fact that the programme was provided free of charge, and the diversity of strategies and activities. Taste testing unfamilliar foods, the recipe contest, the social influence video and the fruit shake preparation, were frequently mentioned as the most highly appreciated activities. Some of the teachers added that lower vocational students must be actively encouraged to work with the materials, because they are easily distracted. All teachers expressed the opinion that the Krachtvoer materials were appropriately tailored to the general educational level of the students. Some teachers said that they would have preferred the inclusion of a more general introduction to the topics, information on the recommended daily intake, label reading and food hygiene in the Krachtvoer programme, topics that are part of the existing curriculum. Some teachers also commented that the Krachtvoer lessons took more time than the standard curriculum and that it was difficult to estimate the duration of some activities. Some would like to see examination papers included. Ten teachers indicated that they thought that the students had become more aware of their own dietary behaviour as a result of the Krachtvoer programme. However, three teachers expressed their doubts as to 
Table 2

Means, SD and analysis of variance of the general impressions about the nutritional lessons (measured on scales from -2 to +2 )

\begin{tabular}{|c|c|c|c|c|}
\hline (3) & $(1001910)$ & 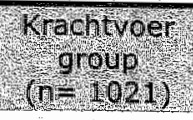 & control group & Analysis of varifnge \\
\hline Pleasantness & $0.17(1.19)$ & $0.44(1.13)$ & $-0.31(1.14)$ & $\begin{array}{c}F(1,1544)=156.13 \\
p=0.000\end{array}$ \\
\hline Interestingness & $0.16(1.15)$ & $0.38(1.09)$ & $-0.22(1.15)$ & $\begin{array}{c}F(1,1545)=104.45 \\
p=0.000\end{array}$ \\
\hline Easiness & $0.67(0.93)$ & $0.81(0.86)$ & $0.43(0.99)$ & $\begin{array}{c}F(1,1542)=63.91 \\
p=0.000\end{array}$ \\
\hline Novelty & $0.14(1.01)$ & $0.30(0.97)$ & $-0.13(1.01)$ & $\begin{array}{c}F(1,1541)=65.84 \\
p=0.000\end{array}$ \\
\hline
\end{tabular}

* More positive scores indicate a higher score on perceived pleasanthess, interestingress, easiness and novelty of the nutritional lessons

whether the students would really adopt successful healthy dietary changes in their regular diets. The teachers' monitoring reports and interviews both indicated that some teachers intended to keep using the Krachtvoer program.

The student questionnaires showed that the students were moderately positive about the Krachtvoer programme. The students in the Krachtvoer schools perceived their nutritional lessons as significantly more pleasant, more interesting, easier and newer than those in the control schools (Table 2).

\section{Opinion on programme materials}

Based on the monitoring reports, in-class observations and teacher interviews, the survival kit was the most successful of the materials of phase one and was perceived as enabling the students to become enthusiastic and curious about the Krachtvoer programme. The teachers were less positive about the information and questionforms of phase one. Teachers experienced these forms as boring and poorly-structured mainly because of the number of forms. Most teachers reported that the task forms themselves were well-structured.

Favourite activities in phase two were taste-testing unfamiliar foods, making a fruit shake, reading the magazine, taking part in the recipe contest and taking home the bag with a newsletter and the food items for the parents. The main reason was the practical approach and the many different strategies used in the activities. Because the students could really taste, feel and smell the products, they were very motivated to participate in the taste testing and fruit shake lessons. In some cases, however, not enough facilities and equipment were available and a great deal of organisation skill was needed to do the taste testing with unfamiliar foods and making a fruit shake in the classroom. It was further perceived to be important that the products for the taste testing should not be too close to the expiry date, and that different brands of products should be provided.

Most teachers reported that the question-form used to formulate specific and 
Tablle 3

Teachers' opintons on the programme materials

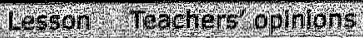

1 Warv teachers reported that the students were enthusiastic and surpised about receiving the posteard and that it raised their curiosity about the programme. Some teachers noted that the students had regarded recewing the postcard as weird and had thrown the card away. They recommended not to repealt this programme element.

The posters seemed to support the Krachtwoer programme. The cartoon characters were appreciated. However, the link with the nutrition lessons should be more clearly explained on the poster.

* The action form to do a quiz seemed a sultable introductory efement, though in future some prior knowledge should be provided to the students before they do the quiz.

* The survival kit was one of the great successes of the programime and made the students enthusiastic for the programme. The teachers considered very special that the students got their ow lunchibox with healthy food tems. The lunchboxes were often spotted during the in-class observations. The teachers reported that the lunchbox was still being used by many students sonine monthis after the intervention.

2 * The fruit fuice test was appreciated because it was a practical lesson and helped the students to distinguish real fruit juices from fruit drinks containing sugar.

3 The lessons were perceived as boring and disorderly because of the many information and question forms. The forms should be combined. Most teachers ewaluated the task forms themselves as well organised and prowiding enough space to ffill in the arswers. 4 The question forms to help students assess their own reasons for not performing a healthy
(start) behawow were appreciated. It sparked a great deal of debate and students liked to inven-
bory the answers of athers.

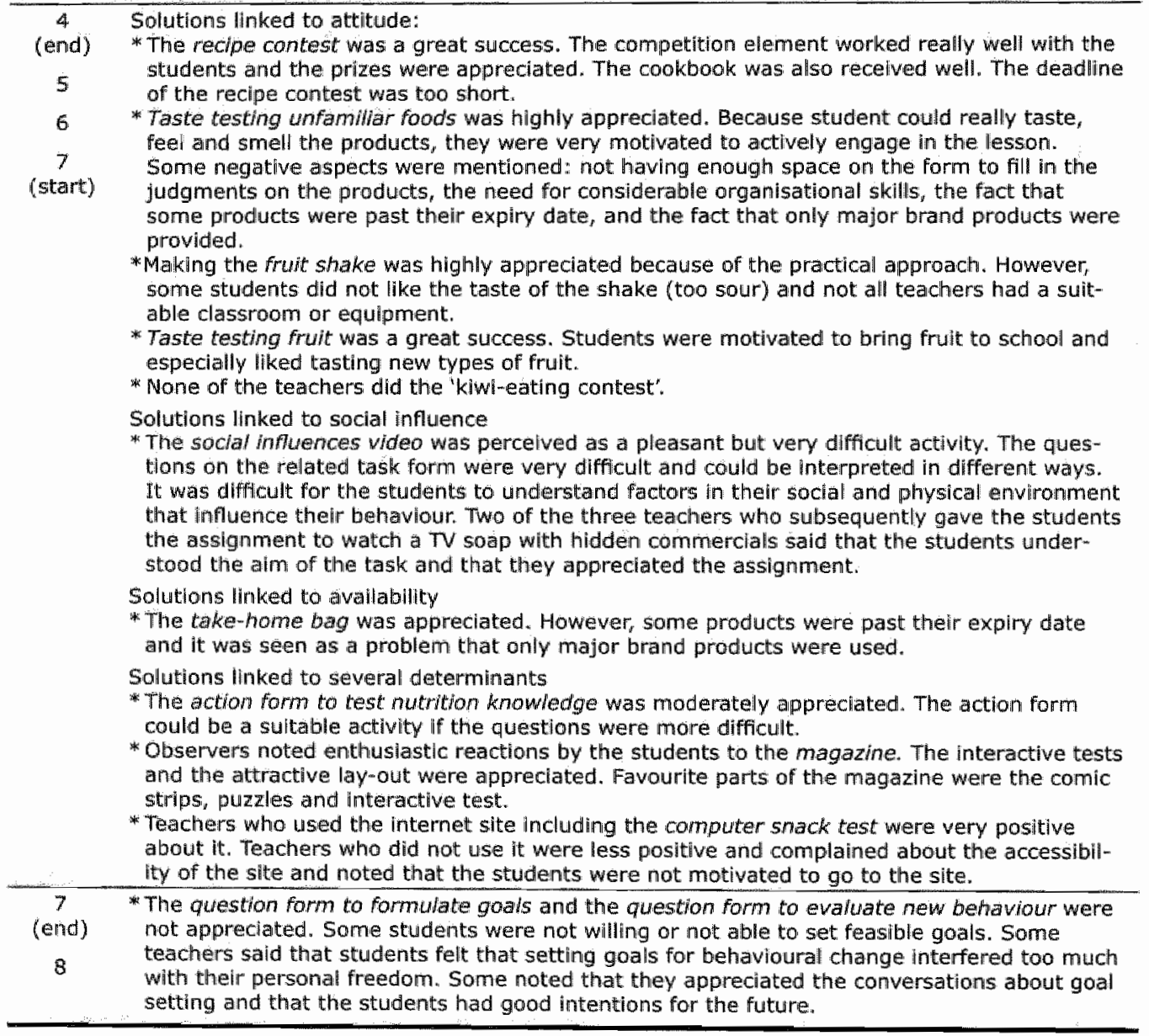


achievable goals in phase three was difficult to use. Some students were not willing or able to set feasible goals. Some teachers said that students felt that setting goals for behaviour-change interfered too much with their personal freedom. Some teachers noted that they appreciated the conversations about goal-setting and that the students had formulated valuable intentions. Our in-class observations revealed that some teachers integrated phase three with activities belonging to phases one and two.

The students of the Krachtvoer schools rated the various programme materials as positive (Table 4). The recipe contest and the video illustrating social influences were appreciated most. Further ${ }_{z}$ the task forms, magazine and website were perceived as easy-to-use and clear.

\section{Table 4}

Means, $\mathrm{SD}_{t} \%$ agreement and $\mathrm{N}$ of evaluations of the specific Krachtvoer materials*1

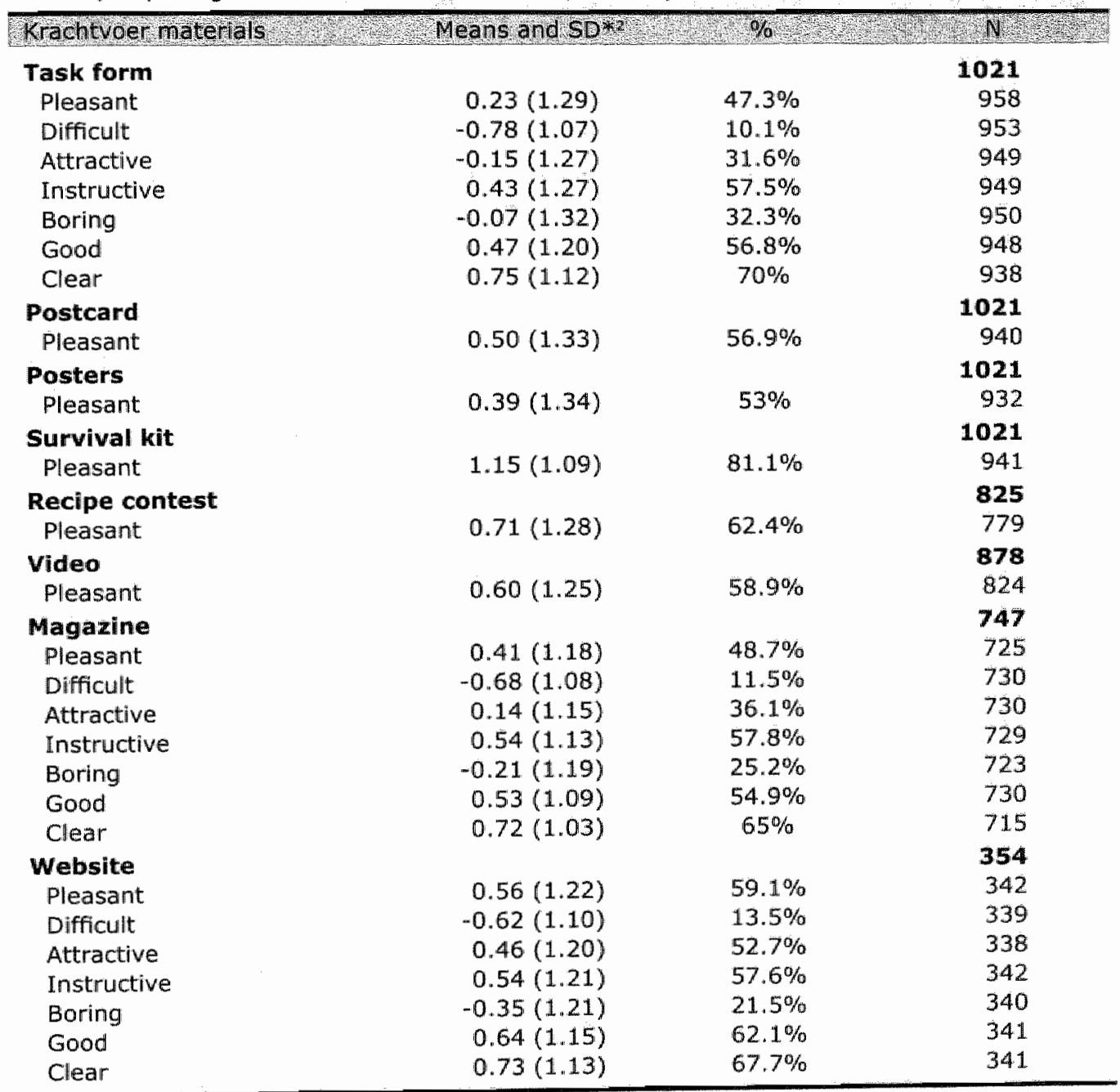

*1 Only students who were actually exposed to the specific materials were included in the analysis

*2 Measured on scales from -2 to +2 
The students evaluated the programme with a mark of 7.2 on a scale of $1-10$. Elghty-elght percent of the students had read the magazine; $47 \%$ of the students had read the information on the website. Fifty-four percent of the students reported to have asked their parents to buy products that were taste tested during the lessons. Students in the Krachtvoer schools were more likely to talk about the nutrition lessons at home $(60 \%)$ than the control students $(20 \%)\left(X^{2}(1)=213.20 ; p=0.000\right)$.

\section{Discussion}

The findings of the present study indicate that teachers implemented the Krachtvoer programme largely according to plan, that the teachers appreciated most parts of the programme and that the students who were exposed to Krachtvoer were more appreciative of their nutrition education lessons than students who followed the usual curriculum.

Although the teachers added extra activities and materials to the Krachtvoer programme, the degree of completeness of the implementation of the programme was quite good. In most cases, the order and content of lessons was in accordance with the phased structure of the Krachtvoer programme. However, better guidance for the teachers might have resulted in even better implementation. The process evaluation also indicated non-optimal implementation of phase three by both teachers and students, which may have prevented greater behaviour change effects from occurring, since phase three was especially designed to translate positive intentions into actions. It seems that students felt that setting goals for behavioural change interfered too much with their personal freedom, and this may have made the teachers hesitant to implement this part of the programme. For future use of the Krachtvoer programme, phase three may thus need revision.

Although our study indicates that the fidelity of the implementation of the Krachtvoer programme was good, some teachers used procedures and activities in their nutrition education lessons that conflicted with the Krachtvoer programme. During the intervention, we tried to avoid this by providing a clear description of the main alm and the specific sub-aims of the Krachtvoer programme and its lessons in the teacher's manual. Perhaps a more intensive training programme for the teachers might have resulted in greater intervention fidelity.

The degree of implementation may have been influenced by the student's preferences. Teachers were less enthusiastic about those lessons which their students reported not to have enjoyed. Some teachers did not even ilmplement those lessons which they expected not to be appreciated by their students. Previous research had also found that students" preferences were perceived by teachers as important factors in the decision to adopt specific classroom-based education (Paulussen, Kok ${ }_{n}$. Schaalma, 1994).

The positive opinions about Krachtvoer among the teachers were also reflected by the fact that some of the teachers reported their intention to use the Krachtvoer programme again in the future. Of course, such a positive intention on the part of the teachers is no guarantee of actual adoption or continuation (Levenson, Gottlieb, 
\& Brink, 1994; Rohrbach, Graham, \& Hansen, 1993) and teachers should be actively encouraged and supported to keep using the programme in their nutrition education classes.

By collecting data from multiple sources and using multiple methods, we believe that we were able to carefully evaluate the implementation of the Krachtvoer programme and the opinions about the programme among teachers and stuidents. Even though the individual methods had their limitations, such as the limited number of observations and incomplete monitoring, we were able to identify successful and less successful elements of the programme.

We conclude that the present study, combined with the results of the effect evaluation, shows that the Krachtvoer programme is a promising tool to encourage students in lower vocational schools to adopt healthier diets. The present study revealed the stronger and weaker parts of the programme and can thus guide the revision process for further programme improvement. 


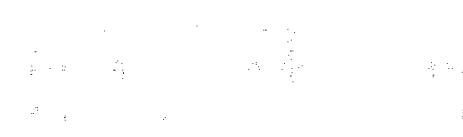




\section{GIAPTER G}

Family-related correlates of adolescents' intakes of fruit and snacks and programme-induced changes in such intakes 


\begin{abstract}
We assessed the association between a number of family-related factors and fruit and snack consumption by adolescents aged $12-14$ years. We also assessed whether these family-related factors affected the changes in these two health-related dietary habits induced by the Dutch educational programme called Krachtvoer, implemented at vocational schools. Questionnaires were malled to the parents of the students who participated in the programme, assessing migrant status, education, employment status, dietary intakes, parenting styles, food purchase considerations, family food rules, and availability and accessibility of food items at home. Questionnaires of 502 parents were matched with those of their children. Regression analyses revealed a positive association between parents' fruit intake and children's fruit intake, and a negative association between the importance of weight control in family food purchasing habits and chlldren's snack intake. We found no significant family-related predictors of programme-induced changes in either frut or snack intake. We conclude that in the present adolescent population, the influence of family-related factors seems limited and that there are no indications that these factors modified the programme's effect. For the Krachtwoer project, this means that we found no evidence that there are subgroups of children who might profit less due to their family background.
\end{abstract}

Submitted as: Martens MK, Van Assema P, Knibbe R, Engels R, \& Brug J. Family-related correlates of adolescents' intakes of fruit and snacks and programme-induced changes in such intakes 


\section{Introduction}

Unhealthy eating habits among young people are a major public health problem (Vereecken et al., 2004; WHO, 2003). Several studies have examined the causes of children's and adolescent's unhealthy diets. Family-related factors, such as parental modelling and food availability at home, are among the factors that have been studied for their potential association with young people's eating habits. The present study assessed the association between a number of family-related factors and fruit and snack consumption by adolescents. It also examined whether these factors were associated with the changes in these two health-related behaviours induced by a healthy nutrition education programme implemented at schools. Fruit intake is assumed to contribute to the prevention of chronic diseases such as cardiovascular disease and cancer, and a recent study showed that fruit intake in youth contributes particularly to a lower cancer risk at a later age (Maynard, Gunnell, Emmett ${ }_{\text {i Frankel, }}$ \& Davey Smith, 2003). Snacking among young people has increased, and now contributes substantially to energy intake; it may be a determinant of increased weight gain in this age group (Zizza, Siega-Riz, \& Popkin, 2001).

To our knowledge, no studies have so far examined whether family-related factors modify the effects of healthy diet promotion interventions. Previous cross-sectional studies have found associations between several family-related factors and young people's dietary intake, viz., parental dietary intake, parenting style, family food purchase considerations, family food rules, availability and accessibility of foods at home and socio-economic status of the family. However, results for some of these factors have been inconsistent. Fruit intake by parents has consistently been shown to be positively associated with children's fruit intake (Brown \& Ogden, 2004; Cullen-Weber et al „, 2001; Feunekes, De Graaf, Meyboom, \& Van Staveren, 1998; Fisher, Mitchell, Smiciklas-Wright, \& Birch, 2002; Gibson, Wardle, \& Watts, 1998; Olivera et al., 1992; Woodward et al., 1996; Young et al., 2004). Snack food intake by parents has also been found to be positively related with that of their children (Brown \& Ogden, 2004), while a study by Gibson et al. (1998) did not find a relation between mothers' sweets intake and the consumption of sweets in their children (Gibson et al., 1998). With regard to general parenting styles, Young (2004) failed to find a correlation between perceived authoritative parenting style and children's fruit consumption (Young et al, 2004). Cullen et al. (2001) found only a weak correlation between parental control and children's fruit juice consumption (Cullen-Weber et al., 2001). Kremers et al. (2003) found that fruit consumption by adolescents was most favourable among those who were being raised with an authoritative parenting style, and that children of parents with indulgent parenting styles consumed more fruit than those from authoritarian or neglectful homes (Kremers et al., 2003). Lytle et al. (2003) also found a positive association between the use of an authoritative style by mothers and high children's fruit consumption, although for fathers, the non-authoritative style was associated with greater consumption of fruit (Lytle et al., 2003).

A study by Glanz and colleagues (Glanz, Basill, Maibach, Goldberg, \& Snyder, 1998) found that family food purchase considerations, that is, the importance attached to taste, cost, convenience or weight control in product selection, were associated with 
dietary behaviours among adults, and this may also hold for children's dietary intake. With regard to family food rules, parental pressure to eat fruit has been found to discourage intake of fruits among young girls (Fisher et al., 2002). In a study by Brown (2004), children whose parents reported greater attempts to control their children's diet reported higher intakes of both healthy and unhealthy snacks (Brown \& Ogden, 2004). In a study by De Bourdeaudhuif (1997), adolescents who reported more permissiveness in their family ate more fat and sweet foods and more snacks, and reported less healthy food choices in the family, but no relationship was found between compulsion to eat a "proper meal" in childhood and healthy food patterns in adolescence (De Bourdeaudhuij, 1997). A number of studies have found a positive association between the availability and accessibility of fruits at home and children's fruit consumption (Cullen-Weber et all., 2001; Hearn et al., 1998; Kratt, Reynolds, \& Shewchuk, 2000; Young et al., 2004). However, one study found that children's fruit consumption was not significantly associated with its availability at home (Edmonds, Baranowski, Baranowski, Cullen, \& Myres, 2001). Finally, a study by De Bourdeaudhuij (1997) found no association between children's dietary habits and their parents' educational level and employment status (De Bourdeaudhuij, 1997), while several other studies did find associations between low socioeconomic status and increased nutritional risk (De Bourdeaudhuij \& Van Oost, 1998; Höglund, Samuelson, \& Mark, 1998; Hulshof, Brussaard, Kruizinga, Telman, \& Lowik, 2003; Lytle et al., 2003; SerraMajem et al., 2002; Story, Neumark-Stainzer, \& French, 2002; Warwick, McIlveen, \& Strugnell, 1999).

In summary, the work done so far has reported some inconsistent findings regarding the association between family-related factors and children's dietary intake. Most studies have focused on one or a few family-related factors and were conducted among several age groups. To increase our knowledge about the influence of the family environment on young people's diets as well as on the effects of interventions, the present study investigated the association between a number of family-related factors and fruit and snack consumption by children aged 12 to 14. It also examined whether family-related factors were associated with changes in these dietary habits induced by the Krachtvoer educational programme. This theory-and evidence-based programme for lower vocational schools intended to increase the consumption of fruit and fruit juice, decrease the consumption of high fat snacks and increase breakfast. frequency and quality. It consisted of eight lessons lasting fifty minutes each, and used a combination of theory-based materials, such as various so-called task forms for the different lessons, a video, a magazine, a website and a take-home bag with a newsletter and food items for the parents (Martens et al., submitted). A randomised pre-test / post-test experimental study among 879 students of ten schools involved in the Krachtvoer programme, described in chapter 4, found small but significant increases in the consumption of fruit, and decreases in the consumption of high fat snacks in students with the highest snack consumption at baseline, relative to 734 students of six schools that used the normal curriculum (Martens et al., submitted). 


\section{Method}

\section{Design and sample}

The study was based on data collected among students who participated in the Krachtvoer programme and completed a baseline questionnaire administered in the classroom before the start of the programme, as well as a post-test questionnaire administered shortly after the programme (about three months after baseline). During the implementation of the programme, a questionnaire was malied to all parents of the children participating in the programme, using lists of addresses provided by the schools. We asked the children's mothers to fill in this parent questionnaire, or if that was not possible, the father or other caregiver. If more than one child in one family participated in the Krachtvoer programme, the mother was asked to fully complete the questionnaire for one child and to only enter the date of birth and gender in the questionnaires relating to the other child or children. The questionnaires completed by the students were matched with those of the parents using school number, date of birth and gender of the students.

\section{Measures}

Dietary intakes and some demographic characteristics were assessed by both student and parent questionnaires, in similar ways. All other measures used in the present study were based on the parent questionnaire.

\section{Dietary intakes}

Fruit consumption was assessed with a validated food frequency questionnaire (Van Assema et al., 2002). In two separate items, students as well as parents indicated on how many days a week they consumed fruit and the number of servings of fruit they consumed on such days. Frequency and quantity were multiplied to obtain estimates of mean fruit consumption in servings per day. Items to assess the consumption of snacks were derived from a larger validated questionnaire measuring total and saturated fat intake (Van Assema et al., 2001). Two items were used to assess on how many days a week students and parents consumed sweets and savoury snacks and the number of servings of sweets and savoury snacks they consumed on such days. Frequency and quantity were multiplied to obtain an estimate of the mean consumption of sweets and savoury snacks, also in servings per day.

\section{Parenting style}

From an extensive questionnaire developed on the basis of earlier work by Steinberg and others (Steinberg, Elmen, \& Mounts, 1989), Lamborn and others (Lamborn, Mounts, Steinberg, \& Dornbusch, 1991) and Sessa (Sessa, 1992), a number of items were selected that correspond with the parenting style dimensions of involvement and strictness. The questionnaire was adapted to allow it to be completed by parents. Items were measured on a completely untrue - completely true bipolar fivepoint scale. The involvement scale included nine items $(a=0.75)$, for example: 'I 
encourage my child to do better if he or she gets a poor mark at school. Strictness was measured by seven items $(a=0.73)$, for example: 'I know where my child is after school. Dichotomising the sample on each dimension and examining the two variables simultaneously defined four parenting categories. Parents who scored in the upper half on both involvement and strictness were categorised as authoritative, whereas parents who scored in the lower half on both dimensions were categorised as neglectful. Parents who scored in the lower half on involvement and in the upper half on strictness were categorised as authoritarian, whereas parents who scored in the upper half on involvement and in the lower half on strictness were categorised as indulgent (see Kremers et al., 2003. for an earlier study that applied this parenting style classification).

\section{Food purchase considerations}

Based on earlier work by Glanz and colleagues (Glanz et all, 1998), five items were used to assess purchase considerations of parents by asking how important the factors taste, nutrition, cost, convenience and weight control were in selecting products at the supermarket, on a bipolar very unimportant - very important five-point scale.

\section{Family food rules}

The existence of family rules relating to fruit was assessed by two items (i.e. are there rules at home for the number of servings of fruit your child is expected to eat and for the times when your child is expected to eat fruit). The items were summed ( 1 for yes, 0 for no) to obtailn one score for the presence of rules on fruit. The existence of rules relating to snacks was assessed in a similar way, using three items (i.e., are there rulles at home for how many snacks your child is allowed to eat, for the times when your child is allowed to eat snacks or for the type of snacks your child is allowed to eat).

\section{Avallability and accessibility}

Three items assessed avallability and accessibility of fruit (i,e., if your child indicates that he or she likes a certain type of fruit, would you buy it; is there fruit at home that your child likes; is fruit avallable in a place where it catches the eye). The items used different answering scales, which were recoded to a uniform three-point scale (usually yes (1), sometimes (0.5), usually no (0)). The item scores were summed to form a single score for fruit availability and accessibility. Snack availability was assessed in a similar way, using two items (i.e. If your child indicates that he or she likes a particular snack, would you buy it; are snacks usually available at home).

\section{Family socio-demographics}

The student questionnaire asked about the students' age and sex and about the students' possible migrant origin (i.e., whether one or both parents had been born abroad). The parent questionnaire included questions on marital status, own educational level and employment status. 
Statistical analyses were performed using the SPSS program (version 11, SPSS, 2001). Descriptive statistics (percentages and means) were used to describe the relevant student and parent characteristics. In order to explore possible selection bias, a multiple logistic regression analysis was conducted to identify potential differences in demographics and dietary intakes between the children included in the present study $(n=502)$ and all children participating in the Krachtvoer programme $(n=879)$ (Martens et al., submitted). Multiple linear regression analyses were conducted to identify potential family environment correlates of the dietary intakes of the children at baseline and the programme-induced changes in children's fruit and snack intakes. Baseline dietary intake and change in dietary intake were regressed on parents' migrant status, education, employment status, dietary intakes, parenting styles, purchase considerations, family food rules and availability and accessibility of food items. Parenting styles were dummy coded with the authoritative style as the reference style. All family environment variables were initially included in the model, after which non-significant variables were excluded from the analysis one by one. $A$ significance level of $p<0.05$ was used.

\section{Results}

\section{Response rates and respondent characteristics}

Approximately 1100 parents received the questionnaire*; 724 completed and returned it and $502(69 \%)$ were matched with the questionnaires of their children and were thus included in the present study. The other parent questionnaires could not be matched with those of their children because their children had not completed the baseline questionnaire or because the matching criteria did not correspond. Dietary change data were available for 456 of the $502(91 \%)$ children in the present study, as they had completed both the baseline and follow-up questionnaires.

Table 1 shows that boys and girls were almost equally represented in the sample and most students were aged 12 or 13 . On average, the mothers were in their early forties and the fathers in their mid-forties. A large majority of the parents were married or living together with a partner, and most parents had been born in the Netherlands. The mean age of the children in the present study was somewhat younger (12.7 years in the present study versus 12.8 years for all children who participated in the Krachtvoer programme $(\beta=-0.30, P$-value $<0.01)$ and the sample included fewer students from immigrant parents than the 879 children in the Krachtvoer programme who participated in the effect evaluation (11\% in the present study versus $17 \%$ of all children who participated in the Krachtvoer programme; $\beta=0.89$, P-value

\footnotetext{
* Since some schools mailed the questionnaires themselves, we do not know the exact number of questionnaires.
} 
Table 1

Means (SD) and percentages of participant characteristics and family-related factors $(N=502)$

\begin{tabular}{|c|c|c|}
\hline \multirow[t]{2}{*}{$\begin{array}{l}\text { Socio- } \\
\text { demographic } \\
\text { data of } \\
\text { students }\end{array}$} & $\begin{array}{l}\text { Gender }(\%) \\
=\text { Boys } \\
\text { - Girl's }\end{array}$ & $\begin{array}{l}48 \% \\
52 \%\end{array}$ \\
\hline & $\begin{array}{l}\text { Age }(\%) \\
-12 \text { years or younger } \\
-13 \text { years } \\
-14 \text { years or older }\end{array}$ & $\begin{array}{l}40 \% \\
49 \% \\
11 \%\end{array}$ \\
\hline \multirow[t]{2}{*}{$\begin{array}{l}\text { Socio } \\
\text { demographilc } \\
\text { data of parents }\end{array}$} & $\begin{array}{l}\text { Age (in mean; } 50 \text { ) } \\
\text { - Mother } \\
\text { - Father }\end{array}$ & $\begin{array}{l}41.87(4.15) \\
44.17(4.55)\end{array}$ \\
\hline & $\begin{array}{l}\text { Marital status of parents }(\%) \\
\text { - Married or living together with a partner } \\
\text { - Single }\end{array}$ & $\begin{array}{l}89 \% \\
11 \%\end{array}$ \\
\hline \multirow[t]{24}{*}{$\begin{array}{l}\text { Family } \\
\text { environment } \\
\text { factors }\end{array}$} & $\begin{array}{l}\text { Migrant }(\%) \\
\text { - One or both parents born abroad } \\
\text { - Both parents born in the Netherlands }\end{array}$ & $\begin{array}{l}11 \% \\
89 \%\end{array}$ \\
\hline & $\begin{array}{l}\text { Educational level of mother } \\
\text { - Low }(\%) \\
\text { - Intermediate or high }(\%)\end{array}$ & $\begin{array}{l}57 \% \\
43 \%\end{array}$ \\
\hline & $\begin{array}{l}\text { Educational level of father } \\
\text { - Low (\%) } \\
\text { - Intermediate or high }(\%)\end{array}$ & $\begin{array}{l}50 \% \\
50 \%\end{array}$ \\
\hline & $\begin{array}{l}\text { Employment status of paremts }(\%) \\
\text { - No or one parent working } \\
\text { - Both parents or single parent working }\end{array}$ & $\begin{array}{l}41 \% \\
59 \%\end{array}$ \\
\hline & Dietary intake of parent (in mean; SD) & \\
\hline & - Fruit (servings per day) & $1.11(0.77)$ \\
\hline & - Snacks (servings per day) & $1.21(1.03)$ \\
\hline & Parenting style & \\
\hline & - Authoritative $(\%)$ & $42.4 \%$ \\
\hline & - Neglectful $(\%)$ & $30.6 \%$ \\
\hline & - Authoritarian $1 \%$ ) & $14.6 \%$ \\
\hline & - Indulgent $(\%)$ & $12.4 \%$ \\
\hline & Purchase influences (in mean; SD) & \\
\hline & - Taste $(-2$ to 2$)$ & $1.62(0.53)$ \\
\hline & - Nutrition $(-2$ to 2$)$ & $1.14(0.73)$ \\
\hline & - Cost $(-2$ to 2$)$ & $0.96(0.86)$ \\
\hline & - Convenience $(-2$ to 2$)$ & $0.32(0.92)$ \\
\hline & - Weight controll ( -2 to 2$)$ & $0.40(0.89)$ \\
\hline & Number of food rules ${ }^{2}$ & \\
\hline & - Fruit (0 to 2$)$ & $0.38(0.62)$ \\
\hline & - Snacks (0 to 3$)$ & $1.97(1.05)$ \\
\hline & Avallability and accessibility ${ }^{3}$ & \\
\hline & - Fruit $(0$ to 3$)$ & $2.77(0.42)$ \\
\hline & - Snacks $(0$ to 2$)$ & $1.64(0.40)$ \\
\hline
\end{tabular}

${ }^{1}$ A positive score indicates that respondents perceived a particular food purchase consideration to be important.

${ }^{2}$ A higher score indicates a larger number of food rules.

${ }^{3}$ A higher score indicates greater avaliability and accessibility of food items 
Table 2

Means and SD of dietary intakes by students at baseline (TO) and post-test (T1), and change $(N=456)$

\begin{tabular}{|c|c|c|c|}
\hline Behavour(mean) sD) & TOO & & \\
\hline Fruit frequency (servings per day) & $0.89(0.78)$ & $1.09(0.83)$ & $0.20(0.71)$ \\
\hline Snack frequency (servings per day) & $1.78(1.39)$ & $1.66(1.30)$ & $-0.13(1.06)$ \\
\hline
\end{tabular}

$=0.000$ ) (Martens et al. ${ }_{r}$ submitted). No significant differences between the two samples on the behavioural measures were found.

The dietary intakes of the parents were, in general, more favourable than those of their children. The authoritative parenting style was the most common one next to the neglectful parenting style. Furthermore, taste and nutritional value were particularly important food purchase considerations. The parents reported to enforce more rules on snacks than on fruit, and reported fairly high availability and accessibility of food items.

Before the start of the Krachtvoer programme, the 456 students were eating an average of $0.9(\mathrm{SD}=0.8)$ pieces of fruit and $1.8(\mathrm{SD}=1.4)$ snacks per day. The mean behavioural change that was induced by the Krachtvoer programme among the 456 students was an increase of 0.2 in the number of servings of fruit per day and a decrease of 0.13 in the number of servings of snacks per day (table 2). The Krachtvoer effect evaluation study revealed, based on fixed regression intention-totreat analyses, that the Krachtvoer intervention had a significant favourable effect on fruit intake and snack intake among students with the least desirable values at baseline (Martens et al., submitted).

\section{Family environment influences on dietary behaviours}

Regression analyses revealed a positive association between parents' fruit intake and that of the children at baseline $(\beta=0.15$, P-value $<0.01)$. No other significant factors were found for fruit. A negative association was found between the importance of weight control in food purchase considerations and the children's snack intake at baseline $(\beta=-0.21$, P-value $<0.01)$; the children of parents who reported weight control to be an important consideration in family food purchase consumed fewer snacks than the children of parents who considered weight control a less important issue in food purchase.

\section{Family environment influences on changes in fruit and snack consumption}

The regression analyses revealed no significant family environment predictors of programme-induced changes in either fruit or snack intake. Furthermore, the bivariate correlations listed in Table 3 indicate low associations between family factors and behaviour change for both fruit and snack intake. 
Table 3

Correlations between fruit and snack variables and potential family environment influences

\begin{tabular}{|c|c|c|c|c|}
\hline 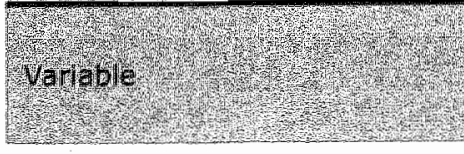 & 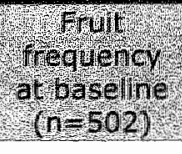 & 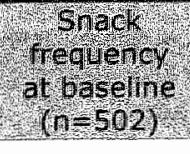 & $\begin{array}{l}\text { Change } \\
\text { consumpurign } \\
\text { con } \\
(n=456)\end{array}$ & 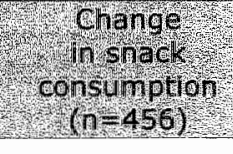 \\
\hline Migrant status & $-0.10^{*}$ & -0.04 & 0.08 & 0.01 \\
\hline Education of mother & 0.02 & 0.05 & 0.05 & 0.04 \\
\hline Education of father & -0.01 & 0.03 & -0.01 & 0.02 \\
\hline Employment status of parents & -0.02 & 0.04 & 0.05 & 0.04 \\
\hline Dietary intake of parents & $0.14 * *$ & 0.07 & -0.04 & 0.01 \\
\hline Porenting style & 0.01 & -0.05 & -0.01 & -0.02 \\
\hline Taste & -0.01 & -0.02 & -0.02 & 0.00 \\
\hline Nutrition & 0.08 & 0.01 & -0.02 & -0.05 \\
\hline Cost & -0.03 & -0.03 & 0.04 & 0.01 \\
\hline Convenience & -0.03 & 0.01 & 0.00 & -0.02 \\
\hline Weight contral & -0.03 & $-0.13 *$ & 0.01 & 0.05 \\
\hline Family food rules & 0.02 & -0.05 & 0.03 & 0.08 \\
\hline Avallability and accessibility & 0.04 & 0.09 & -0.02 & -0.05 \\
\hline
\end{tabular}

* Correllation is significant at the 0.05 levell ( 2 -talled)

* Correlation is significant at the 0.01 lewel (2-tailed)

\section{Discussion}

The present study assessed the association between a number of family-related factors and two health-related dietary habits among children aged 12 to 14 years. We also investigated whether these family-related factors were associated with changes in dietary habits induced by the Dutch healthy diet programme for vocational schools called Krachtwoer. In terms of fruit intake, we only found a positive association between the parents' reported intake and that of the children. As regards snack intake, we only found a negative association between the importance of weight control in family food purchase considerations and children's snack intake. No significant family environment predictors of programme-induced changes were found in either fruit or snack intake.

The relation we found between fruit intake by parents and children supports the already consistent pattern of results in previous research into parental modelling and children's fruit intake (Cullen-Weber et al., 2001; Feunekes et al., 1998; Fisher et al.; 2002; Gibson et al., 1998; Woodward et all., 1996; Young et al., 2004). This implies that nutrition education interventions designed to get adolescents to consume more fruit may be improved by including a parental component aimed at increasing parents' fruit intake. What parents actually do may be more important than what they say. The negative association between snack intake and the importance of weight control in family food purchase was also found in the study by Glanz and colleagues, who studied an adult population (Glanz et al., 1998). This implies that nutrition edu- 
cation programmes for adolescents should include a component convincing parents that snacks are fattening and therefore unhealthy. Some other associations between family-related factors and young peoples' dietary intake that were found in previous research could not be replicated in the present study A possible reason for this is that previous studies were conducted among different age groups, were not limited to students at the lower educationall levels, and included slightly different behaviours. As regards eating practices, it has been found that the influence of parents declines during adolescence while the influence of peers becomes increasingly important (Quandt, 2000; Seifert \&. Hoffnung, 1997). Subsequently, adolescents from lower wocational schools may be less inclined to comply with parental rules and/or examples, but this is mere speculation that should be studied in further research. Besides, there was an over presentation of low educated parents in the study, and it may be that low educated parents give possibly less support and control to the eating practices of there children compared to intermediate or high educated parents (Hupkens, Knibbe, A.H., \& Drop, 1998; Van Zundert, Van Der Vorst, Vermulst, \& Engels, submitted). Therefore, our findings can only be generalized to the population of students of lower vocational schools aged 12 to 14 (although immigrants were somewhat underrepresented in the present sample), and not to youngsters in general.

Our study also differed from most other studies in that the family-related factors were measured among the parents, and not among the children. Children may have other perceptions of family-related factors than their parents, and children's dietary intake might be more closely associated with the children's own perceptions than with those of their parents. However, the fact that we measured the parental influences in parents and the behaviours in children may also be regarded as a specific strength. In studies in which both potential parental influences as well as intake levels are assessed in children only, a shared rater bias may occur. Another strength of our study may be the relatively large sample; the lack of significant associations found is therefore not likely to be the result of lack of statistical power. Furthermore, we were able to measure a wide range of potential parental influences on children's intakes as well as intervention-induced changes in these intakes.

However, several important limitations of the study also need to be addressed in interpreting the findings. All of the data were self-reported by students and their parents, and thus subject to memory and recording errors. Also, measurement problems may be responsible for the limited association between the familly-related factors and the dietary habits of their children. Family food rules and avallability and accessibility of fruit and snacks at home were measured using two to three items, which may be less reliable than the extensive multiple-item assessments used in earlier studies. Further, parental response may have been selective. No data are available on the parents who did not participate in this study. However, the parents' response rate was quite high and no major differences were found between the children whose parents did participate and those whose parents did not participate.

We conclude that the influence of the family-related factors we selected seems limited for our population and that there are no indications that the family-related characteristic influenced the programme's effect. For the Krachtvoer project, this means that there is no evidence that subgroups of students might profit less due to 
their family background. In other words, it may be not necessary to achieve familyrelated changes through family involvement before it is possible to achieve behavioural changes among the students. However, this does not exclude that involving parents in a school-based programme may influence the effect of the intervention in a positive or negative way. 


\section{Introduction}

This thesis reports on a project consisting of a number of studies into the development ${ }_{x}$ implementation and evaluation of Krachtvoer, a school-based educational programme to promote healthy eating habits among lower vocational school students aged 12 to 14 . Prior to the start of the project, project aims were formulated and decisions were made on how to achieve these aims. The purpose of this final chapter is to examine whether the aims were accomplished and whether the approaches that were chosen were the best options. The chapter first reviews the initial aims and a number of key decisions that were taken in the process of achieving these aims, after the main findings of the studies are summarized. Subsequently, the findings of the separate studies are related to each other, and the findings and main methodological considerations are discussed in relation to the key decisions. The chapter ends with an overall conclusion and recommendations for further development of the Krachtvoer programme.

\section{Initial aims and key decisions}

The project aimed to develop a healthy diet promotion programme for adolescents that could be used in school settings, and to assess its effectiveness. Evidence-based programmes for this target population were not available in the Netherlands at the time, and still are not, even though youngsters' unhealthy eating habits are recognized as a major public health problem, and the government has made solving this problem a policy priority. Many youngsters have unhealthy eating habits, which are considered to have adverse consequences for their health in the short and longer run (Hirasing et al. 2001; Vereecken et al., 2004; Voedingscentrum, 1998; WHO, 1998).

In the process of developing an effective and usable healthy diet promotion programme, a number of key decisions were taken.

The first key decision was to invest a great deal of effort in the development of the nutrition education programme. The stepwise development used key aspects of the Intervention Mapping method (Bartholomew et al., 2001). Avallable theoretical and empirical knowledge about risk behaviours, potential specific target groups, determinants of risk behaviours, effective intervention strategies and general criteria for the successful development and structural implementation of nutrition education programmes were thoroughly studied. Additionally, preparatory studies were conducted among the target population and among parents and teachers. Aithough these additional studies were time-consuming, they were considered relevant to the development of a programme that is tailored to the needs of and appreciated by teachers as well as students, and that is effective in promoting healthy dietary behaviours. During the whole development process, a consultation team consisting of experts in the field of nutrition and education advised us about the practical usability of the programme. Furthermore, the intervention materials were pre-tested among members of the target population. 
A second key decision was to evaluate the programme extensively, combining an evaluation of the behavioural effects and the effects on behavioural determinants with a comprehensive process evaluation. This was deemed important to establish not only whether the program would be effective, but also why it would or would not be effective in order to obtain information that could be used for possible programme improvements (Bartholomew et al, 2001).

A third key decision was to develop a programme aimed at students in lower vocational education (preparatory secondary vocational education) aged 12 - 14 years, despite the fact that such students are seen as hard to reach and their behaviour appears to be difficult to change. This specific target group was chosen because such students often belong to groups in lower sacio-economic positions (SEP). Some previous cross-sectional studies have found associations between lower SEP groups and increased nutritional risk (Koivisto Hursti, 1999; Roos et all, 1998). This key decision is also in line with priorities indicated by the Dutch government, which intends to reduce socio-economic inequalities in health by at least $25 \%$ by 2020 , by improving the health status of groups with a low socio-economic status (RIVM, 2005).

A fourth key decision was to pay special attention to the role of the family environment in the nutrition of adolescents, a topic about which little was known at the start of the project. A greater understanding of the potential moderating effect of the family environment in shaping and changing dietary habits of youngsters was needed to find out if involving the family, and in what way, could help to further improve interventions like the Krachtvoer programme.

\section{Main findings}

Chapters 2 and 3 presented the results of the two studies that were conducted while the programme was being developed. Chapter 2 described the focus group interviews that were conducted with 25 adolescents aged 12-14, 21 teachers and 14 parents. The aim of the focus group interviews with students was to explore their need for nutrition information, their specific areas of interest and their views about nutrition education. The focus group interviews with teachers also examined the requirements in terms of overall programme design that would promote adoption and implementation of a healthy diet intervention in the schools, such as the number and duration of the lessons. The interviews with parents gave additional information about their need for participation.

The results of the focus group interviews indicated that students were not very enthusiastic about nutrition education, but accepted the fact that they were asked by the school to work on the topic. They felt that nutrition education could be fun, if it met certain criteria. The information should not be too complex and they should be able to absorb it in an active manner, for instance by means of games. The students preferred all activities and materials to be challenging, funny, colourful, exciting and preferably even a bit shocking, and not to be childish. These requirements were also confirmed by the teachers and parents. This implies that a nutrition education programme for adolescents should meet these criteria if it is to reach the teachers and 
adolescents. The interview studies further indicated that taste preferences should be taken into account when trying to change nutrition habits. Teachers indicated that lessons about nutrition were mostly given at the beginning of the school year, and an average of 12 hours were spent on this topic in the current curriculum. Teachers said that they preferred a number of optional elements in the programme that would leave them some room to tailor the programme to their own teaching situation. The parents reported that they generally liked to be involved in a nutrition education programme for their children, but doubted if their children would also appreciate their direct involvement. This implies that students and parents should be approached separately during a nutrition education programme.

Chapter 3 described the relative importance of personal and social environment predictors of the consumption of fruit, high-fat snacks and breakfast, three types of dietary behaviour on which the Krachtvoer intervention focussed. Data were collected by means of written questionnaires, which were completed in eight schools by 601 students of preparatory secondary vocational education schools. The results of this study indicated that a nutrition education programme for lower vocational education students aged $12-14$ should mainly aim to create positive attitudes and subjective norms towards the healthy behaviours, since more positive attitudes and subjective norms in particular appeared to be associated with greater intentions to improve all three dietary behaviours, while more positive self-efficacy expectations were associated with greater intentions to increase fruit intake. Attitude was also the main predictor of actual consumption. Perceived behaviour of the mother as well as the availability of snacks at home were found to be the main correlates of snack consumption. This implies that a nutrition education programme for adolescents should also target these factors, especially if it is to change snack intakes.

These preliminary studies and a literature study, as well as the consultations with the advisory committee, resulted in a programme that targets three specific behaviours, namely fruit intake, high-fat snack intake and breakfast habits. The Krachtvoer programme consists of eight lessons lasting fifty minutes each, and uses a combination of theory-based materials, such as various so-called task forms for the different lessons, a video, a magazine, a website and a take-home bag with a newsletter and food items for the parents (Martens et al., submitted). Krachtvoer uses a three-phase structure. Phase one includes initial activities aimed to raise students' enthusiasm for the programme and awareness of their risk behaviour. In phase two, all activities aim to help students overcome their personal reasons for not eating a healthier diet. In this phase, teachers are allowed to vary the activities and the order in which they are carried out. In the third and final phase, the activities involve the implementation of solutions and an evaluation of students' personal goal performance.

Chapters 4 and 5 described the evaluation studies of the Krachtvoer programme. The evaluation consisted of an effect study assessing changes in the targeted dietary behaviours and behavioural determinants (Chapter 4), and a process study investigating several aspects of the implementation and appreciation of the programme (Chapter 5).

The effect study used a cluster-randomised baseline-posttest experimental de- 
sign, with data being collected by means of written questionnaires. The study included 10 experimental schools with 13 teachers, 37 classes and 879 students, and 8 control schools with 31 classes and 734 students. Fixed regression intention-to-treat analyses revealed predominantly beneficial effects on some, but not all behavioural measures with regard to fruit intake, high-fat snack intake and breakfast habits. Some favourable behavioural effects occurred in the entire target population, others mainly or only among those students who had the least desirable values at baseline. Similar patterns were found with respect to effects on intention to change, attitudes, subjective and descriptive norms, self-efficacy, awareness of risk behaviour, interest in the topic. perceived food rules and the availabillity and accessibility of food items at home. Although there were also some unfavourable effects among students with the most desirable values at baseline, these effects were smaller than the favourable effects among the students with the least desirable baseline values. This indicates that the programme did reach the students who needed it most. The complete cases and mixed regression analysis found comparable $\beta$ values and effect sizes for the behavioural outcomes. However, many of the main significant favourable behavioural butcomes were not found in mixed regression analyses.

The process study assessed the completeness and fidelity of the programme implementation, as well as the opinions of teachers and students about the programme. In addition, it examined the association between opinions and level of implementation. Data were collected through structured monitoring reports prepared by the teachers, in-class observations, in-depth interviews with teachers and items in the post-test student questionnaire. The findings indicated that the teachers implemented the Krachtvoer programme largely according to plan, that the teachers appreciated most parts of the programme and that the students who were exposed to Krachtvoer were more appreciative of their nutrition education lessons than students who followed the usual curriculum. However, programme elements that teachers did not like very much were often not implemented. The teachers were less enthusiastic about the information and question forms to be used in phase one of the programme. Teachers experienced these forms as boring and poorly structured, mainly because of the number of forms. Furthermore, not enough facilities and equipment were available, and a great deal of improvisational skill was needed for some of the taste testing and food preparation tasks. A particularly weak part of the programme was phase three, where the activities involved implementation of solutions and an evaluation of personal goal performance. Most teachers evaluated the programme elements in phase three as too difficult and interfering too imuch with the students' personal freedom, and therefore did not implement the lessons of this phase.

The study in chapter 6 investigated the association between a number of family-related factors and fruit and snack consumption by the adolescents, and whether these family-related factors affected the changes in the two health-related dietary habits effected by the Krachtvoer programme. Mritten questionnaires were mailled to the parents of the students who participated in the programme, assessing migrant status, education, employment status, dietary intakes, parenting styles, food purchase considerations, family food rules, and availability and accessibility of food items at 
home. Questionnaires of 502 parents were matched with those of their children. The study revealed a positive association between parents and children's fruit intake, and a negative association between the importance of weight control in family food purchasing habits and children's snack intake. No significant family-related predictors were found of programme-induced changes in either fruit or snack intake.

\section{Discussion}

\section{Key decision 1: The intensive process of developing a nutrition education programme}

The substantial effort invested to explore the preferences and needs of the various people involved and the ensuing adjustment of the programme seem to have paid off. The programme was rated quite favourably, It seems that the programme was largely in line with the preferences of teachers and students, which is an important condition for proper implementation of the programme, and hence for its effectiveness (Bartholomew et al., 2001). The programme was indeed largely implemented according to plan. Additionally, the investments made for the development of Krachtvoer have been used for the development of other, somewhat similar school-based programmes, such as the Do-It programme, which was developed as part of a comprehensive project aimed at prevention of obesity, and the Europe-wide Pro Children intervention (Klepp et al., in press; Kremers et al ", 2005).

However, the process evaluation also identified some weaker aspects of the programme, which a more extensive intervention pre-test in the development phase might have helped to avoid. Although individual intervention materials were pretested, this was not the case for the integrated programme as a whole. Obviously, however, it is almost impossible to develop a perfect programme before actual implementation. Improving a programme implies a continuous process of revision and readjustment based on ongoing experiences and induced by ongoing changes in the target population and intervention intermediaries and settings. Another major issue in the developmental phase was that the needs and desires of the teachers and theit" students were not always consistent with the conditions for an effective programme that evidence from previous studies had identified. For instance, earlier research had indicated that a minimum of 50 intervention exposure hours is important for intervention effects (Hoelscher et al., 2002). The teachers, however, reported that they could only spend about eight hours of teaching on a nutrition education programme. Based on the results of the preliminary study among the teachers, it was therefore decided to develop and implement a nutrition education programme with a minimum of eight school lessons lasting fifty minutes each.

Based on the outcome of the preliminary studies and the literature findings, the Krachtvoer intervention mainly focussed on influencing attitudes, with special emphasis on the more affective side of attitudes, including taste preferences, using strategies providing opportunities for adolescents to taste and enjoy a wide variety of healthy foods. It seems that the carefully planned developmental phase did indeed enable the proper strategies to be selected, since the results of the effect evalua- 
tion in particular showed beneficial effects on attitudes towards fruit consumption; snack quality and having breakfast regularly. Subjective norms (of the mother, father; brother(s)/sister(s) and friends), were further identified as an important potential determinant for all three behaviours. During the second phase of the Krachtvoer intervention, a magazine, video and knowledge test addressed subjective norms. Intervention effects were found on the subjective norm of friends about fruit consumption, snack frequency and breakfast frequency. No overall effects were found on the subjective norm of parents. The determinant study found self-efficacy to be only directly relevant for fruit intake, and falled to show any effects on self-efficacy in the intervention study. During the second phase of the Krachtvoer intervention, the activities aimed to help students increase their self-efficacy to eat a healthier diet, and self-efficacy was discussed during the final phase, which involved an evaluation of the personal goal peiformance. The lack of effect in terms of the self-efficacy measure was probably due to the fact that most students already had great confidence in their ability to eat a healthy diet before the intervention. A measurement issue may also have been responsible for the lack of effect in terms of self-efficacy, since self-efficacy was measured by only one item. The determinant study also found the perceived behaviour of the mother and the availability and accessibility of snacks to be important correlates of snack consumption. During the intervention a take-home bag for the parents with a newsletter and food items addressed the perceived behaviour of the parents as well as the availability and accessibility of snacks. Students were also encouraged to ask their parents to buy the products that had been taste-tested during the lessons. Intervention effects on the perceived behaviour of the parents were found only among the students with the highest snack consumption at baseline. The results of the effect evaluation showed that the availability and accessibility of snacks decreased as result of the intervention.

At the same time, it is possible that the lack of behavioural effects in some cases reflects a failure to target the right determinants in the intervention. The associations between a selection of potential personal and social-environmental determinants of the consumption of fruit, high-fat snacks and breakfast were identified by means of a cross-sectional study, which could only establish cross-sectional associations between these potential determinants and intakes, and was unable to make predictions or identify causes (Baranowski, Cullen, Nicklas, Thompson, \& Baranowski, 2003i). Furthermore, even though the amount of variance explained in the "determinant" study was in line with what had been found in similar previous studies, and a broad range of possible determinants were included in the analyses, only about $30 \%$ of the variance in the three nutritional behaviours could be explained. The intervention was therefore targeted to determinants that accounted for only a part of the variation in intakes, which may explain the modest effects found. More research, with stronger study designs, is needed to examine other factors that could further increase the proportion of explained variance in adolescents' dietary behaviours.

\section{Key decision 2: The extensive evaluation of the Krachtvoer programme}

Evaluation is important to prove that resources were spent wisely, and to identify 
strengths and weaknesses of the intervention, in order to enable improvements. Both of these evaluation goals are best served by a combination of effect and process evaluations. The effect study revealed effects on a number of behavioural determinants and behaviours, but no effects on a number of other measures. The process study provided an opportunity to identify the weaker parts of the programme, which might be responsible for these negative outcomes. Phase 3 appeared to be the weakest part of the programme, which is perhaps iliustrated by its having a greater effect on the behavioural determinants than on the behaviours themselves.

Although the effect and process studies were both essential, they also had their limitations. A considerable shortcoming of the effect study was that it was not possible to investigate the longer-term effects of the Krachtvoer programme. The funding and timing of the study only allowed one post-programme assessment. Multiple and longer-term effect assessments would also have further burdened the teachers involved. An important methodological problem of the effect study was that more control than experimental schools withdrew, so that the number of participants differed quite substantially between the study arms. This probable introduced bias because of selective dropout. We dealt with this problem by using intention-to-treat analyses. Respondents with missing post-test values due to school, class or individual dropout were included by replacing the missing post-test value with the baseline value (i.e., the last-observation-carried-forward method). Although the intention-totreat method is perceived as a conservative method, this might be questionable. The intention-to-treat method assumes that dropped-out students do not change after the pre-test, but based on the positive trend in our control group, it is reasonable to assume that the students did change which may have resulted in an underestimation of the standard errors (Heyting, Tolboom, \& Essers, 1992; Verbeke \& Molenberghs, 2000). Therefore, all analyses that yielded a significant effect on a behavioural outcome were rerun with complete-cases analyses (i.e. excluding respondents with a missing post-test value). Another possible limitation is that all of the data were self-reported by students and may thus have been subject to memory and recording errors. However, the study included multiple self-reported measures, viz, food frequency questions and daily consumption records, and the results for these different self-reports were largely consistent. A shortcoming of the process study was the limited number of in-class observations and incomplete teachers' monitoring reports. However, data was collected by multiple qualitative sources and methods. For example, the lack of information regarding the incomplete teachers' monitoring reports was counterbalanced by the teacher interviews. Based on the multiple qualitative sources and methods the successful and less successful elements of the programme could still be identified.

\section{Key decision 3: The selected target population}

The Krachtvoer programme achieved small effects in a population seen as hard to reach and influence, namely students of preparatory secondary vocational education aged $12-14$. The Krachtvoer intervention was appreciated and accepted by teachers as well as students. This study shows that it is possible to reach and influence this 
target group as long as the programme ties in with the desires of this target population and its perceptions of the world around them.

The Krachtvoer intervention was aimed at students of preparatory secondary vocational education. However, to avoid too large a variation between the schools in the study, it included only schools with a maximum of $50 \%$ students of foreign origin and students from the highest two levels of preparatory secondary education (In the Netherlands, preparatory secondary vocational education is divided into four levels). The findings of the present study can only be generalized to the type of students that were included in it, and not to youngsters in generall. It remains unknown whether the effects and appreciation of the Krachtvoer programme at other educational levels and in schools with more students of foreign origin would differ from those found in the present study: In the present study population $17 \%$ of the students was migrant. No significance differences in effects were found in relation to foreign origin. Comparable healthy diet programmes, which focus on other educational levels, such as the Do-It program, used strategies similar to those used in the Krachtvoer programme (Kremers et al., 2005). However, the results of the process and effect evaluation of these studies are not available yet.

\section{Key decision 4: Understanding the role of family-related factors}

The possible role of several family-related factors was studied, also factors that are not included in common behavioural determinant models such as the theory of planned behaviour (Ajzen, 1991) and the ASE (attitude-social-influence-efficacy) model (De Vries et al., 1988). The results of the determinant study conducted among students in chapter 3 , and those of the study conducted among the parents of students participating in the programme in chapter 6 , suggest a limited influence of the family environment on the dietary habits of our study population and the changes in these habits. However, the associations we found between parents' and children's dietary intakes, as well as those between the importance of weight control in family food purchasing habits and avallability on the one hand and children's snack intake on the other; indicate that it is important to include a programme component that focuses on the parents. Some previous cross-sectional studies did find more and/or stronger associations between young people's dietary intake and several family-related factors, such as parental dietary intake, parenting style, family food purchase considerations, family food rules, availability and accessibility of foods at home and socio-economic status of the family, although some findings are inconsistent. Reasons for the different outcomes of the studies might be that the studies were conducted among different age groups and students of different educational levels, and included slightly different behaviours.

Measurement problems may also be responsible for the limited role of family-related factors found in the present research project. Some family-related factors that were included were measured among the parents, while most other studies used data collected among the children to assess these factors. Children may have other perceptions of family-related factors than their parents, and children's dietary intake might be more closely associated with the children's own perceptions than with those 
of their parents. Secondary analyses confirmed this disagreement between parents and their children in terms of the familly-related factors of food rules and availability and accessibility. Future research into the cause of this disagreement could be useful. Another measurement problem was that the family food rules and the availability and accessibility of fruit and snacks at home were measured in the present studies by only two or three items. This may be less reliable than the extensive multiple assessments used in other studies (Cullen-Weber et al., 2001; De Bourdeaudhuij, 1997; Fisher et al., 2002; Hearn et al., 1998; Kratt et al., 2000; Young et al., 2004). The size of the survey questionnaire, however, led to the decision to use fewer items to assess the rules and the availlability and accessibility. It would seem useful to further explore the reliability and validity of the measures relating to food rules, availability and accessibility.

\section{Overall conclusion and recommendations}

It can be concluded that the systematic development of Krachtvoer has led to a programme that provides a promising tool to encourage students in lower vocational education to adopt healthier diets. However, the effects of the present Krachtvoer programme have been small. Since some conditions for improvement were identified, it seems advisable to revise the Krachtvoer programme before considering large-scale implementation. The revised programme should again be evaluated to ensure that the revised programme will produce the expected larger effects and that the revised parts will be better appreciated and implemented. Also, more information is needed about the long-term effects of the revised programme and its effects at different levels of education. Possible large-scale implementation of the revised programme will necessitate a better understanding of the supporting and impeding factors affecting the adoption and maintenance of the nutrition education programme. 
Ajzen, I. (1991). The theory of planned behavior. Organizational Behavior and Human Decision Processes, 50, 179-211.

Ammerman, A. S., Lindquist, C. H., Lohr, K. N., \& Hersey, 3. (2002). The efficacy of behavioral interventions to modify dietary fat and fruit and vegetable intake: a review of the evidence. Preventive Medicine, 35, 25-41.

Baranowski, T., Cullen, K.W., \& Baranowski, J. (1999). Psychosocial correlates of dietary intalke: advancing dietary intervention. Annual Review of Nutrition, 19, 17-40.

Baranowski, T., Cullen, K. W., Nicklas, T., Thompson, D., \& Baranowski, J. (2003). Are current health behavioural change models helpful in guiding prevention of weight gain efforts? Obesity Research, 11 Suppl, 235-43S.

Baranowski, T., Davis, M., Resnicow, K., Baranowski, J., Doyle, C., Lin, L. S., et al. (2000). Gimme 5 fruit, juice, and vegetables for fun and health: Outcome evaluation. Health Education and Behavior, 27(1), 96-111.

Bartholomew, L. K., Parcel, G. S., Kok, G., \& Gottlieb, N. (2001). Intervention Mapping: designing theory and evidence-based health promotion programs. California: Mayfield Publishing Company.

Boekaerts, M., Rintrich, P. R., \& Zeider, M. (2000). Handbook of self regulation. San Diego, CA: Academic Press.

Branen, L., \& Fletcher, J. (1999). Comparison of college student's current eating habits and recollections of their childhood food practices. Journal of Nutrition Education, 31(6), 304-310.

Brown, B., \& Ogden, J. (2004). Children's eating attitudes and behavior: a study of the modelling and control theories of parental influence. Health Education Research, 19(3), 261-271.

Brug, J., Lechner, L., \& De Vries, H. (1995). Psychosocial determinants of fruit and vegetable consumption. Appetite, 25(3), 285-296.

Brug, J., Schaalma, H., Kok, G., Meertens, R. M., \& Van Der Molen, H. T. (2000). Gezondheidsvoorlichting en gedragsverandering: een planmatige aanpak. Assen: Van Gorcum.

Brug, J., Van Assema, P., \& Kok, G. (1998). Misconsumptie van vet, groente en fruit: oorzaken en implicaties voor voedingsvoorlichting. Tijdschrift voor Gezondheidswetenschappen, $76(1), 17-23$.

Brug, J., Van Assema, P., Kolk, G., Lenderink, T., \& Glanz, K. (1994). Self-rated dietary fat intake: associations with objective assessments of fat, psychosocial factors, and intention to change. Journal of Nutrition Education, 26, 218-223.

Cameron, L., \& Howard, L. (2003). The self-regulation of health and illness behavior. New York: Routledge.

Conner, M., \& Sparks, P. (1996). The theory of planned behaviour and health behaviours. In: Conner $M$, Norman $P$ (eds.). Predicting health behaviour. In (pp. 121-162). Philadelphlal: Open University Press.

Contento, I., Balch, G. I., Bronner, Y. L., Lytle, L. A., Maloney, S. K., White, S. L., et al. (1995). The effectiveness of nutrition education and implications for nutrition education pollicy, programs and research: nutrition education for school-aged children. Journal of Nutrition Education, $27(6), 298-311$.

Contento, I. R., \& Michela, J. L. (1999). Nutrition and food choice behavior among children and adolescent. In A. J. Goreczny \& M. Hersen (Eds.), Handbook of pediatric and adolescent health psychology (pp. 1-38). Boston: Allyn \& Bacon.

Contento, I. R., Randell, J. S., \& Basch, C. E. (2002). Review and analysis of evaluation measures used in nutrition education intervention research. Journal of Nutrition Education and Behavior, 34(1), 2-25.

Cueto, S. (2001). Breakfast and performance. Public Health Nutrition, 4(6A), 1429-1431.

Cullen-Weber, K., Baranowski, T., Rittenberry, L., Cosart, C. Hebert, D., \& de Moor, C. (2001). Child-reported family and peer influences on fruit, juice and vegetable consumption: Reli- 
ability and validity of measures. Health Education Research, 16(2), 187-200.

Currie, C., Roberts, C., Morgan, A., Smith, R, Settertobulte, W, Samdal, O., et al. (2004). Young people's health in context. Health Behavior in School-aged Children (HBSC) study: international report from the 2001/2002 survey. Copenhagen: WHO.

De Bourdeaudhuij, I. (1997). Family food rules and healthy eating in adolescents. Journal of Health Psychology, 2, 45-56.

De Bourdeaudhuif, I. \&an Oost, P. (1998). Family members' influence on decision making about food: differences in perception and relation with healthy eating. American Joumal of Health Promotion, $12(2), 73-81$.

De Bourdeaudhuij, I., Van Dost, P. (2000). Personal and family determinants of dietary behavlour in adolescents and their parents. Psychology and Health, 15, 751-770.

De Vries, $H_{2}$, Dijkstra, M. \& Kuhiman, P. (1988). Self-efficacy: the third factor besides attitude and subjective norm as a predictor of behavioural intentions. Health Education Research, 3 , $273-282$.

De Vries, H. C. B., Lucker, T. P. C, Cremers, S. B. L., \& Katan, M. B. (1990). Food choice and caries experience in Dutch teenagers as a function of the level of education of their parents. European Journal of Clinical Nutrition, 44, 839-846.

De Vries, M., \& Da Costa Senior, R. (1992). Scholieren en tussendoortjes: onderzoek naar eeten drinkgewoonten tijdens schooltijd van leerlingen in het basis en voortgezet onderwijs in Midden-Holland. Gouda: GGD Midden Holland.

Dennison, C. M. S Stepherd, R. (1995). Adolescent food choice: an application of the theory of planned behaviour. Journal of Human Nutrition and Dietetics, 8, 9-23.

Department of Health. (2000). The NHS Plan: A plan for investment, a plan for reform. London: HMSO.

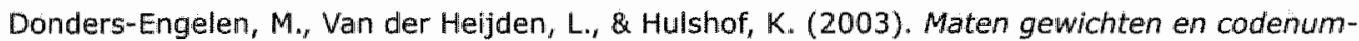
mers. Wageningen: Afdeling Humane Voeding Wageningen.

Edmonds, J., Baranowski, T., Baranowski, J., Cullen, K. W., \& Myres, D. (2001). Ecological and socioeconomic correlates of fruit, juice, and vegetable consumption among african-american boys. Preventive Medicine, 32, 476-481.

Feunekes, G. I, De Graaf, C., Meyboom, S., \& Van Staveren, W. A. (1998). Food choice and fat intake of adolescents and adults: associations of intakes within social networks. Preventive Medicine, 27, 645-656.

Fisher, J. O., Mitchell, D. C., Smiciklas-Wright, H., \& Birch, L. L. (2002). Parental influences on young girls' fruit and vegetable, micronutrient, and fat intake. Journal of the American Dietetic Association, 102(1), 58-64.

Gezondheidsraad. (1986). Richtijnen goede voeding: Samenvatting van het advies van de voedingsraad. Voeding, 47(5), 140-142, 154-183.

Gezondheidsraad. (2003). Overgewicht en obesitas. Den Haag.

Gibson, E. L.y Wardle, 1.* \& Watts, C. J. (1998). Fruit and vegetable, nutritional knowledge and belief in mothers and children. Appetite, 31, 205-228.

Glanz, K., Basill, M., Maibach, E., Goldberg, J., \& Snyder, D. (1998). Why Americans eat what they do: taste, nutrition, cost, convenience, and weight control concerns as influences on food consumption. Journal of the American Dietetic Association, 98(10), 1118-1126.

Gollwitzer, P. M. (1999). Implementation intentions. Strong effect of simple plans. American Psychologist, 54, 474-483.

Green, L. W., \& Kreuter, M. W. (1999). Health promotion planning: an educational and ecological approach ( 3 rd ed.). Palo Alto, California: Mayfield Publishing Company.

Health Education Authority. (1999). Young people and health: health behaviour in school aged children. A report of the 1997 findings, London: HEA.

Hearn, M. D., Baranowski, T., Baranowski, J, Doyle, C., Smith, M., Lin, L. S., et al. (1998). Environmental influences on dietary behavior among children: Avallability and accessibility of fruits and vegetables enable consumption. Journal of Health Education, 29(1), 26-32. 
Heyting, A., Tolboom, J. T. B. M., \& Essers, J. G. A. (1992). Statistical handling of dropouts in longitudinal clinical trials. Statistics in Medicine, 11, 2043-2061.

Hirasing, R. A. Fredriks, A. M., Van Buren, S., Velloowe-Van Horick, S. P., 2 Wit, J. M. (2001). Toegenomen prevalentie van overgewicht en obesitas bij Nederlandse kinderen en sionalering daarvan aan de hand van internationale normen en nieuwe referentiediagrammen. Nederlands Tijdschrift voor Geneeskunde, 145(27), 1303-1308.

Hoelscher, D. M. Evans, A., Parcel, G. S., \& Kelder, S. H. (2002). Designing effective nutrition interventions for adolescents. Journal of the American Dietetic Association, 102(3), 552-563.

Höglund, D., Samuelison, G., \& Mark, A. (1998). Food habits in Swedish adolescents in relation to socioeconomic conditions. European Journal of Clinical Nutrition, 52(11), 784-789.

Hu, F. B., \& Willet, W. C. (2002). Optimal diets for preventing of coronary heart disease. Journal of the American Medical Association, 288, 2569-2578.

Hulshof, K., Brussaard, J. H., Kruizinga, A. g., Telman, 1., \& Lowik, M. R. (2003). Socio-economic status, dietary intake and 10 y trends: The Dutch National Food Consumption Survey. European Journal of Clinical Nutrition, 57(1), 128-137.

Hupkens, C. L. H., Knibbe, R. A. A.H., V. O., \& Drop, M. J. (1998). Class differences in the food rules mothers impose on their children: a cross-national study. Social science \& Medicine, $47(9), 1331-1339$.

Kelder, S. H., Perry, C. L, Klepp, K. I., \& Lytle, L. L. (1994). Longitudinall tracking of adolescent smoking, physical activity, and food choice behaviors. American Journal of Public Health, 84(7), 1121-1126.

Klepp, K.-I., Perez-Radrigo, C., Thorsdottir $I_{r}$, Due, P., Daniel Vaz de Almelda, M. \& Elmadfa, I. (in press). Promoting and sustaining health through increased vegetable and fruit consump. tion among European schoolchildren: The Pro Children Project. Journal of Public Health.

Koivisto Hursti, U. K. (1999). Factors influencing children's food choice. Annals of Medicine, 31 , 26-32.

Kratt, $P_{u}$, Reynolds, K., \& Shewchuk, R. (2000). The role of availability as a maderator of familly fruit and vegetable consumption. Health Education and Behavior, 27(4), 471-482.

Krebs-Smith, S. M., Heimendinger, J., Patterson, B. H., Subar, A. F, Kessler, R., \& Plvonka, E. (1995). Psychosocial factors associated with fruit and vegetable consumption. American Journal of Health Promotion, 10, 89-104.

Kremers, S. P. J., Brug, J., De Vries, H., \& Engels, R. C. M. E. (2003). Parenting style and adolescent fruit consumption. Appetite, 41(1), 43-50.

Kremers, S. P. J., Visscher, T. L. S., Brug, J., Chin A Paw, M. J. M., Schouten, E. G., Schuit, A. J., et al. (2005). Netherlands Research programme weight Gain prevention (NHF-NRG): rationale, objectives and strategles. European Journal of Clinical Nutrition, 59(4), 498-507.

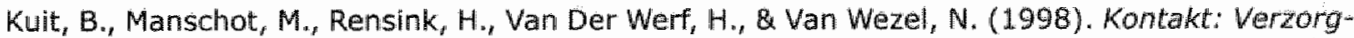
ing voor de basisvorming. Docentenhandleiding wbo/mavo. Groningen: Wolters-Noordhoff.

KWF (2004). De rol van voeding bij het ontstan wan kanker. Signaleringscommissie Kanker van KWF Kankerbestrijding. Oisterwijk: KWF Kankerbestrijding.

Lamborn, S. D., Mounts, N. S. Steinberg, L., \& Dornbusch, S. M. (1991). Patterns of competence and adjustment among adolescents from authoritative, authoritarian, indulgent, and neglectful families. Developmental Psychology, 29, 1049-1065.

Levenson, G. C., Gottlieb, N., \& Brink, S. (1994). Increasing teacher receptivity towards use of tobacco prevention education programs. Journal of Drug Education, 24(2), 163-176.

Lien, N., Lytle, L. A., \& Klepp, K. (2001). Stability in consumption of fruit, vegetable, and sugary foods in a cohort from age 14 to age 21. Preventive Medicine, 33, 217-226.

Lytle, L. A., Seifert, S., Greenstein, J., \& McGovern, P. (2000). How do children's eating patterns and food choices change over time? Results from a cohort study. American Journal of Health Promotion, 14(4), 222-228.

Lytle, L. A., Varnell, S., Murray, D. M., Story, M., Perry, C., Birnbaum, A. S., et al. (2003). Predicting adolescents" intake of fruit and vegetables. Journal of Nutrition Education and Be. havior, 35(4), 170-175. 
Martens, $M$, Van Assema, $P, \&$ Brug, $J$, (n press). Why do adolescents eat what they eat? Personal and social environmental predictors of fruit, snack and breakfast consumption among Dutch 12-14-year-old students. Public Health Nutrition.

Martens, M., Van Assema, P. \& Brug, J. (submitted). Krachtvoer: Effect evaluation of a Dutch healthy diet promotion curriculum for lower vocational schools.

Martens, M., Wind, M., Van Assema, P., \& Brug, J. (2002). De (on) mogelijkheden van voedingsvoorlichting aan twaalf- tot veertienjarige jongeren. Nederlands Tijdschrift voor Dietistien, $57,71-77$.

Martens, M. K. Van Assema, P., Paulussen, G. W., Schaalma, H., \& Brug, J. (submitted). Krachtvoer: Process evaluation of a Dutch healthy diet promotion curriculum for lower vocational schools.

Matthews, R. (1996). Importance of breakfast to cognitive performance and health. Perspective Applied Nutrition, 3, 204-212.

Maynard, M., Gunnell, D., Emmett, P., Frankel, S., \& Davey Smith, G. (2003). Fruit, vegetable and antioxidants in childhood and risk of adult cancer: the Boyd Orr cohort. Journal of Epidemiology and Community Health, 57(3), 218-225.

McGraw, S. Av, Sellers, D., Stone, E. J., Bebchuk, J., Edmundson, E. W., Johnson, C. C., et al. (1996). Using process data to explain outcomes. Evaluation Review, 20, 291-312.

Morgan, D. L., \& Kreuger, R. A. (1998). The focusgroup kit. Thousand Daks, CA.. Sage.

Munoz, K. A., Krebs-Smith, S. M., Ballard-Barbasch, Ra \& Cleveland, L. E. (1997). Food intake of US children and adolescents compared with recommendations. Pediatrics, 100, 323-329.

Olivera, S. A., Ellison, R. C., Moore, L. L., Gillman, M. W., Garrahie, E. J., \& Singer, M. R. (1992). Parent-child relations in nutrient intake: The Framingham Children's Study. American Journal of Clinical Nutrition, 56, 593-598.

Paulussen, T., Kok, G., \& Schaalma, H. (1994). Antecedents to adoption of classroom-based AIDS education in secondary school. Health Education Research, 9(4), 485-496.

Perez-Rodrigo, C., \& Aranceta, J. (2003). Nutrition education in schools: experiences and challenges. European Journal of Clinical Nutrition, 57(1), 582-585.

Pollit, E. (1995). Does breakfast make a difference in school? Journal of the American Dietetic Association, 95, 1134-1339.

Pollit, E. (1998). Breakfast and cognition: an integrative summary. American Journal of Clinical Nutrition, 67, 8045-8135.

Quandt, S. A. (2000). Social and cultural influences on food consumption and nutrition status. In S. M. e. al. (Ed.), Modern nutrition in health and disease ( $\mathrm{pp}$. 1783-1792). Baltimore: William \& Wilkins.

Rasbash, J., Browne, W. Goldstein, H., Yang, M., Plewis, I., Draper, D.y et al. (1999). A user's guide to MIWin. Londion: Institute of Education.

Resnicow, K. (1991). The relationship between breakfast habits and plasma cholesterol levels in schoolchildren. Journal of School Health, 24, 37-40.

RIVM. (2005). Sociaal-economische gezondheidsverschillen. Retrieved June, 2005, from the World Wide Web: http://rivm/vtv/object document/o1696n21022.htm/.

Rohrbach, L., Graham, J, \& Hansen, W. (1993). Diffusion of a school-based substance abuse prevention program: predictors of program implementation. Preventive Medicine, 22, 237 260.

Roos, E., Lahelma, E, Virtanen, M., Prattala, R, \& Pietinen, P. (1998). Gender, socioeconomic status and family status as determinants of food behaviour. Social Science \& Medicine, 46 , 1519-1529.

Ruxton, C. H. S., \& Kirk, T. R. (1997). Breakfast: a review of association with measures of dietary intake, physiology and biochemistry. British Journal of Nutrition, 78, 199-213.

Schaalma, H., Bolman, C., De Nooijer, J., De Vries, H., Paulussen, T., Aarts, T., et al. (1997). Jongeren en de preventie van hart- en vaatziekten: een leefstijl en determinanten analyse. Den Haag: Nederlandse Hartstichting. 
Seifert, K. L., \& Hoffnung, R. J. (1997). Child and Adolescent Development (Vol. 463,464). Boston/ New York: Houghton Miffin Company.

Serra-Majem, L., Ribas, L., Perez-Rodrigo, C. Garcia-Closas, Rx, Pena-Quntana, L., \& Aranceta, 1. (2002). Determinants of nutrient intake among children and adolescents: results from the enKid Study. Annals of Nutrition and Metabolism, 46(suppl 1), 31-38.

Sessa, F. M. (1992). Family structure, parenting, and adolescent adjustnient. Temple University. Philadelphia.

Snijders, T. A. B., \& Bosker, R. J. (1999). Multilevel analysis. An introduction to basic and advanced multilevel modelling. London: Sage.

Steinberg, L., Elmen, J., \& Mounts, N. (1989). Authorative parenting, psychosocial maturity, and academic success among adolescents. Child Development, $96,109-123$.

Stewart, D. W. \& Shamdasane, P. N. (1991). Focus groups: theory and practice. London: Sage.

Story, M., Neumark-Stainzer, D. \& French, S. (2002). Individual and environmental infuences on adolescent eating behaviors. Journal of the American Dietetic Association, 102, 40-51.

Van Assema, P., Brug, J., Dolders, M., Kok., G., \& Steenhuis, I. (1996). Misconceptie van vetconsumptie: een kwalitatief onderzoek naar oorzaken. Tijdschrift Sociale Gezondheidszorg. $74,347-355$.

Van Assema, P., Brug, J., Ronda, G., \& Steenhuis, I. (2001). The relative validity of a short Dutch questionnaire as a means to categorize adults and adolescents to total and saturated fat intake. Journal of Human Nutrition and Dietetics, 14, 377-390.

Van Assema, P., Brug, 3., Ronda, G., Steenhuis. I., \& Oenema, A. (2002). A short Dutch ques" tionnaire to measure fruit and vegetable intake: relative validity among adults and adolescents. Nutrition and Health, 16, 85-106.

Van Assema, P., Mesters, I., \& Kok, G. (1992). Het focusgroep-interview: een stappenplan. Tijidschrift Sociale Gezondheidszorg, $70(431-437)$.

Van 't Bosch, G., \& Spruijt, W. J. A. (1992). Ontbijten en overgewicht bij schoolkinderen. Tijdschrift Jeugdgezondheidszorg, 24, 37-40.

Van Zundert, R., Van Der Vorst, H., Vermulst, A. A., \& Engels, R. C. M. E. (submitted). Parenting and parental use as related drinking in children in regular and special education.

Verbeke, G., \& Molenberghs, G. (2000). Linear mixed models for longitudinal data. New York: Springer-Verlag.

Vereecken, $C_{x,}$ Ojala, K., \& Delgrande Jordan, M. (2004). Eating habits. In: Currie C, Roberts C, Margan A, et al., eds. Young people's health in context. Health behaviour in school-aged children (HBSC) study: international report from the 2001/2002 survey. Copenhagen: WHO Regional Office for Europe.

Visscher, T. L. S. \& Seidell, J. C. (2001). The public health impact of obesity. Annwai Review of Public Health, 22, 355-375.

Voedingscentrum. (1992). Praktische voedingsmiddelengids. Den Haag: Voedingscentrum.

Voedingscentrum. (1998). Zo eet Nederland, resultaten van de voedselconsumptiepelling 19971998. Den Haag: Voedingscentrum.

voedingscentrum. (2000). Goede voeding voor iedereen?l Adwies op basis van platformdiscussie over effectieve voedingsinterventies gericht op achterstandsgroepen d.d. 8 februari 2000, Den Haag.

Voedingsraad. (1986). Adviesrichtijinen goede voeding. 's Gravenhage: Voedingsraad.

Voorlichtingsbureau woor de Voeding. (1997). De Voedingswijzer: toelichting en achtergronden, criteria voor voedingsmiddelen. Den Haag: Voedingscentrum/ Voorlichtingsbureau voor de voeding.

Warwick, J., Mcilveen, $H_{\text {, }}$ \& Strugnell, C. (1999). Food choices of 9-17-year olds in Northern Ireland-influences and challenges. Nutrition \& Food Science, 5, 229-236.

WHO. (1998). Life in the 21 st century - A vision for all. The world health report. Geneva: World Health Organisation. 
WHO (2003). Dlet, Nutrition and the prevention of chronic diseases. Report of a joint WHO/FAO Expert Consultation. (WHO technlical Report Series, No. 916; http://wholibdoc. who int/trs/ WHO TRS 916.pdf, accessed 10 february 2004). Geneva: World Health Organisation.

Willet, W. C. (1994), Diet and health: what should we eat? Science, 264, 532-537.

Woodward, D. R, Boon, J. A, Cumming, F, J, Ball, P. J., Williams, H. M., \& Hornsby, H. (1996). Adolescents' reported usage of selected foods in relaltion to their perceptions and social norms for those foods. Appetite, 27(2), 109-117.

Young, E. M, Fors, S. W, \& Hayes, D. M. (2004). Associations between perceived parent behavhors and middle school student fruit and vegetable consumption. Journal of Nutrition Education and Behavior, $36,2-12$.

Zajonc, R. B. (1968), Attitudinal effects of mere exposure. Journal of Personality and Social Psychology, 9, $1-27$.

Zizza, C. Siega-Riz, A. M. \& Popkin, B. M. (2001). Significant increase in young adults' snacking. between 1977-1987 and 1994-1996 represents a cause for concern! Preventive Medicine, $32(4), 303-310$ 


\section{Summary}

This thesis reports on a number of research studies into the development, implementation and evaluation of Krachtvoer, a school-based educational programme to promote healthy eating habits among 12-14-year-old students. Unhealthy eating habits of young people are a major public health problem. It is particularly important to develop effective healthy diet promotion interventions for young people, as healthy eating at an early age may be an important determinant of dietary choices in later life. To meet this challenge, the Krachtvoer nutrition education programme has been developed, implemented and evaluated. The overall goals of the programme were to increase the consumption of fruit and fruit juice, decrease the consumption of high-fat snacks and increase breakfast frequency and quality among 12-14-year-old students at lower vocational schools.

The first two studies reported on in this thesis were conducted to support the development of the Krachtvoer programme. The subsequent evaluation of the programme consisted of an effect study and a process study. The final study investigated the influence of the family environment on students' dietary behaviours and the effects of the programme.

The Introduction (chapter 1) describes the programme, which consisted of eight school lessons and included task forms, postcards, posters, a lunchbox with healthy food items, a magazine, a video, a website, a take-home bag with a newsletter and food items for the parents, taste-testing of various products and a manual with instructions for the teacher on the various lessons. The first chapter also discusses the rationale for the choice of behaviours to be targeted and for developing the programme for students of lower vocational education.

Chapter 2 describes the results of focus group interviews that were conducted with students, teachers and parents. These interviews helped us gain insight into the need for nutrition information, specific areas of interest and views about nutrition education among our target population. The focus group interviews with teachers aiso examined the requirements in terms of overall programme design that would promote adoption and implementation of a healthy diet intervention in the schools, such as the number and duration of the lessons. The students who took part in the interviews were not very enthusiastic about nutrition education, but accepted the fact that they were asked by the school to work on the topic. They felt that nutrition education could be fun if it met certain criteria. The information should not be too complex and they should be able to absorb it in an active manner, for instance by means of games. The students wanted all activities and materials to be challenging, not childish, funny, colourful, exciting and even a bit shocking. These requirements were also confirmed by the teachers and parents. The interviews further indicated that taste preferences should be taken into account when trying to change nutrition habits. Teachers indicated that lessons about nutrition were mostly given at the beginning of the school year, and an average of 12 hours was being spent on this topic in the current cur- 
riculum. Teachers said that they preferred a number of optional elements in the programme that would leave them some room to tailor the programme to their own teaching situation. We conduded that although designing nutrition education materials for students is not an easy task, it is essential to address nutrition in view of the current unfavourable dietary patterns and their adverse short-and long-term health consequences. Adolescents judge educational activities by certain criteria, which can be taken into account when designing these activities. Specific topics that interest some of the adolescents, like the consequences of skipping breakfast, can be used as a basis.

Chapter 3 describes the relative importance of possible personal and social environment predictors of the consumption of fruit, high-fat snacks and breakfast. More positive attitudes and subjective norms appeared to be associated with greater intentions to change, for all three dietary behaviours, and more positive self-efficacy expectations with greater intentions to increase fruit intake. With regard to actual consumption, a more positive attitude towards eating fruit was the only significant correlate of greater fruit consumption. A perceived lower intake by the mother and greater food availability and accessibility were found to be the main correlates of high-fat snack consumption. The results indicate that adolescents ${ }^{\prime}$ attitudes are the most important determinants of various health-related eating behaviours and intentions to change. Interventions to promote a healthy diet among adolescents should include creative strategies to achieve positive associations with healthy dietary changes.

Chapter 4 presents the results of a trial to assess the effects of the Krachtvoer programme on dietary behaviours and behavioural determinants. The study revealed beneficial effects on some, but not all behaviourall measures relating to fruit intake, high-fat snack intake and breakfast habits. Some of the favourable behavioural effects accurred in the total target population, others mainly or only among those students who had the least desirable intakes at baseline. Similar patterns were found for the effects on intention to change, attitudes, subjective and descriptive norms, self-efficacy, awareness of risk behaviour, interest in the topic, perceived food rules and the availability and accessibility of food at home. Some unfavourable effects occurred among students with the most desirable values at baseline, but these effects were smaller than the favourable effects among the students with the least desirable values at baseline. This indicates that the programme did reach the students who needed it most. Although we did not find effects on all outcome indicators, the total pattern of results suggests that Krachtvoer offered added value over the existing curriculla.

Chapter 5 deals with the completeness and fidelity of the programme implementation, as well as the opinions of teachers and students about the Krachtvoer programme. It was found that the teachers had implemented the programme largely according to plan, that the teachers appreciated most parts of the programme and that the students who were exposed to Krachtvoer were more appreciative of their nutrition education lessons than students who took the usual curriculum. The process evalu- 
ation also indicated non-optimal implementation of phase three, where activities involved implementation of solutions and an evaluation of personal goal performance. We concluded that the process study revealed the stronger and weaker parts of the programme and could be used to guide the revision process for further programme improvement.

Chapter 6 reports on a study assessing the association between a number of familyrelated factors and fruit and snack consumption by students and ascertaining whether these family-related factors affected the Krachtvoer-induced changes in these two health-related dietary habits. The study revealed a positive association between parents' fruit intake and children's fruit intake, and a negative association between the importance of weight control in family food purchasing habits and children's snack intake. No significant family-related predictors of programme-induced changes in either fruit or snack intake were found. The conclusions were that in the present adolescent population, the influence of family-related factors seems limited and that there are no indications that these factors modified the programme's effect. For the Krachtvoer project, this means that we found no evidence that there are subgroups of children who might profit less due to their family background.

The final chapter (chapter 7) first summarises the main findings of the studies, and then reviews the initial aims and a number of key decisions that were taken in the process of achieving these aims. The chapter also relates the findings of the individual studies to each other, and discusses the findings and main methodological considerations in relation to the key decisions. We concluded that the systematic development of Krachtvoer has led to a programme that provides a promising tool to encourage students in lower vocational education to adopt healthier diets. However, the effects of the present Krachtvoer programme have been small. Since some conditions for improvement were identified, it seems advisable to revise the Krachtvoer programme before considering large-scale implementation. 



\section{Samenvatting}

Dit proefschrift beschrijft de ontwikkeling van een aantal studies naar de ontwikkeling, implementatie en evaluatie van het lespakket Krachtvoer. Uitgangspunt van het onderzoek is dat er (vooral via scholen) al diverse voedingsvoorlichtingsactiviteiten voor jongeren worden uitgevoerd, maar dat deze activiteiten nauwelijks op elkaar zijn afgestemd en dat er geen onderzoek is gedaan naar de gedragseffectien van deze activiteiten. Tevens is de bestaande empirische en theoretische kennis over effectieve voedingsvoorlichtingsprogramma's voor jongeren slechts gedeeltelijk toegepast in bestaande programma's. Tijdens het project is het geïntegreerde voedingsvoorlichtingsprogramma 'Krachtvoer' voor jongeren in de basisvorming ontwikkeld. Krachtwoer probeert te stimuleren dat jongeren meer fruit en minder vette snacks gaan eten en vaker en beter gaan ontbijten. Veel jongeren in Nederland hebben ongezondere eetgewoontes dan wensellijk is. Het is in het bijzonder belangrijk om effectieve voedingsvoorlichtingsinterventies voor jongeren te ontwikkelen. Enerzijds kan het ongezonde eetgedrag voor een deel nog worden voorkomen en anderzijds is het al ontstane onglezonde gedrag nog niet verworden tot een jarenlange gewoonte en daardoor wellicht gemakkelijker te beïnloeden.

Het eerste deel van het proefschrift toont de resultaten van de onderzoeken die zijn gebruikt om het lespakket Krachtvoer vorm te geven. Het Krachtvoerprogramma is in een veldexperiment op haalbaarheid en effectiviteit gletoetst. Tevens zijn gedurende de gehele interventieperiode procesgegevens verzameld om na te kunnen gaan of het programma werd geïmplementeerd zoals gepland en of alle programma-onderdelen als haalbaar werden ervaren door de uitvoerders. Ook is tijdens de interventieperiode een vragenlijst bij ouders van leerlingen in de experimentele groep afgeinomen waarin onder andere familiekarakteristieken en voedingsregels zĭjn nagevraagd.

In de introductie (hoofdstuk 1) wordt een beschrijving gegeven van het lesprogramma Krachtvoer. Krachtvoer bestaat uit acht voedingslessen en in de lessen wordt gebruik gemaakt van werkbladen, ansichtkaarten, een lunchtrommel met drie gezonde voedingsmiddelen, een magazine, een video, een website, een tasje met een nieuwsbrief en voedingsproducten voor thuis, smaaktesten en een docentenhandleiding voor de docent. In de introductie wordt tevens de keuze van de drie voedingsgedragingen en doelgroep gemotiveerd.

Hoofdstuk 2 beschrijft de focusgroepinterviews die zijn gehouden met adolescenten, docenten en ouders. Door deze interviews kregen we inzicht in de informatiebehoeften, specifieke interesses en ideeën van jongeren, hun docenten en ouders op het gebied van voedingsvoorlichting. Uit het onderzoek bleek dat jongeren niet warm lopen voor voedingsvoorlichting, maar ze accepteren wel dat op school hun inzet wordt gevraagd voor dit onderwerp. Voedingsvoorlichting kan ook best heel leuk zijn, maar moet dan wel aan verschillende eisen voldoen. Zo moet de informatie niet te ingewikkeld zijn en op een actieve manier opgenomen kunnen worden, bijvoorbeeld via een spell. Eisen die aan alle activiteiten en materialen worden gesteld, 
zijn dat ze uitdagend, niet kinderachting, humoristisch, kleurrijk, spannend of zelfs een beetje grof moeten zijn. Deze eisen werd ook door de docenten en leraren ondersteund. Tevens bleek uit de interviews dat er rekening gehouden moet worden met smaakvoorkeuren van de jongeren. Wij concludeerden dat het ontwikkelen van voedingsvoorlichtingsactiviteiten voor jongeren geen gemakkelijke klus is. Bij de ontwikkeling van de voorlichtingsactiviteiten kan rekening gehouden worden met de door de jongeren zelf gestelde eisen. Verder kunnen subonderwerpen, zoals wat zijn de gevolgen van het overslaan van een ontbijt, waarvoor bij in leder geval een deel van de jongeren belangstelling lijkt te zijn als ingang worden gebruikt.

In hoofdstuk 3 wordt ingegaan het belang van verschillende persoonlijke en sociale omgevingsfactoren voor de consumptie van fruit, snoep en snacks die veel verzadigde vetten bevatten, en ontbijt. Een meer positieve attitude en subjectieve norm lijken voor de consumptie van fruit, snoep en snacks die veel verzadigde vetten bevatten en ontbijt belangrijke factoren te zijn voor de intentie tot verandering, en meer positieve eigen-effectiviteitsverwachtingen voor een hogere intentie om fruit inname te verhogen. Attitude leek tevens de belangrijkste factor voor de consumptie van fruit. Een lage ervaren inname van snacks door de moeder, en een hoge beschikbaarheid en bereikbaarheid van snacks leken belangrijke factoren voor snackconsumptie. Bij de ontwikkeling van voedingsvoorlichtingsprogramma's zouden creatieve lesactiviteiten ingezet moeten worden om positieve associaties voor van de consumptie van fruit, snoep en snacks die veel verzadigde vetten bevatten en ontbijt te bereiken.

Hoofdstuk 4 beschrijft de haalbaarheid en effectiviteit van het Krachtvoerprogramma. Er zijn kleine maar significante gedragseffecten van de interventie gevonden. Jongeren die deelnamen aan het Krachtvoerprogramma gaven in de nameting aan meer fruit te eten, minder snacks met veel verzadigd vet te eten en bij het ontbijt meer koolhydraat- en vitamine $C$ rijke producten te eten dan de controlegroep jongeren. Sommige positieve effecten werden gevonden in de totale populatie, andere voornamelijk of alleen in de subgroep van studenten met de meest ongezonde eetgewoontes op de voormeting. Naast gedragseffecten is er bij de meeste gedragingen ook een positief effect te zien op de attitude ten aanzien van de gedragingen. Dit was een determinant die veel aandacht heeft gehad in de interventie. Er werden ook negatieve effecten gevonden in de subgroep van studenten met de meest gezonde eetgewoontes op de voormeting. Deze effecten waren echter kleiner dan de positieve effecten in de subgroep van studenten met de meest ongezonde eetgewoontes op de voormeting. Het Krachtvoerprogramma is dus in staat geweest om juist die jongeren te bereiken die er het meest baat bij hadden. Het totaal plaatje van de effecten geeft aan dat het lesprogramma Krachtvoer een meerwaarde heeft boven het gebruikelijke curriculum.

In hoofdstuk 5 wordt ingegaan op de procesgegevens die tijdens de interventieperiode zijn verzameld. In deze studie werd nagegaan of het programma werd geimplementeerd zoals gepland en hoe de algemene opzet evenals de diverse onderdelen werden beoordeeld. Vervolgens werden er verbanden gelegd tussen de opinies en 
niveau van implementatie. De belangrijkste resultaten zijn dat het lespakket redelijk goed is geimplementeerd door docenten en dat het algemene oordeel over het lespakket van docenten positief was. Leerlingen waren gematigd positief over de voedingslessen. Leerlingen in de Krachtvoergroep vonden de voedingslessen leuker en interessanter dan dan jongeren in de controlegroep. Door de procesgegeven in kaart te brengen zijn de sterke en zwakke onderdelen van het Krachtvoerprogramma zichtbaar gemaakt. Deze inzichten zijn goed bruikbaar voor revisie en verbetering van het Krachtvoerprogramma.

Hoofdstuk 6 beschrijft de vragenlijststudie onder ouders van leerlingen in de Krachtvoergroep waar onder andere familiekarakteristieken en voedingsregels zijn nagevraagd. Er werd een positieve relatie tussen fruitinname van de ouders en fruitinname van hun kind, en een negatieve associatie tussen de belangrijkheid van gewichtscontrole van ouders en snackinname van het kind gevonden. Er werden geen significante associaties gevonden tussen familiekarakteristieken en de programmageïnduceerde veranderingen in fruit- of snackinname. Geconcludeerd werd dat de invloed van familiekarakteristieken beperkt is en daarnaast bleken er geen indicaties te bestaan dat familiekarakteristieken programma-effecten kunnen beïnvloeden. Voor Krachtvoer betekend dit dat er geen bewijs is dat er subgroepen leerlingen zijn die minder geprofiteerd hebben als gevolg van hun achtergrond.

In het laatste hoofdstuk van dit proefschrift (hoofdstuk 7) worden de belangrijkste resultaten van de verschillende studies samengevat en aan elkaar gerelateerd. Tevens wordt er ingegaan op de keuzes die de basis hebben gevormd van het Krachtvoerprogramma. Wij concludeerden dat de systematische ontwilkkeling van het programma Krachtvoer heeft geleid tot een programma dat een aanvullende waarde heeft boven de bestaande voedingsvoorlichtingsprogramma's voor de doelgroep van 12-14 jarige jongeren op het vmbo. Het programma Krachtvoer is redelijk goed geïmplementeerd en gewaardeerd, maar dient op een aantal punten verbeterd te worden. Het onderzoek heeft duidelijke aanwijzingen opgeleverd voor verbetermogelijkheden. 


\section{Dankwoord}

Veel mensen hebben op hun manier bijgedragen aan het tot stand komen van dit proefschrift. Ik wil iedereen hiervoor bedanken!

Allereerst will ik mijn co-promotoren en promotor bedanken. Patricia, jij hebt een belangrijke rol gespeeld in de totstandkoming van dit project en in de dagelijkse begeleiding. Jouw steeds weer verfrissende en kritische kijk op het onderzoek, je vertrouwen in mij, de manier waarop je me steeds weer kon motiveren en de vrijheid die je me hebt gegeven om het lespakket Krachtvoer op mijn manier in te vullen heb ik erg gewaardeerd. Hans, ik heb veel waardering voor jouw kritische feedback, je waardevolle adviezen en de inzet die je tijdens het project hebt getoond. Theo, jij hebt vooral in het begin van het project, bij de totstandkoming van het lespakket Krachtvoer, een belangrijke rol gespeeld. Maar ook tijdens het project was je altijd bereid om suggesties te doen, bedankt daarvoor! Daarnaast is het geweldig dat het gelukt is om een vervolg aan Krachtvoer te geven.

Bij de ontwikkeling en uitvoering van Krachtvoer heb ik dankbaar gebruik gemaakt van de inzet van Marianne en Maartje: Marianne, we hebben samen naar een mooi lespakket toegewerkt. Ik denk nog vaak terug aan die week dat we samen in jouw huisje teksten aan het schrijven waren. Het waren lange, productieve, maar ook hele gezellige dagen! Maartje, jij was mijn steun en toeverlaat rondom de hectische tijd van de implementatie. De wervingsgesprekken met docenten, het inpakken van de lespakketten, het toeren door Nederland met de minivrachtwagen en de vele telefoontjes naar docenten hebben zijn vruchten afgeworpen!

Het project is een gezamelijk initiatief geweest van de Nederlandse Hartstichting, het Voedingscentrum en de Capaciteitsgroep GVO van de Universiteit Maastricht. Tijdens het project hebben veei organisaties en mensen in de vorm van een begeleidingscommissie, kerngroep of interventieteam advies gegeven over het project. Algemeen Pedagogisch Centrum (Frits Prior), GGD Rivierenland (Linda de Heer), Nederlandse Hartstichting (Karen van Reenen, Ineke van Dis), Nederlandse Kankerbestrijding (Mona van der Steeg), NIGZ (Pieter Iedema, Goof Buijs), NOCNSF (Gwendolijn Boonekamp), TNO Kwaliteit van Leven (Theo Paulussen), Trimbos Instituut (Rudi Loof, Puck Fillekes), Universiteit Maastricht (Herman Schaalma, Mar" tijn Berger, Ronald Knibbe, Hans Brug), Universiteit Wageningen (Maria Koelen), Voedingscentrum (Marianne Luchinger, Jeltje Snel), Voorlichtingsbureau Groenten en Fruit (Marja Slagmoolen), bedankt voor jullie interesse en meedenken bij het project.

Bij het zoeken van sponsoren, het invoeren van voedingsgegevens in het programma Becel, het uittypen van gesprekken, en het inpakken van de lespakketten heb ik veel hulp gehad van student(assistent)en. Annette, Cecile, Geertje en Marije, bedankt! Bij het schrijven van de docentenhandleiding en het pretesten van vragenlijsten bij jongeren heb ik zeer goede adviezen en medewerking gekregen van mijn (onderwijs)vrienden: Arjenne, Annemieke, Dienke en Linda, heel erg bedankt voor jullie onmisbare hulp. Bij het inhoudelijk goed in elkaar stekende lespakket Krachtvoer hoorde een passende vormgeving en daar is bureau LaVerbe zeer goed in geslaagd. Het was een feest om met jullie samen te werken. Gerard van Breukelen, 
bedankt voor je adviezen en bijdrage op statistisch gebied. Voor de correcties van de Engelstalige publicaties ben ik dank verschuldigd aan Jan Klerx. Marja, het was heel erg fijn dat ik zoveel praktische zaken rondom de promotie aan jou kon overlaten. Anna, bedankt voor de speelse vormgeving van mijn proefschrift.

In het bijzonder will ik ook de directies, docenten en jongeren bedanken die mee hebben gewerkt aan de implementatie van Krachtvoer. Ondanks de eisen die er vanuit Maastricht werden gesteld bleven jullie tot het einde toe bereidwillig om het onderzoek tot een succes te maken.

Ook wil ik mijn collega's bij GVo bedanken voor de fijne samenwerking maar ook de gezellige funches, heerlijke peren ijsjes op de trap bij de vijver en kennismaking met (ambtenaren) carnaval. Tevens wil ik mijn nieuwe collega's bij TNO Kwaliteit van Leven en Rescon bedanken. Jullie waren altijd erg geïnteresseerd in de vorderingen rondom mijn proefschrift en hoe ik dit nu combineerde met twee banen. Het was niet de makkelijkste weg maar ik vond het fijn om mij naast het afronden van mijn proefschrift te kunnen verdiepen in andere onderwerpen en onderzoeken.

Vanaf het begin stond vast dat Marieke en Monique mijn paranimfen zouden zijn. Marteke, wat was het bijzonder dat onze projecten precies gelijk op liepen en wat hebben we tijdens ons promotie traject mooie en avontuurlijke reizen gemaakt. De wandeltocht door de Loita Hills, champagne in Kopenhagen, autorit naar Okanagan, baseball wedstrijd, 12 druiven om 24 uur in Andalusië, de geur van Jamaica, chicken patties in devon house, salsa les in een huiskamer, laaaaaaaang tafelen in Berlijn, kennismaking met tropisch regenwoud, de tweedaagse fietstocht door de plantages en een dagje ziekenhuis in Parimaribo, is een kleine greep uit de onvergetelijke dingen die we meegemaakt hebben. Monique, ik heb je leren kennen als collega, wat uitgegroeid is tot een hele mooie vriendschap. Ik kijk met heel veel plezier terug op de ontspannende avondjes op de boerderij. En je blijft natuurlijk mijn held door het verjagen van de inbrekers. Tja, en dat reisje naar Venetië met zijn drieën was natuurlijk een ervaring om nooit te vergeten! Debby, het is niet nodig maar ik vond het erg fijn dat jij mijn reserve-paranimf wilde zijn. Onze vriendschap, die al sinds de kleuterschool bestaat, is heel bijzonder en ik ben blij dat daar in de loop der jaren ook Edwin en Andior bij zijn gekomen. Jullie betekenen heel veel voor mij. Inge en Jordy ik vind het geweldig dat jullie veel praktische zaken op jullie hebben genomen rondom de promotie en ik kijk nu all uit naar de lekkere hapjes op mijn feest.

Verder ook dank aan mijn familie omdat ze er altijd zijn als dat nodig is. Moeders, wat zijn die telefonische gesprekken toch een verademing en ik vind het geweldig dat je altijd zo meegeleefd hebt. En ten slotte mijn vrienden. Wat is het bijzonder en geweldig om vrienden te hebben uit verschillende fases van mijn leven: basisschool, zomerhuis, middelbare school, HBO-V, vakanties, gezondheidswetenschappen, studentenhuis, jazz (Sparta, Swentibold), werk, etcetera. Velen van jullie weten niet hoe groot hun bijdrage is geweest aan de totstandkoming van het proefschrift. De steun, stimulans en energie die jullie me kunnen geven is niet te beschrijven. Ik hoop nog lang met jullie te kunnen genieten van etentjes, telefoongesprekken, spelletjesavonden, mailtjes, dansen, klussen, uitgaan, weekendjes weg, theater, festivals en verre reizen. 


\section{Curriculum vitae}

Marloes Martens werd geboren op 12 januari 1975 te Putten. In 1992 behaalde ze haar HAVO-diploma aan het Regionaal Scholen Gemeenschap $t$ Slingerbos te Harderwijk. In datzelfde jaar startte zij met de Hogere Beroepsopleiding tot Verpleegkundige aan de Hogeschool van Utrecht waar zij in 1996 voor afstudeerde. In 1997 startte ze met de doorstroom variant van de studie Gezondheidswetenschappen aan de Universiteit Maastricht. In 1999 studeerde ze af met als afstudeerrichting Gezondheidsvoorlichting (GVO), Van september 1999 tot en met juni 2004 werkte ze als AIO aan haar promotieonderzoek 'De ontwikkeling, implementatie en evaluatie van een voedingsvoorlichtingsprogramma voor 12 tot en met 14 jarige ymbo jongeren:. Van april 2004 tot oktober 2005 werkte zij halftime en momenteel één dag in de week als wetenschappelijk medewerker bij TNO Kwaliteit van Leven aan een project dat zich richtte op de preventie van gehoorschade door lawaai bij jongeren. Sinds februari 2005 werkt zij, eerst deeltijd en momenteel vier dagen per week, als sociaal wetenschappelijk onderzoeker bij het onderzoeksbureau Rescon te Haarlem. 